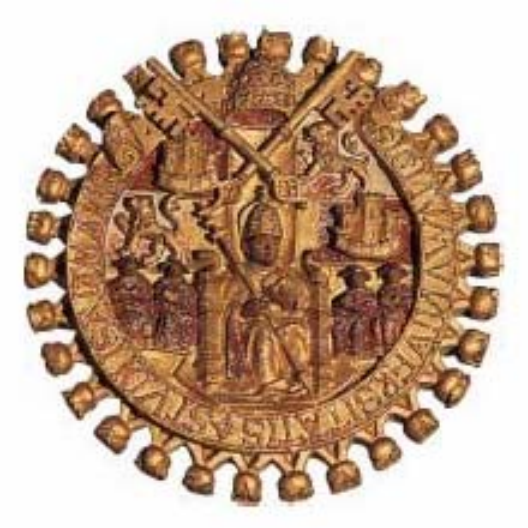

VNiVERSIDAD

BSALAMANCA

FACULTAD DE PSICOLOGÍA

DEPARTAMENTO DE PSICOLOGÍA SOCIAL Y ANTROPOLOGÍA

\author{
Tesis Doctoral
}

\title{
POTENCIA Y DESFASES CULTURALES DE LOS EQUIPOS DE TRABAJO: INFLUENCIAS EN EL COMPROMISO LABORAL
}

PRESENTADA POR: BLANCA TEJERO CLAVER

DIRIGIDO POR: DR. D. JOSÉ CARLOS SÁNCHEZ GARCÍA 
El Dr. D. José Carlos Sánchez García, Profesor Titular del Departamento de Psicología Social y Antropología de la Facultad de Psicología de la Universidad de Salamanca.

\section{CERTIFICA QUE:}

El presente trabajo de Tesis Doctoral, titulado “"Potencia y Desfases Culturales de los Equipos de Trabajo: Influencias en el Compromiso Laboral, realizado por Blanca Tejero Claver licenciada en Psicología y en posesión del Titulo de Grado de Suficiencia Investigadora de la Universidad Nacional de Educación a Distancia, se ha desarrollado bajo mi dirección y supervisión, reuniendo, a mi juicio, los méritos suficientes de originalidad y rigor científico para obtener el Grado de Doctor.

Para que conste, firmamos la presente certificación en Salamanca a Treinta de Mayo de dos mil ocho

Fdo.: Dr. D. José Carlos Sánchez García 
Hace mucho tiempo que inicie este proyecto y durante este tiempo me han acompañado muchas personas, cada una de ellas me ha enseñado algo y han contribuido de diversas formas a que este trabajo se desarrollase y pudiera terminarlo. Por todo ello, quiero mostrarles mí

\section{AGRADECIMIENTO}

Al Doctor José Carlos Sánchez porque desde el principio confió en mí, siempre me ha animado y me ha dedicado todo su tiempo, conocimientos y consejos mostrándome y transmitiéndome su interés por mi desarrollo profesional. Se que ha intentado hacerme este largo viaje fácil y seguro.

Al Doctor Esteban Alonso que fue la primera persona que me abrió la puerta a este mundo totalmente desconocido para mí y durante muchos años estuvo a mi lado hasta su jubilación

A la Doctora Carmen Huici por su ayuda en los cursos de Doctorado y en el DEA, y por el trato exquisito que siempre me ha dispensado.

A la Universidad de Salamanca y especialmente a su Departamento de Psicología Social y Antropología de la Facultad de Psicología que me ha acogido y ha hecho posible que termine este gran proyecto personal de mi vida.

A todos los miembros del Departamento de Psicología Social y de las Organizaciones de la UNED, por su disponibilidad, conocimientos y apoyo durante todos los años que he colaborado con su Departamento. 
A D. Carlos, que me ayudo a romper con las barreras informáticas y me apoyo en momentos casi imposibles.

A Antonio Bustillo, un amigo que he encontrado en este mundo, me ha dado fuerzas en los bajos momentos y nos hemos mantenido unidos durante todos estos años.

A mi familia porque han creído en mi, sobre todo en mi constancia.

\section{Gracias}




\section{ÍNDICE}

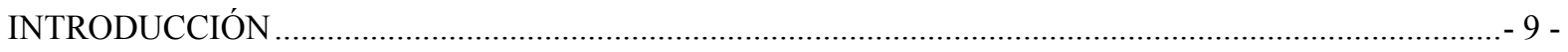

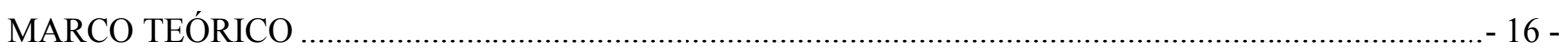

CAPITULO 1. LA ORGANIZACIÓN COMO SISTEMA SOCIAL ............................................................. 17 -

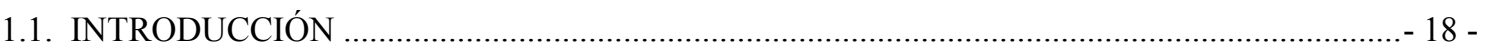

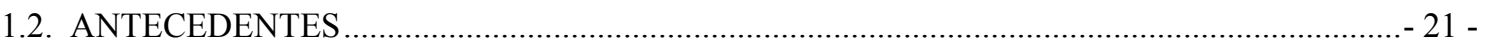

1.3. ENFOQUES TEORICOS Y UNIDADES DE ANÁLISIS DE LA ORGANIZACIÓN. .................- 23 -

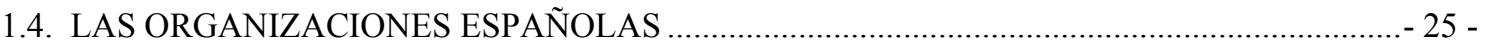

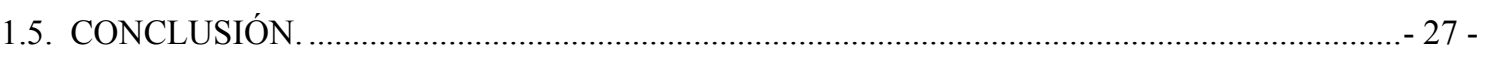

CAPITULO 2. UNA APROXIMACIÓN TEÓRICA AL ESTUDIO DE CULTURA.......................................... 29 -

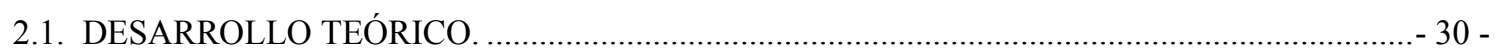

2.2. CONCEPTUALIZACIONES BÁSICAS DE LA CULTURA ……………………………........- 34 -

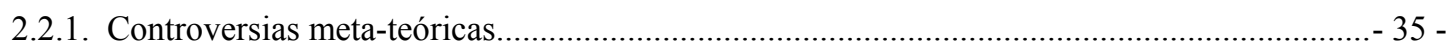

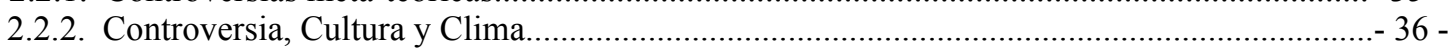

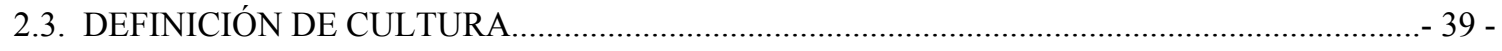

2.3.1. Cultura dominante y subculturas en la organización..............................................................- 40 -

2.4. LOS ELEMENTOS QUE FORMAN PARTE DE LA CULTURA...............................................- 42 -

2.4.1. Posturas fundamentales: holística y diferenciadora...............................................................- 46 -

2.5. CULTURA Y NIVELES DE LA ORGANIZACIÓN...................................................................... 47 -

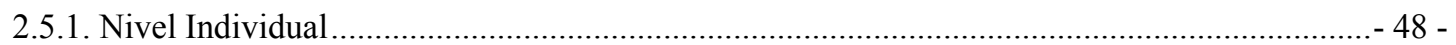

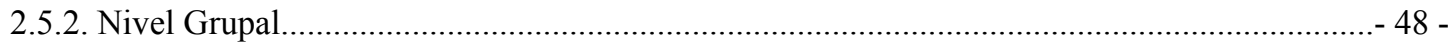

2.5.3. Nivel Organizacional............................................................................................................ - 49 -

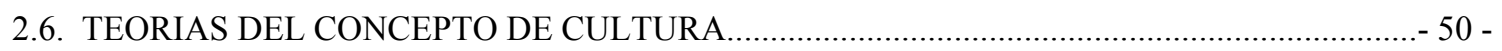

2.6.1. La cultura como variable de la organización ................................................................................ 51-

2.6.2. La organización como cultura: Constructivismo.......................................................................... 53 -

2.7. EVALUACIÓN DE LA CULTURA ORGANIZACIONAL...........................................................- 54 -

2.7.1. Modelos que comparan las diferentes culturas..................................................................... 55 -

2.7.1.1. El modelo de Hofstede............................................................................................. 55 -

2.7.1.2. El modelo "Desfases Culturales"........................................................................... 56 -

2.7.1.3. El perfil de Cultura Organizacional..................................................................... 56 -

2.7.1.4. Proyecto Globe..................................................................................................... 57 -

2.7.1.5. El cuestionario FOCUS ..................................................................................... 57 -

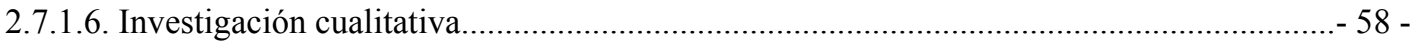

2.7.1.7. El método de Calibrado.......................................................................................... 59 -

2.7.1.8. Metodologías diferentes: cualitativa y cuantitativa................................................... 61 -

2.8. FORMACIÓN Y CONSOLIDACIÓN DE LA CULTURA..............................................................- 64 - 


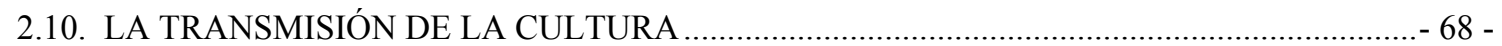

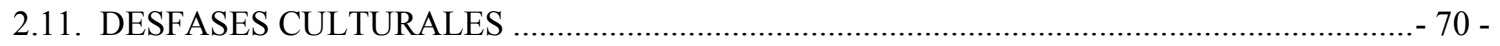

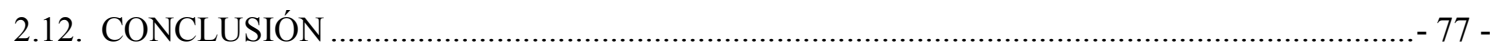

CAPITULO.3. UNA APROXIMACIÓN TEÓRICA AL ESTUDIO DEL COMPROMISO

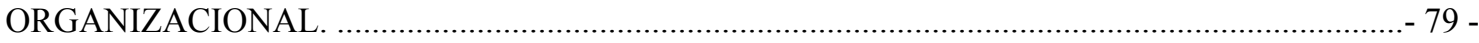

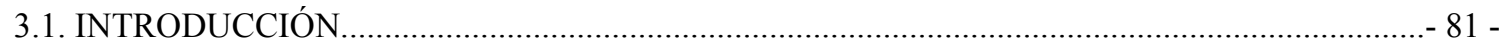

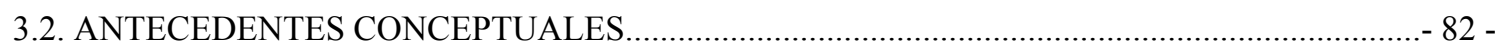

3.3. DEFINICIONES DE COMPROMISO ........................................................................... - 85 -

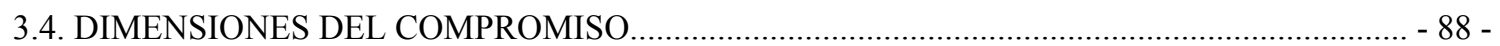

3.4.1. Compromiso afectivo................................................................................................. - 88 -

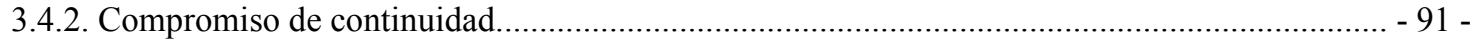

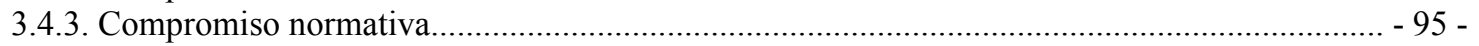

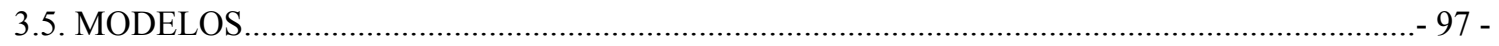

3.5.1. El modelo de tres componentes de Meyer y Allen................................................................. 97 -

3.5.2. El modelo de O'Reilly y Chatman................................................................................. 98 -

3.6. FACTORES DETERMINANTES DEL COMPROMISO........................................................ 99 -

3.6.1. Factores organizacionales determinantes del comromiso afectivo......................................... 99 -

3.6.1. Factores personales determinantes del comromiso afectivo............................................... 102 -

3.7. PREDICCIÓN DEL COMPROMISO ................................................................................ 104 -

3.8. CONSECUENCIAS DEL COMPROMISO ORGANIZACIONAL...........................................- 110 -

3.9. RELACIONES ENTRE COMPROMISO Y CULTURA ORGANIZACIONAL.........................- 112 -

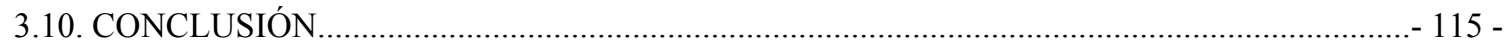

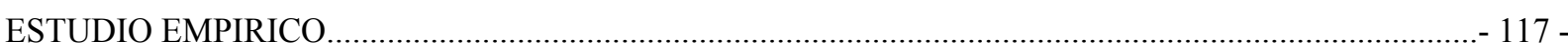

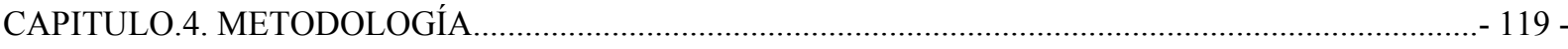

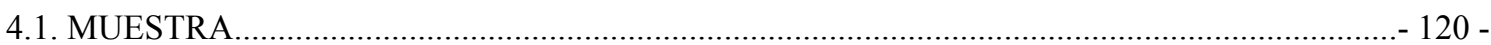

4.2. LOS INSTRUMENTOS DE MEDIDA......................................................................... 121 -

4.2.1. Cuestionario de Conductas Normativas CNO 2 ................................................................. 121 -

4.2.2. Cuestionario de Conductas Normativas OCQ......................................................................-131 -

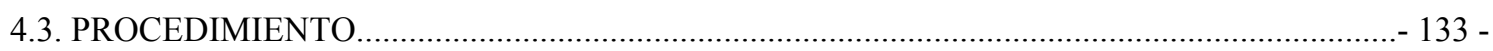

4.3.1. Análisis del cuestionario CNO2 inicial........................................................................... 133 -

4.3.2. Cultura de grupos..................................................................................................... 137 -

4.3.3. Categorización de los equipos de trabajo según su nivel cultural........................................... 139 -

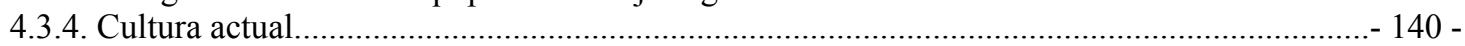

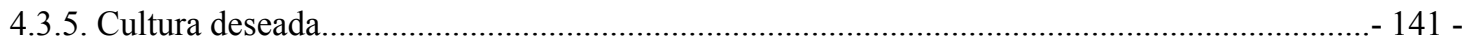




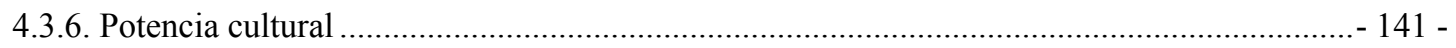

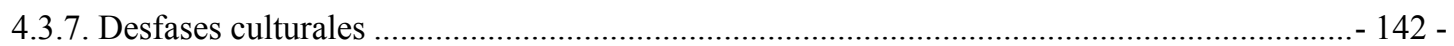

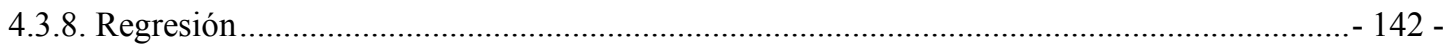

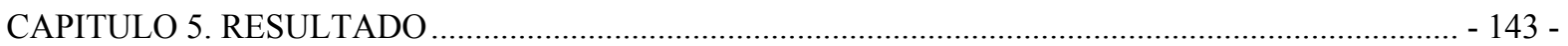

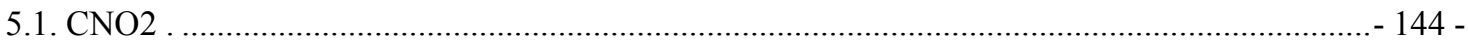

5.1.1. Análisis del instrumento inicial........................................................................................ 144 -

5.1.2. Análisis del instrumento reformulado..................................................................................- 146 -

5.1.3. Análisis factorial confirmatorio ……………………………………………………………- 147 -

5.1.4. Modelo final del instrumento......................................................................................... 150 -

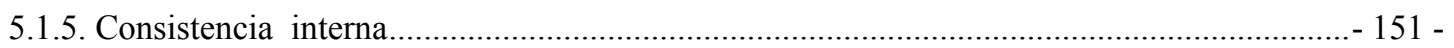

5.2. CUESTIONARIO DE COMPROMISO ORGANIZACIONAL (OCQ) .........................................- 154 -

5.3. CATEGORIZACIÓN DE LOS EQUIPOS DE TRABAJO SEGÚN SU NIVEL CULTURAL...- 155 -

5.3.1. Cultura actual.

$-156-$

5.3.2. Cultura deseada. $157-$

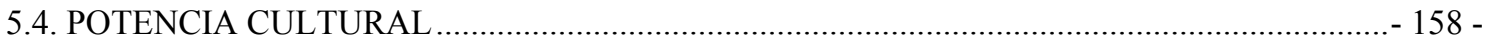

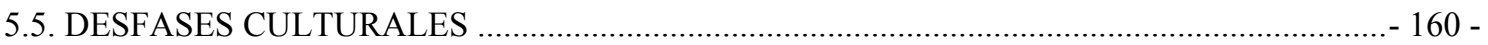

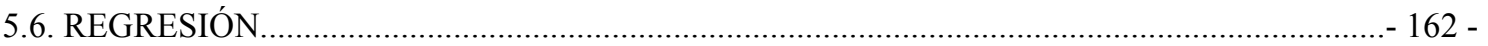

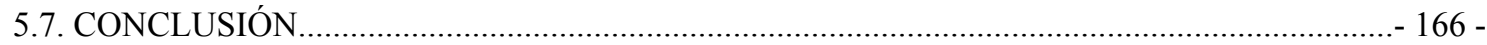

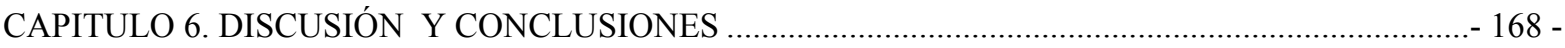

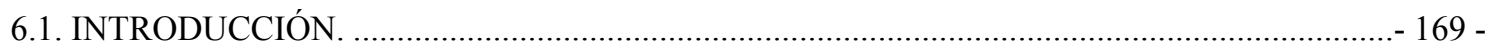

6.2. RESUMEN DEL PLANTEAMIENTO TEÓRICO. ……........................................................... 170 -

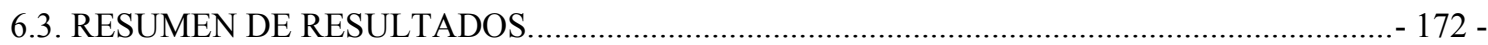

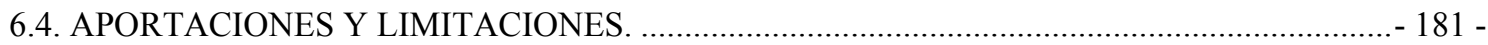

6.5. LINEAS DE INVESTIGACIÓN FUTURA.................................................................................... 183 -

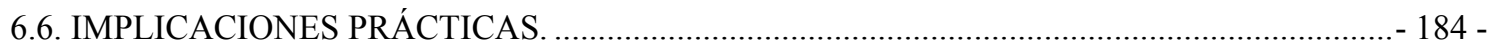

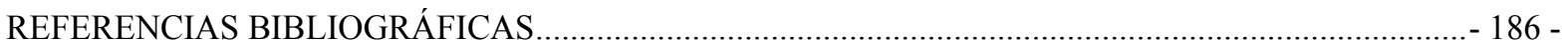

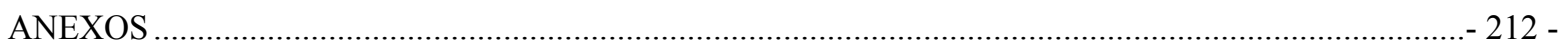

1. INSTRUCCIONES PARA COMPLEMENTAR LOS CUESTIONARIOS. ...................................-213 -

2. CUESTIONARIO DE CONDUCTAS NORMATIVAS ORGANIZACIONALES (CNO-2).........- 216 -

3. CUESTIONARIO DE COMPROMISO CON LA ORGANIZACIÓN................................ - 219-

4. CUESTIONARIO DE CONDUCTAS NORMATIVAS ORGANIZACIONALES(CNO-2). - 220- 
INTRODUCCIÓN 


\section{INTRODUCCIÓN}

El concepto de "cultura organizacional" es deudor del concepto más general de "cultura". La cultura ha sido analizada y estudiada desde la filosofía y la antropología, pero cuando se aplica al campo organizativo tiene unas connotaciones particulares, que son el objeto de nuestro estudio.

El uso del término de "cultura organizacional" se lanza a comienzos de los años setenta, en el ámbito de la sociología industrial, aunque será en los años ochenta cuando adquiera una gran importancia. Las causas teóricas y prácticas que han confluido para este despegue del concepto "cultura organizacional" son numerosas, desde la vertiente práctica, la crisis económica -cuya salida no se entreveía en un primer momento- y la crisis de eficacia y competitividad del modelo de gestión empresarial norteamericano ante el éxito de la empresa japonesa.

Desde la vertiente teórica, podemos señalar como factores del despegue del término que estudiamos la crisis del positivismo lógico y la aparición de nuevos paradigmas científicos que han permitido un mayor desarrollo de las teorías constructivistas, fenomenológicas, de la acción, y sociocognitivas en el ámbito de la psicología social y de la sociología (Peiró, 1985).

Hoy en día, "cultura organizacional" vuelve a ser un término de actualidad por la necesidad de generar culturas participativas que contribuyan al funcionamiento de las organizaciones y que éstas realmente sean eficaces en la consecución de sus objetivos. 
Las organizaciones son la expresión de una realidad cultural que se pueden adaptar a la realidad cultural que está en permanente cambio, tanto en el aspecto social como en el ámbito económico, o, por el contrario, pueden encerrarse en el marco de sus límites formales. En ambos casos, esa realidad cultural refleja un marco de valores, creencias, ideas, sentimientos y voluntades de una comunidad. Por todo ello la cultura organizacional interesa en el estudio e intervención en las organizaciones, porque ofrece una perspectiva privilegiada para observar la organización en profundidad, para comprender la importancia de los símbolos y para entender la relación entre la organización y su entorno.

Además, el término "cultura organizacional" posiblemente sea uno de los conceptos que mayor atención ha recibido en las dos últimas décadas, pues ha acaparado la atención de psicólogos, sociólogos, antropólogos, teóricos de la organización e incluso economistas, debido en gran medida a la relación que se presupone entre cultura y rendimiento.

En cualquier caso, hablar sobre "cultura organizacional" es referirse a unos de los términos más complejos del lenguaje organizacional, porque todas las organizaciones tienen una cultura, pero no todas tienen claro cuál es su propia cultura. En este sentido, hacemos una primera consideración importante al apuntar que no hay un consenso claro en relación a la definición de qué es "cultura organizacional” y, aunque ha ocupado un lugar importante en la teoría organizacional, existen desacuerdos básicos en su estudio.

Las definiciones ofrecidas por los especialistas sobre el término "cultura organizacional"(Zander, 2004), aunque discrepantes en muchos puntos, contemplan los aspectos organizacionales sobre los que incide esta cultura-el contenido de la 
organización, la formación social que la delimita, sus objetivos, sus resultados- y convergen en aspectos como las dimensiones históricas implicadas en cualquier cultura organizativa, los aprendizajes de significados compartidos o los contenidos culturales.

El debate actual en torno a la cultura organizacional se basa en el hecho de dilucidar si las organizaciones tienen cultura o son cultura. Desde la postura de ver la cultura como una variable más en la ecuación de la organización, dicha cultura se examinará en término de variables y la relación con otros aspectos de la organización. Esta concepción de la cultura organizacional como algo que tienen per se las organizaciones ha sido criticada (Smircich 1985) por quedarse corta, y se propone una aproximación alternativa que parte de un enfoque interpretativo (Geertz, 1973) que considera las organizaciones como construcciones sociales, simbólicamente constituidas y reproducidas a través de la interacción social. Esta posición se centra sobre todo en el sistema de creencias y de significados compartidos en una organización.

Resulta difícil explicar los procesos mediante los cuales las personas llegan a compartir esos fenómenos de comportamiento, mentales y sociales, pero podría lograrse una primera aproximación si se definiera la cultura como el resultado del aprendizaje psicosocial del grupo que se produce en un ambiente social determinado, requiere un contexto social e implica una transmisión de generación a generación.

Para Van Maanen y Barley (1985) es más adecuado hablar de "organización cultural" que de "cultura organizacional”, para enfatizar que en las organizaciones coexisten más de una cultura, por lo que el grupo de trabajo será una unidad de análisis más adecuada que la organización en su conjunto y, en este marco, la cultura será el resultado del 
aprendizaje del grupo; por lo tanto, las organizaciones no tienen cultura sino culturas y por eso es tan difícil su cambio (Weick 1985).

Así, dentro de una organización pueden existir una cultura dominante y unas ciertas subculturas (Van Maanen y Barley 1985) y desde este punto se entiende la cultura organizacional como la intersección de los sistemas interpretativos de las subculturas organizacionales insertadas en la cultura dominante.

La importancia de la cultura también se pone de manifiesto en la relación positiva existente entre el contenido de la cultura de las organizaciones y los resultados afectivos de los individuos. Odom, Box y Dunn (1990), Quinn y Spreitzer (1991), Cameron y Freeman (1991), Wang (2006), encuentran que las culturas caracterizadas como orientadas a las personas, al apoyo y al personal estaban asociadas a resultados afectivos positivos como la satisfacción del trabajo, el compromiso organizacional y el deseo de permanecer en la empresa. Estos estudios asumen que el mecanismo psicológico por el que una cultura configura los resultados afectivos es el de congruencia entre el individuo y la organización.

Otros estudios que han examinado las relaciones entre cultura y resultados afectivos se han centrado en las implicaciones que la congruencia individuo-cultura tiene sobre el compromiso con la organización. Koberg y Chusmir (1987) encontraron que la congruencia entre las personalidades de los individuos y sus percepciones de la cultura de la organización estaba asociada con una mayor satisfacción en el trabajo, así como con mayores dosis de compromiso y cohesión. En los trabajos de Chatman (1991) y O'Really, Chatman, Caldwell (1988) también se puso de manifiesto que el ajuste persona-cultura se correlacionó con el compromiso, el intento de permanecer en la 
empresa y la rotación. Garr, M. (1998), con su trabajo puso de manifiesto la relación entre el tipo de cultura organizacional y el compromiso organizacional y el tipo de compromiso que establecía los sujetos con la empresa según los desfases culturales existentes

La base teórica ya expuesta es uno de los pilares que motiva el interés por la Cultura Organizacional, interés que, a su vez, se convierte en el principal motivo de la investigación que se presenta y viene dado por el incremento de trabajos científicos acerca de este tema y sus posibles aplicaciones prácticas.

El objetivo de esta tesis será dilucidar hasta qué punto las dimensiones de la cultura de los equipos de trabajo pueden ayudar a determinar el compromiso organizacional en las empresas españolas. Para lograr dicho objetivo será primero necesario clarificar qué entendemos por "cultura organizacional” y cómo debe medirse ésta.

Aunque en la mayoría de los estudios la cultura y el compromiso han sido analizados a nivel organizacional, al igual que Van Maanen y Barley (1985), nosotros consideramos más oportuno analizarlos a nivel de grupos o equipos de trabajo, porque las normas pueden cumplirse en determinados equipos de la organización pero no ser ampliamente compartidas por otros equipos de trabajo; por este motivo, la muestra se dividió en equipos o grupos de trabajo, que son las unidades de investigación.

El objetivo anteriormente expuesto también incluye comprobar que el modelo propuesto muestra variaciones entre "grupos culturales" y "no culturales" y examinar cómo las variables "intensidad cultural" y "desfases culturales" puede afectar a la relación entre cultura y compromiso organizacional para repercutir en el rendimiento laboral de los empleados. Así, examinaremos si el análisis de los desfases y la 
intensidad cultural nos indican la dirección del cambio para que el compromiso, el rendimiento y la satisfacción de los empleados sea mayor.

El marco teórico de este trabajo de investigación se desarrollará en los siguientes capítulos:

1. En el primer capítulo se analiza qué son las organizaciones en general y se hace una breve revisión de las características de las organizaciones españolas.

2. En el segundo capítulo se realiza una revisión sobre la "cultura organizacional" con el fin de profundizar en los problemas inherentes al estudio de este constructo y clarificar así las distintas aproximaciones existentes en él.

3. El capítulo tercero aborda el concepto de "compromiso organizacional" para dilucidar sus orígenes, su evolución histórica y su definición.

4. En el capitulo cuarto planteamos el estudio empírico, donde se expone el método utilizado para contrastar las hipótesis planteadas, y se señalan el procedimiento, la muestra, las variables e instrumentos de medida.

5. En el capítulo quinto se muestran los resultados obtenidos en los diversos análisis realizados.

6. En el capítulo sexto se inicia la discusión: en primer lugar se señala el estado de la investigación respecto al tema de estudio; después se aportarán los resultados de los análisis realizados y se discutirán, aportándose por último las conclusiones sobre los mismos, así como las limitaciones y aportaciones de la tesis doctoral, para señalarse por fin sugerencias para futuras investigaciones. 


\section{MARCO TEÓRICO}


CAPITULO 1

LA ORGANIZACIÓN COMO SISTEMA SOCIAL 
El objetivo de este capitulo es delimitar un concepto tan complejo como es la organización, para ello analizamos los antecedentes organizacionales y el surgimiento de nuevos tipos de organizaciones como consecuencia de los efectos provocados por los movimientos sociales y la acción colectiva. A continuación se estudia algunas características de las organizaciones actuales que resultan de la influencia de esos cambios.

Se ha realizado un repaso por los diversos enfoques teóricos y unidades de análisis de la organización interesándonos en identificar las limitaciones que impiden alcanzar el logro de su misión.

Seguidamente se ha estudiado las características de las organizaciones en España, las cuales las diferenciará de las organizaciones de otros países. Finalmente, se propone una reflexión acerca de las posibilidades de desarrollo de las organizaciones que se despliegan a partir de las relaciones que se establecen entre los individuos y las organizaciones de las que forman parte.

Dar una definición de “organización” es complejo, no es fácil decir qué es una organización aunque todos nosotros hemos pasado buena parte de nuestras vidas en una. 
Esencialmente, la organización nació de la necesidad humana de cooperar. Los hombres se han visto obligados a cooperar para obtener sus fines personales, por razón de sus limitaciones físicas, biológicas, psicológicas y sociales. En la mayor parte de los casos, el individuo como tal no puede vivir aislado, sino en continua interacción con sus semejantes. Los individuos tienen que cooperar unos con otros, por sus restricciones personales, y deben constituir organizaciones que les permitan lograr algunos objetivos necesarios que con el trabajo individual no se podrían alcanzar.

Según estas características, una organización se define como un sistema formado por dos o más personas que realizan actividades conscientemente coordinadas, siendo esencial la cooperación entre ellas para la existencia de la organización.

En las últimas décadas, el trabajo y las organizaciones han experimentado cambios importantes en las sociedades avanzadas y muchas de las transformaciones ocurridas en las actividades, en condiciones de trabajo y en las propias organizaciones tienen su origen en cambios más globales de tipo socioeconómico, cultural y tecnológico.

Después de la revisión realizada de manuales y monografías, Peiró (1999) sintetiza el análisis de las tendencias teóricas sobre la situación actual de las organizaciones en tres puntos: el primero se refiere al replanteamiento del análisis de las organizaciones como realidades socialmente construidas mediante la interacción de sus actores más relevantes, e implicada en la gestión de mitos, imágenes y símbolos; el segundo punto hará referencia a la emergencia de la teoría de la acción o de control, que considera la autonomía y la autorregulación como criterios básicos que permiten a las organizaciones crear su propia capacidad de aprendizaje mediante el análisis de los errores; y por último, encontramos la consideración de la relación persona- 
organización, donde la interacción es mutua y donde las personas tratan de construir su entorno, al tiempo que ellas mismas son construidas parcialmente por el entorno.

Las organizaciones actúan en un medio que les impone cada vez mayores exigencias, por lo que deben elevar sistemáticamente sus recursos para lograr la satisfacción de las crecientes necesidades de la sociedad. Para lograr esto, la organización debe buscar alternativas que se caractericen por su nivel de creatividad y en la que se conjuguen todos los recursos utilizados por la organización para obtener un resultado satisfactorio.

En la empresa, para poder sobrevivir en este entorno, se produce una acelerada busqueda de métodos de cambio. Estos cambios deben estar orientados hacia la dirección, la organización y las personas y debe garantizarse la plena correspondencia entre ellos para lograr un desempeño global de la organización.

Como punto de partida en este cambio, una vez definida la misión de la organización, la dirección no sólo debe conocer qué hay que cambiar sino también qué debe provocar el cambio y, no sólo definir dicha misión sino también transmitirla hasta asegurarse que es comprendida y compartida por todo el resto del sistema.

Para lograr el cambio, la organización debe ser capaz de identificar cuáles son las limitaciones que le impiden alcanzar el logro de su misión. Estas limitaciones pueden estar localizadas en cualquiera de los eslabones que conforman su sistema logístico y, una vez identificadas, deben de adoptarse medidas para su eliminación.

Como se ha planteado, la dirección establece las estrategias y la organización debe ser capaz de funcionar de tal manera que dé respuestas a esas estrategias, pero 
quienes gestan este proceso de búsqueda son las personas, las cuales están presentes en todo el sistema.

En este proceso es imprescindible que las personas que integran la organización sean conscientes de que, para que la organización mejore su rendimiento y como consecuencia, pueda funcionar en un mundo caracterizado por una gran competitividad, ellas mismas deben estar plenamente identificadas con los objetivos trazados por la organización (Robison, 1998). Esto se debe a que, como se ha expuesto antes, precisamente las personas constituyen la fuerza motriz en la conducción y ejecución de todo el proceso de cambio.

\subsection{ANTECEDENTES}

A lo largo de los últimos años se ha puesto de manifiesto la importancia y la necesidad de estudiar científicamente las organizaciones como sistemas abiertos de tipo social. Según Robbins (1987), la idea de ver las organizaciones como cultura es un fenómeno relativamente reciente. A mediados de los años ochenta, las organizaciones eran concebidas como un medio racional con departamentos verticales, pero las organizaciones son mucho más que eso, pues tienen personalidades como los individuos y pueden ser flexibles o rígidas e innovadoras o conservadoras. Por ello, la contribución de la Teoría General de Sistemas a su estudio ha sido fundamental, principalmente por la contribución de Katz y Kahn (1978). Para estos autores, las organizaciones están conformadas como un conjunto de elementos (técnicos, humanos, financieros), con una estructura organizativa y con una serie de subsistemas con funciones específicas y complementarias, que se integran y coordinan para el logro de unos resultados. 
Las posibilidades que ofrece concebir las organizaciones como sistemas abiertos quedan manifiestas cuando se contrasta con los problemas y limitaciones de los sistemas cerrados. En el primer caso, se propone una concepción de la organización como sistema abierto que procesa energía, materia e información del entorno y, mediante procesos internos de transformación, se crea un producto nuevo.

La organización será un sistema adaptativo en la medida en que sus miembros adapten su comportamiento a otros integrantes y a los requerimientos del medio. Esas interacciones producen propiedades globales que no son predecibles a partir de un simple examen de sus miembros y tampoco son la suma de las propiedades individuales de la organización. Las propiedades globales reflejan la organización como un sistema vivo que evoluciona y cambia a través del tiempo.

Como forma social compleja, concebiremos la organización como un sistema de roles, de toma de decisiones, con redes de comunicación, con grupos funcionales diferenciados según la tarea y coordinados entre sí, y que presenta aspectos estructurales y procesos internos de funcionamiento.

Para delimitar un fenómeno tan complejo como son las organizaciones se han realizado muchos esfuerzos Porter, Lawler y Hackman (1975) delimitan cinco de sus aspectos esenciales: 1) están compuestas de individuos y grupos, 2) se constituyen para la consecución de fines y objetivos específicos, 3) presentan cierta permanencia temporal y delimitación espacial, 4) se trata de entidades sociales en las que la gente toma parte y a las que reacciona y 5) sus métodos suelen ser la diferenciación de funciones y los intentos de coordinar y dirigir las actividades. En las últimas décadas, los teóricos organizacionales han destacado el importante papel de la cultura en las organizaciones 
y en la década de los ochenta aparece una serie de libros- "En busca de la excelencia" de Thomas Peters y "Teoría Z”, de Robert Waterman, entre otros-, a partir de los cuales se toma conciencia de la importancia que reviste la cultura para una organización. Andrade (1991) señala que no existe una organización sin cultura; ésta puede ser fuerte o débil, manifiesta o encubierta, adecuada o inadecuada para el logro de la eficiencia y productividad organizacional, pero el hecho es que siempre esta ahí.

Dado que el contexto en el que se mueven las organizaciones cada vez es más complejo y diverso culturalmente, nos tendremos que preguntar cuál será el modo más eficaz para considerar su identidad cultural y conceptuar esa cultura.

En el análisis histórico de la cultura, teniendo presente el fenómeno de la globalización, se consideran las organizaciones desde una perspectiva multicultural y desde esta perspectiva se defiende que no operan dentro de un contexto cultural específico, por lo que se tratará de determinar cuándo y bajo qué condiciones determinadas culturas llegarán a ser más relevantes y también se tratará de explicar cómo diferentes culturas interactúan en determinadas circunstancias (Sánchez, Alonso y Palací, 1999).

\subsection{ENFOQUES TEORICOS Y UNIDADES DE ANÁLISIS DE LA ORGANIZACIÓN.}

Si se agrupan los diversos enfoques teóricos se comienza hablando de la teoría clásica con representantes tan importantes como Weber, Taylor y Farol, cuyos principios se siguen manteniendo en numerosas organizaciones. A finales de los años veinte y principios de los treinta se desarrolló la teoría humanista, que resaltaba los factores sociológicos y psicológicos en la organización y cuyos representantes -Mayo, Lewin, 
McGregor- ponen de manifiesto la necesidad de comprender las organizaciones como entes sociales.

A partir de los años cincuenta, el enfoque de sistemas pone el énfasis en la apertura al medio y la influencia del contexto. Sus principales representantes, Trist o Katz y Kahn, señalan que toda organización forma un sistema social, económico y técnico. Woodward, Burns y Stalker, Lawrence y Lorsch son los principales representantes de la teoría contingente que da un peso muy importante a la influencia del medio ambiente o contexto.

En 1992 Silva, ante la diversidad de niveles de análisis y enfoques teóricos, plantea utilizar unidades múltiples de teoría y de análisis para captar la complejidad de la organización. Al ser un fenómeno tan complejo se requerirá un planteamiento teórico que recoja e integre las diferentes dimensiones consideradas por los distintos enfoques teóricos.

El tema de la unidad de análisis es especialmente complejo cuando se trata de la teoría organizacional, donde con frecuencia se confunden los niveles de análisis, creando confusión. En la literatura son múltiples los niveles de análisis y enfoques teóricos que se han adoptado a la hora de investigar los fenómenos organizacionales.

Robbins (1987) distingue tres niveles de análisis organizacional: un nivel individual, un nivel de grupo y un nivel de sistema organizacional. Hannan y Freeman (1977), desde el enfoque ecológico de la organización, distinguen cinco niveles de análisis: miembros, subunidades, organizaciones, poblaciones de las organizaciones y comunidades de organizaciones. Para estos autores, no se puede pensar en términos de una organización en sí misma, sino de una población de organizaciones. 


\subsection{LAS ORGANIZACIONES ESPAÑOLAS}

Las organizaciones han experimentado un fuerte desarrollo en nuestro país y para analizar su evolución y describir su situación actual se requiere tomar en consideración las transformaciones económicas, sociales, políticas y empresariales que se han dado en los últimos años y en los cambios que dichas transformaciones han producido.

Así, realizando una revisión de la literatura existente encontramos que entre los directivos españoles existe un acuerdo en lo que concierne al significado de cultura empresarial, que se considera un "conjunto de valores, normas y manifestaciones que se refleja en las actitudes y comportamientos de las personas que configuran la empresa y como un instrumento que facilita la identificación del directivo y del personal con los objetivos y valores de la empresa".

Debido a una diferente interpretación de la cultura empresarial en relación con el nivel de institucionalización de la empresa como corporación integradora de hombres, existe una gran diferencia en la valoración que realiza el directivo de la empresa española y por ejemplo el directivo de la empresa alemana, según los datos que se han tomado del estudio realizado por Iwd en 1992. Para el directivo alemán, la cultura empresarial contribuye y define la institución empresa, mientras que para el directivo de la empresa española, la cultura empresarial posee más bien un carácter instrumental para la realización de sus objetivos.

El directivo español no asume que la cultura empresarial sea el vínculo entre la empresa y la sociedad; para ellos, la creación de identidad corporativa se sitúa en segundo lugar y es más importante alcanzar los objetivos o reducir costes de coordinación, entre otros puntos. 
En su conjunto, puede afirmarse que al directivo español le falta la dimensión corporativa y confiere a la institucionalización de la empresa el papel prioritario de la coordinación tanto interna como externa.

Pero la empresa española se encuentra en un momento de transición, muy relevante, que significa el paso del diseño de la institución empresarial de economías administradas a economías competitivas. No se trata de un cambio instrumental, sino de un cambio de concepción empresarial, tanto por lo que se refiere a la interpretación de la corporación como en cuanto a la instrumentación de todo el proceso directivo.

En el examen del panorama español para el estudio del éxito de una empresa se analizan los valores que constituyen la base de la misma, su Cultura Corporativa. Para ello se ha valorado cuál es su actual estructura directiva y cómo se valora en estos momentos su conducta organizativa. En el perfil de los valores en los que se basa la estructura directiva de la empresa española destacan los siguientes aspectos:

$>$ Un primer conjunto de valores lo configurarán la comunicación, la asunción de muchas responsabilidades, la participación en las decisiones, una alta formación y una clara orientación hacia los mercados.

> Un segundo grupo de valores serán los orientados al hombre, al comportamiento directivo, la alta flexibilidad los recursos humanos y el riesgo

$>$ el tercer grupo de valores, con un nivel bajo de aceptación, son el cambio generacional, el reparto del poder y la participación en los resultados.

Esta estructura directiva se corresponde con una estructura pensada para un sistema económico abierto y competitivo. 
En todo lo expuesto hay un hecho fundamental: que las personas son las protagonistas. La diferencia entre una organización más competitiva y otra que no lo sea tanto estriba en la capacidad de las personas que la componen para interpretar los nuevos valores, su capacidad para salir de la zona de confort mental y adaptarse a una visión de cambio continuo. Como se ha señalado anteriormente, en el proceso de cambio juegan un papel fundamental las personas, ya que ellas son las conductoras y ejecutoras del proceso y sin ellas seria imposible realizarlo. Esto obliga a la implicación y motivación de las personas en el trabajo para producir y buscar sistemas de incentivos que ayuden a lograr el fin estipulado, y logra además el compromiso con la organización.

Si consideramos que una organización es un conjunto de personas comprometidas a un fin común, lo deseable es que ese fin se corresponda con el fin que busca la organización, porque de esa manera se lograría la identificación de los trabajados con la cultura de la empresa.

\subsection{CONCLUSIÓN.}

Las ciencias sociales han señalado en que en las sociedades modernas la vida de las personas transcurren en torno una gran variedad de organizaciones. En las últimas décadas se hace hincapié en el poder de las organizaciones en nuestras vidas ya que influyen y regulan desde los actos individuales más simples hasta las decisiones de mayor trascendencia. En los últimos treinta años se han producido una serie de cambios que han dado lugar a la configuración de nuevas formas organizacionales al igual que han cambiado los miembros de estas organizaciones.

Los individuos construyen organizaciones, pero también las organizaciones construyen a los individuos. Las interacciones personas-organización es bidireccional constructiva 
(Munduate, 1997). Las organizaciones vienen definidas básicamente por su estructura, sus actividades, sus procedimientos y sus objetivos, es decir, todo aquello que configura y regula las posibilidades del comportamiento de sus miembros.

Queda patente la transformación sufrida por las organizaciones en las dos últimas décadas, pasando de ser relativamente homogéneas a convertirse en escenarios donde se relacionan e interactúan personas que presentan un gran número de diferencias que introducen cambios en los procesos organizacionales.

En España y más concretamente en sus organizaciones también se ve reflejada la influencia de la mejora de la actividad económica y la consolidación de la integración europea. 
CAPITULO 2

UNA APROXIMACIÓN TEÓRICA AL ESTUDIO DE CULTURA 


\section{CAPITULO 2. APROXIMACIÓN TEÓRICA AL ESTUDIO DE CULTURA}

En este segundo capitulo se ha estudiado uno de los términos más complejos de las organizaciones por su relevancia para el entendimiento y el rendimiento de la organización. Primeramente, se ha realizado una revisión de su desarrollo teórico y las controversias teóricas halladas en su investigación. A continuación se ha efectuado una síntesis de su evolución y la relación existente entre los conceptos de clima y cultura en la investigación organizacional. Como la cultura en una organización no es unitaria hablaremos de la cultura dominante y de las subculturas y de la importancia de la cultura para promover la estabilidad social y el compromiso en la organización.

Se ha descrito los componentes esenciales a partir de los cuales se configuran las culturas y las subculturas y en relación a estos elementos distinguiremos entre las posturas totalizadoras u holísticas y las diferenciadoras. Seguidamente se ha analizado los diferentes niveles de la cultura, individual, grupal $\mathrm{u}$ organizacional y por último evaluamos las funciones, transmisión y principales consecuencias de la cultura para poder abarcar toda su complejidad.

\subsection{DESARROLLO TEÓRICO.}

Las condiciones sociales, económicas, culturales y políticas actuales hacen que el mundo del trabajo y los contextos organizacionales se enfrenten a profundos cambios. 
Entre estos cambios se destaca el contacto entre diferentes culturas debido a la expansión de las economías y la creación de nuevos mercados. Por ello, se siente la necesidad de explicar los sistemas de valores y pautas de conducta de las organizaciones que desarrollan su actividad en contextos culturales muy variados.

Cuando se habla de "cultura organizacional" se está hablando de un término sobre el que existe un débil consenso en relación sobre lo que significa, cómo debe medirse y cómo se debería utilizar en beneficio de las organizaciones. En los estudios existentes sobre cultura existe una diversidad de enfoques posiblemente debido a que la cultura se encuentra en la intersección de algunas ciencias sociales (Schein, 1990) reflejando por ello la influencia de estas disciplinas, especialmente de la antropología, la sociología, la psicología social y la conducta organizacional.

Desde un punto de vista antropológico, la cultura se contempla como algo que se comparte, que se transmite y que moldea el comportamiento de las personas y sus actividades, se trasmite a través de los valores, y se produce en sistemas de creencias y actitudes por medio del comportamiento.

En un sentido sociológico, la cultura se contempla como el conjunto de valores, creencias y actitudes compartidas por una sociedad, a partir de los cuales se configuran y desarrollan determinados tipos de cultura y de relaciones sociales que la definen e identifican.

En las organizaciones, el concepto "cultura" parece cambiar la óptica de las organizaciones y concebirlas como sistemas abiertos, así, este término es utilizado esencialmente para describir los valores compartidos por los miembros de una organización. 
Los psicólogos del trabajo y de las organizaciones han centrado sus investigaciones acerca de la cultura organizacional en variables eminentemente psicológicas, centrándose más en los individuos que en las organizaciones como sistemas (Haire, Ghiselli y Porter, 1966), esto significa que las diferencias observadas se focalizan en las relaciones entre cultura y conducta más que entre cultura y características de la organización.

Algunos estudios (Lammers y Hickson, 1978) han considerado determinadas variables de carácter organizativo, lo que implica que las organizaciones perfilan sus pautas de acción a partir de su cultura, formada desde su grupo de pertenencia y constituida por actitudes, normas, roles, expectativas, valores y creencias en la que los factores económicos y tecnológico juegan un papel importante.

Tomando como punto de partida estas bases teóricas, se define la "cultura organizacional" como un "Sistema de valores y creencias influido por las estructuras de las organizaciones, la tecnología y el entorno para producir normas de pensamiento y acción que son compartidas por todos los miembros de la organización" (Schein, 1990).

Al principio de los años ochenta, el interés por la cultura aumenta considerablemente, y la importancia que adquiere desde el punto de vista organizacional coincide en el tiempo con el inicio del liderazgo japonés en la economía mundial. Japón consiguió este liderazgo por las características de su cultura, que se ha desarrollado con una sólida reputación de calidad, consistencia y funcionalidad de sus productos. Reflexionando y considerando la organización como un fenómeno cultural, que variará según el estado de desarrollo de la sociedad en que se inserte (Beres y Portwood, 1981), hay que 
considerar que los principios aplicados en la cultura japonesa pueden no proporcionar idénticos resultados si se aplican en otras culturas.

Muchos académicos e investigadores han estudiado la importancia de la cultura para el mejor entendimiento de la vida organizacional y la relevancia de dicha cultura en el rendimiento de la organización (Sackmann, 1991). Según Peiró (1990), las razones que han provocado este interés han sido las siguientes: la primera, la crisis del positivismo lógico y la aparición de nuevos paradigmas científicos que permitieron un mayor desarrollo de las teorías constructivistas, fenomenológicas de la acción y sociocognitivas en el ámbito de la psicología social y de sociología; la segunda causa, desde la vertiente práctica, señala que muchos de los problemas que tiene que afrontar la organización se refieren a los aspectos culturales que van más allá de la economía o de las características del mercado laboral.

Para Denison (1996), el estudio de la cultura representó una rebelión ontológica contra el funcionalismo dominante y el paradigma científico planteado. Esta reacción ayudó a iniciar una época de revisiones de los fundamentos de los estudios organizacionales, impulsados por el interés que suscitaban y el impacto que tenían sobre la gestión organizacional.

En 1979, Pettigrew publica un artículo en el que se presenta el concepto de "cultura", señalando como conceptos implicados en el mismo "simbolismo", "mito" o "ritual", que pueden utilizarse en el análisis de las organizaciones con el objetivo de ayudar en el estudio del comportamiento organizacional. A partir de este momento, los conceptos y los métodos de investigación característicos de la cultura organizacional no fueron restrictivos, sino que se presentaron y explicaron ampliamente (Reichers y Schneider, 
1990). Esta circunstancia permitió una rápida expansión de los elementos conceptuales de estos estudios y de sus posibilidades de aplicación e intervención en ámbitos académicos y organizacionales.

En nuestro país, los trabajos que se han realizado sobre cultura organizacional desde un punto de vista teórico se basan en parte en una revisión del panorama de la literatura internacional y desde ella aportan su propia definición de "cultura". Peiró (1990) considera que el concepto hace referencia a unos contenidos culturales que implican un proceso de configuración que fundamentalmente consiste en un aprendizaje de significados compartidos. En 1996, Peiró define la cultura organizacional como “el sistema de creencias y asunciones de una organización, las interpretaciones de lo que ocurre en ellas y de otros fenómenos relevantes".

De esta revisión se puede concluir que el auge del concepto de "cultura organizacional" se debe a una necesidad de entender lo que ocurre en el entorno complejo de las organizaciones y de descubrir medios con los que poder solucionar los problemas provocados por el acelerado desarrollo mundial provocado por los avances tecnológicos y la globalización de la economía.

\subsection{CONCEPTUALIZACIONES BÁSICAS DE LA CULTURA}

Puesta de manifiesto la falta de consenso existente respecto al concepto de "cultura organizacional”, Martín (2002) señala cinco controversias meta-teóricas en la base de su investigación: objetividad y subjetividad, perspectiva étic y émic, conocimiento generalizable y conocimiento específico, foco y amplitud y nivel de profundidad. 


\subsubsection{Controversias meta-teóricas}

La primera polémica, objetividad y subjetividad, en la cultura organizacional se refiere a la consideración de la cultura como algo objetivo, observable, frente a la perspectiva de que la cultura es fruto de la construcción social y por tanto subjetiva. Este debate constituye la base de la disputa entre la conceptualización de la cultura como "algo que las organizaciones tienen” o que “es” cultura (Peiró, 1990; Sánchez y Alonso, 1998, De White y Van Muijen, 1999).

Pero muchos investigadores intentan mantener un punto de vista integrador, considerando la cultura tanto objetivamente como subjetivamente, lo que implicaría que las descripciones culturales deben incluir manifestaciones físicas de la cultura, prácticas y estructuras formales y observables, y además se deben recoger los significados subjetivos asociados con esas manifestaciones (Martín, 2002).

El segundo punto polémico ha sido el enfoque émic o étic. El enfoque émic o interno considera que comprender el significado específico de un grupo cultural dado requiere el punto de vista de aquellos que lo forman más que imponer la perspectiva de los de fuera (Sackman,1991). El enfoque étic o externo contempla que el investigador puede decidir qué categorías y preguntas son apropiadas para investigar un contexto particular o conjunto de cuestiones teóricas (Martín, 2002). Este enfoque incluye cualquier estudio cualitativo y cuantitativo donde las categorías son impuestas por el investigador y no iniciadas por los miembros de la cultura.

En el tercer punto se debate acerca de cuál es el objetivo del conocimiento cultural: obtener conocimiento específico de un contexto concreto, por el contrario, buscar un conocimiento que se pueda generalizar. Este punto refleja el antiguo debate entre la 
investigación ideográfica (interpretación de un solo caso) y la investigación nomotética (desarrollar leyes generalizables del estudio de muchos casos).

En el cuarto punto se analiza que las diferencias que se establecen en el grado de amplitud de los trabajos en los estudios de cultura se centran en la visión de algunos investigadores de focalizarla en una o más manifestaciones culturales, siendo estudios especializados de cultura y siendo sólo necesario examinar una manifestación cultural. Otros estudios enfatizan la amplitud mediante el análisis de una variedad de manifestaciones culturales (Martín, 2002).

Y en el quinto punto, en referencia al nivel de profundidad, Schein (1988) distingue tres niveles en la cultura: artefactos y creaciones, valores y las presunciones básicas. Existen dos grandes escuelas: los adopcionistas, que consideran que la cultura está formada por los elementos directamente observables; y la escuela idealista, que define la cultura como las creencias, valores e ideas que son compartidos por miembros de la comunidad y que están en sus mentes (Peiró, 1990).

\subsubsection{Controversia, Cultura y Clima.}

"Cultura" y "clima" son dos constructos que han ocupado un lugar destacado en la literatura organizacional $\mathrm{y}$, aunque se pueden identificar diferentes tradiciones disciplinares en su estudio, fundamentalmente la Psicología Social y la Antropología, podría decirse que comprenden conjuntos afines de actitudes, valores y prácticas que caracterizan a los miembros de una determinada organización (Ashkanas y Jackson, 2001). 
Existe una cierta confusión en su definición y en su conceptuación, y en la revisión de la literatura organizacional se comprueba que los términos "clima" y "cultura organizacional" se utilizan frecuentemente de manera intercambiable. Ambos términos durante mucho tiempo han sido considerados como sinónimos, y en la actualidad muchos autores tratan de integrarlos dentro de un modelo más comprensivo de análisis organizacional (Suyantek y Bott, 2004).

Los conceptos de "clima" y "cultura" en las organizaciones parecen ser conceptos de diferente signo histórico y de difícil reconciliación en la investigación práctica organizacional. Hasta finales de los años 70, el concepto de "clima" se ha utilizado ampliamente en la investigación organizacional, aunque su aplicación a la práctica ha tenido menor éxito. En contrapartida, la importancia dada al concepto de "cultura organizacional" no ha dejado de aumentar a partir de finales de los años 70 al mismo tiempo que disminuía la atención y la utilización del concepto “clima”.

La fuerza con que se ha desarrollado el concepto de "cultura organizacional" aconseja entrar en dilucidar si "clima" y "cultura" son conceptos que se solapan o son conceptos diferentes y, si esto es así, cabe preguntarse en qué medida uno prevalece o influye sobre el otro. En este sentido, hay quien cree en la primacía de la cultura, algunos ven la cultura como parte del clima y otros abogan por la influencia mutua.

Reichers y Schneider (1990) y Denison (1996) coinciden en que las diferencias entre las investigaciones sobre clima y cultura son debidas principalmente a las distintas tradiciones científicas en las que se basan cada una de ellas, porque los dos conceptos responden a intentos de identificar el ambiente o el contexto social que influye en el comportamiento de las personas en las organizaciones. 
La comparación de Denison permite comprobar que la cultura es diferente, si bien ambos conceptos comparten un núcleo común: tratan de describir y de explicar las relaciones que existen entre grupos de personas que comparten cierto tipo de situación o de experiencia. Alonso (1999) señala que hay un predominio de expertos que consideran "clima" y "cultura" como dos conceptos diferentes, aunque sus argumentos para fundamentar sus posiciones son distintos. Desde su punto de vista, la diferencia reside en el marco de referencia no en los contenidos, porque, respecto a las normas sociales, tanto las descriptivas como las preceptivas son creencias normativas, aunque sean conceptual y motivacionalmente distintas. En los trabajos realizados por Alonso, Sánchez y Tejero (2000), se pone de manifiesto empíricamente que "cultura" y "clima" son dos constructos distintos, pero muestran correlaciones positivas y que su relación se establecerá conforme al nivel de desarrollo cultural que tienen los equipos de trabajo.

Sin embargo, "clima" y "cultura" deben estar relacionados: "clima" expresa percepciones comunes y compartidas de patrones de interacción social, y la "cultura" son los patrones o significados compartidos por la interacción social, que expresan esos patrones o significados en normas, valores, ritos, ceremonias, etc; pero están relacionados en cuanto que parece entenderse que el clima, en parte al menos, está determinado por la cultura.

Ambos conceptos son intentos de identificar el ambiente que afecta al comportamiento de las personas en la organización, porque los dos términos tratan las formas en las que ese ambiente toma sentido para los miembros de la organización (Hemmelgarn; Glisson y James, 2006). Se considera que, en general, existe un solapamiento sustancial entre los dos conceptos, señalando que esto es especialmente cierto cuando el clima y la 
cultura se contemplan como procesos recíprocos causantes uno del otro de forma continua a lo largo del tiempo. Tanto clima como cultura son aprendidos, en gran parte por procesos de socialización.

\subsection{DEFINICIÓN DE CULTURA}

En general, el constructo de "cultura" ha sido tratado por los investigadores de las organizaciones como "un conjunto de cogniciones compartidas por los miembros de una unidad social, que ha sido adquirida a través de un aprendizaje social y procesos de socialización que exponen a los individuos a diversos elementos culturales" (Rousseau, 1990).

Examinando las distintas definiciones de "cultura organizacional", éstas se podrían agrupar en función de considerar el carácter exclusivamente ideacional de la cultura o también en función de la inclusión o no del comportamiento en dicho concepto. Un ejemplo de la clasificación que considera el carácter ideacional de la cultura es la definición de Schein (1988), que es una de las más referenciadas y aceptadas de “cultura organizacional”. Considera que la cultura organizacional está formada por “ideas” (supuestos básicos, valores, creencias, percepciones abstractas del mundo), excluyendo el comportamiento.

“Un modelo de presunciones básicas -inventadas, descubiertas o desarrolladas por un grupo dado al ir aprendiendo a enfrentarse a problemas de adaptación externa y de integración interna-, que hayan ejercido la suficiente influencia como para ser consideradas válidas y, en consecuencia, ser enseñadas a los nuevos miembros como el modo correcto de percibir, pensar y sentir esos problemas". 
En el mismo sentido Kilmann (1986) definen la cultura como "filosofías, ideologías, valores, supuestos, creencias, expectativas, actitudes y normas que se forman de manera conjunta y unen a la comunidad". La cultura refleja una percepción común de los miembros de la organización, que se hace explícita cuando definen la cultura como un sistema de significados compartidos. Por tanto, deberíamos esperar que individuos que trabajan en la misma organización, aunque con distintos niveles, tenderían a describir la cultura de la organización en términos similares.

El segundo componente está formado por las otras concepciones, como la de Van Muijen (1998), que incluyen el comportamiento en la cultura (patrones de actividad, prácticas laborales,...). Para Van Muijen (1998) la Cultura Organizacional son “los valores centrales, normas de conducta, artefactos y patrones de actividad que rigen la forma en que la gente en una organización interactúa con los demás e invierte energía en su trabajo".

\subsubsection{Cultura dominante y subculturas en la organización}

La cultura es un constructo importante en la organización porque permite a los trabajadores entender cuales son los parámetros de conducta que son adecuados y aceptados dentro de ella (Robbins, 1994). A través de la cultura los individuos pueden reconocer si cuanto acontece a su alrededor es normal y ajustar sus comportamientos a los códigos del contexto cultural de que se trate (Pondy, 1978).

Cuando los nuevos miembros ingresan en la organización, se les transmite su cultura, la cual moldea su conducta, les confiere un sentido de identidad, les genera un compromiso con la organización y refuerza la estabilidad del sistema social porque mantiene unida a la organización. 
Así, la mayor parte de las organizaciones tiene una cultura dominante, pero como la cultura en una organización no es algo unitario, que una organización tenga propiedades comunes no significa que no existan subculturas dentro de esa cultura determinada. La cultura dominante expresa valores centrales que comparte la gran mayoría de los miembros de la organización y las subculturas reflejan los problemas, situaciones y experiencias que comparten sus miembros.

La existencia de subculturas no resta valor a la cultura dominante porque, si las organizaciones no tuvieran una cultura dominante y sólo estuvieran compuestas de subculturas, el valor de la cultura organizacional disminuiría por la falta de una interpretación uniforme de la conducta, que puede ser considerada como aceptable o inaceptable.

Pero también las subculturas juegan un papel importante en las organizaciones por el diferente funcionamiento, percepción y categorización de la realidad que se puede establecer en una organización y las dificultades que por ello se pueden plantear para comprender instrucciones, modificar actitudes o establecer líneas comunes de trabajo. Lok, P y Crawford, J. (2002) mostraron en su estudio que las subculturas son más predictivas de compromiso que la cultura organizacional. Aunque las subculturas juegan un papel fundamental, los miembros del grupo no se pueden aferrar a ella de modo excesivo, sino que tiene que existir una apertura para integrar los elementos de su subcultura en una cultura más amplia de la organización.

En conclusión, en las organizaciones, para su buen desarrollo, se tiene que tratar de establecer una cultura organizacional fuerte que facilitará que se genere el compromiso 
con algo superior al interés personal, promoverá una gran estabilidad social y permitirá a los individuos sentirse a gusto con su trabajo, lo que les llevará a producir más.

\subsection{LOS ELEMENTOS QUE FORMAN PARTE DE LA CULTURA}

La cultura es un producto aprendido a través de la experiencia grupal, debido a que la organización está compuesta por grupos que tienen una experiencia común y una historia compartida. Existe entre los autores una clara convergencia en contemplarla como representación cognitiva; pero también existen entre ellos discrepancias a la hora de determinar la naturaleza de los elementos culturales que reflejan esa representación. Formarán parte de la cultura múltiples componentes: normas, valores, reglas y mitos.

Schein clarifica el concepto de cultura realizando la distinción de tres niveles de cultura: presunciones básicas, valores, artefactos y creaciones. La fortaleza de su argumento radica en que la cultura representa la pertenencia de un grupo, conceptualizada ésta tanto en función de que establece límites, como en cuanto la unidad que genera, lo que podría indicar la existencia de consenso en significados compartidos entre los miembros y la inexistencia de sentimientos de ambigüedad, o la consistencia de ambos (Scholz,1987).

Podemos conocer la cultura de una organización a partir de la observación de tres niveles:

- El primer nivel es el de los artefactos visibles. Comprende el ambiente físico de la organización; son datos bastantes fáciles de conseguir pero difíciles de interpretar. En este nivel podemos observar la manifestación de la cultura, pero no sabemos su esencia. 
- El segundo nivel es el de los valores que dirigen el comportamiento de los miembros de la empresa. Un riesgo que corremos en la observación de este nivel es que puede mostrarnos un resultado idealizado o racionalizado, es decir, las personas relatarían cómo les gustaría que fuesen los valores y no cómo efectivamente son.

- El tercer nivel es el de los supuestos inconscientes, que revelan cómo un grupo percibe, piensa, siente y actúa. En un primer momento, las premisas fueron valores conscientes, pero, con el paso del tiempo, estas premisas dejaron de ser cuestionadas, constituyéndose en verdades y volviéndose inconscientes.

Otras clasificaciones muestran como dentro de los componentes esenciales a partir de los cuales se configuraron las culturas y subculturas, se destacan las producciones, los valores y asunciones.

- Las producciones o creencias configuran el nivel más visible de la cultura de una organización. Están formados por los entornos físicos y sociales y su dinámica interna y externa. No siempre pueden ser descifrables.

- El segundo nivel será el conjunto de valores de los individuos acerca de lo que debe ser la organización. Si tienen éxito, los valores pasan a ser creencias y posteriormente, asunciones. Es un componente central de la cultura que sirve para actuar en situaciones de incertidumbre. Si los valores no se arraigan en la organización, serán vistos como valores añadidos (Argyris y Schon, 1978).

- El tercer nivel está constituido por las asunciones básicas que son consideradas como la estructura sobre la que se forman los paradigmas culturales básicos de existencia que determinan el grado de efectividad de la organización. Las 
asunciones están tan arraigadas entre los miembros de la organización, que suelen ser incuestionables y difíciles de cambiar.

Freitas (1991) sistematizó los diversos elementos de la cultura en:

\section{- Valores.}

Para esta autora, los resultados obtenidos muetran que los valores de los ejecutivos entrevistados concuerdan con los valores construidos en su gran mayoría por la cúpula directiva, estando directamente relacionados estos valores con los objetivos de la organización. El nivel de adhesión de los valores se encuentra más expresivo en los escalones jerárquicos más altos.

\section{- Ritos y Ceremonias}

Los ritos, rituales y ceremonias son actividades planeadas que poseen objetivos específicos y directos, pudiendo ser de integración, reconocimiento o valorización al buen desempeño. Son caminos para esclarecer lo que se valoriza en la organización.

\section{- Historias y Mitos}

Las historias son narrativas, se repiten constantemente dentro de la organización y siempre traen aspectos importantes de la cultura; son ejemplos concretos que contienen la filosofía organizacional. Los mitos en las organizaciones crean un sentido de propósito entre sus miembros, desarrollando compromiso y lealtad y confiriendo unidad a éstas. 
Los mitos nos hablan de los procedimientos y métodos empleados, así como de las estrategias y tácticas utilizadas (Morgan, 1986).

\section{- Tabúes}

Los tabúes tienen como objeto orientar el comportamiento delimitado de las áreas prohibidas, dejando claro lo que no es permitido dentro de la organización.

\section{- Normas}

No siempre las normas se presentan por escrito, pero fluyen a través de la organización determinando los comportamientos que son posibles y los que no lo son.

Y estos elementos culturales se clasifican en el núcleo o sustancia de la cultura y en las formas culturales:

- El núcleo de la cultura corresponde a lo que los autores llaman valores, creencias, entendimientos comunes, ideologías, filosofías (Wilkins y Dyer, 1988; Kilmann et al., 1986).

- Las formas culturales son el aspecto expresivo de las acciones humanas. Correspondería a lo que la mayoría de los autores denominan mitos, rituales, historias, leyendas, patrones de comportamiento que de forma general se pueden aplicar a todas las expresiones de la acción humana (Trice y Beyer, 1993).

Según Rousseau (1990) y Schein (1985), las formas culturales son los elementos más objetivos de la cultura, los más accesibles y observables para las personas ajenas a la organización. El núcleo o esencia de la cultura es el elemento principal de la cultura, el más subjetivo y el de más difícil acceso. 
También existen diferencias entre el núcleo y las formas culturales en la naturaleza de los elementos. Los elementos del núcleo son sistemas de creencias compartidas, mientras que las formas culturales son manifestaciones del núcleo, el resultado de las acciones humanas que expresan un conjunto de significados culturales (Leach, 1968; Trice y Beyer, 1993).

El grado de subjetividad u objetividad de las manifestaciones de lo elementos que forman la cultura se debe, según Kilmann (1986), a que cada uno se produce en diferentes niveles de profundidad. Este modelo de estratos se encuentra en diversos autores, como Rousseau (1990), Kilmann (1986), Schein (1986) y Hofstede (1990).

En el modelo de estratos de Rousseau (1990), Kilmann (1986), Schein (1986) y Hofstede (1990), las normas se consideran a medio camino entre los dos extremos, objetivo y subjetivo:

- Los supuestos compartidos son elementos inaccesibles o subjetivos que necesitan la participación activa de los sujetos para determinar su significado (Schein, 1990).

- Las prácticas son elementos accesibles u objetivos que son fácil objeto de observación y medición cuantitativa (Kilmann, 1986).

\subsubsection{Posturas fundamentales: holística y diferenciadora.}

En relación a los elementos que forman parte de la cultura, se puede distinguir dos posturas fundamentales: una holística (totalizadora), que considera que todo lo que genera o adopta un grupo es cultura, y el punto de vista diferenciador, que considera cultura sólo a algunos elementos, los cuales pueden variar de un autor a otro, aunque la 
mayoría puede coincidir en cuáles son los compartidos por los miembros del grupo, de forma que todos los demás elementos serían manifestaciones de la cultura.

Inclinándonos más por el punto de vista diferenciador definimos:

La "cultura" como el conjunto de valores y creencias comúnmente aceptados por los miembros de un sistema cultural.

Las “creencias" son todas las proposiciones o ideas reconocidas como verdaderas por los miembros de un sistema cultural, independientemente de su validez objetiva. No siempre hay una uniformidad en las creencias, pero sí hay ideas que son compartidas por la mayoría de sus miembros y éstas serán las que dominen la cultura y la hagan distinguirse de otras culturas.

L Los "valores" son ideales que comparten y aceptan implícitamente o explícitamente los integrantes de un sistema. Estos se manifiestan en el plano emocional, a diferencia de las creencias, que se aceptan racionalmente. Pero tan importante como identificar los valores que caracterizan a una cultura será comprobar cómo afectan a los resultados de la organización.

Las “manifestaciones culturales" son las expresiones o productos de un sistema cultural que reflejan los valores y creencias básicos de sus miembros y alimentan y enriquecen la cultura.

\subsection{CULTURA Y NIVELES DE LA ORGANIZACIÓN}

Cuando entramos en una organización contemplamos unas manifestaciones visibles, tangibles y no tangibles, que son las que conforman la cultura (Louis, 1981). Estas manifestaciones o impactos varían según sean las organizaciones públicas o privadas, incluso dependen del departamento en el que nos situemos dentro de la organización, 
porque, como hemos comentado anteriormente, dentro de la cultura identificamos subculturas.

Pero esas manifestaciones que percibimos se atribuyen más a las organizaciones y no a los individuos que la integran; con este planteamiento lo que hacemos es integrar a los individuos como parte de las organizaciones. Vamos a señalar los diferentes niveles que aparecen en las organizaciones.

\subsubsection{Nivel Individual}

Los individuos tendemos a categorizar la realidad que observamos mediante esquemas que nos ayudan a integrar de forma coherente nuestro mundo perceptivo (Pulliam y Dunford, 1980). Pero también a través de ellos podemos explicar la conducta de otros, atribuyéndoles un sentido desde nuestra situación cultural. March y Shaspira (1989) han comprobado la dificultad de distinguir entre decisiones individuales y decisiones organizacionales, siendo muy difícil establecer la línea de separación entre fenómenos individuales y organizativos.

Delimitamos la cultura organizacional al consenso que se da en las organizaciones, en la forma de procesar, evaluar la información y comportarse ante los demás. Esto hace que percibamos el comportamiento individual como comportamiento organizacional.

\subsubsection{Nivel Grupal}

La formación de grupos se realiza en base a las percepciones y categorización de la realidad común, la proximidad física, las metas compartidas y las experiencias y tareas comunes del trabajo. La pertenencia al grupo y las relaciones que se establecen en él 
permitirán que los miembros del grupo elaboren categorías de pensamiento, tanto para definirse a sí mismo como miembro del grupo, como para decir la realidad.

No podemos entender una cultura sin grupo ni un grupo sin cultura, porque el proceso de formación del grupo se desarrolla de manera simultánea al proceso de formación de la cultura, encaminándose ambos procesos a conseguir la identidad de grupo. Su cultura será un elemento de unión porque el grupo crea su propia cultura, que dentro de la organización será una “subcultura grupal”. Este término coincide con lo que Lawrence y Lorsch (1967) describen como fenómeno diferenciador entre las distintas partes funcionales de la organización.

\subsubsection{Nivel Organizacional}

La organización entendida como un sistema se ve afectada por la cultura que existe en ella, las características de esa cultura determinarán la imagen que se tenga de la organización tanto internamente como de forma externa. Dentro de la organización es muy importante tener una cultura fuerte y consolidada, porque se podrán ir introduciendo cambios y modificaciones para la adaptación de los tiempos. Las organizaciones tienen que afrontar múltiples problemas para su adaptación externa e interna, siendo la cultura fundamental para poder hacer frente a esas dificultades y canalizarlas hacia soluciones integradoras, consensuadas y compartidas, proporcionando a los miembros de la organización una perspectiva integral de ella y una visión de su identidad. 


\subsection{TEORIAS DEL CONCEPTO DE CULTURA.}

En referencia a las teorías existentes sobre el concepto de "cultura”, Allaire y Firsirotu (1984) habían puesto de manifiesto la ausencia de una sólida teoría. Estos autores, tras analizar las diversas teorías que nacen de la antropología para definir el concepto de "cultura" y su equivalencia con las concepciones de la cultura organizacional, identificaron distintas escuelas de pensamiento que adoptan una definición particular de este concepto y que proponen diferentes formas de estudiarla.

Desde su origen y a pesar de su relevancia, la cultura ha sido una de las áreas más controvertidas de todas las estudiadas por los teóricos de la organización (Yeung, Brockban, y Ulrich, 1991) y sigue planteando problemas tanto en su definición como en la metodología para su evaluación.

Peiró (1990), entre las clasificaciones realizadas por distintos supuestos metodológicos, cita como más claras la distinción entre la aproximación funcionalista - objetivista y la interpretativa - sociocognitiva.

- Desde el enfoque funcionalista, la cultura es algo observable que se da en las organizaciones, y desde la postura sociocognitiva, las organizaciones son consideradas como culturas, algo externo a su propia estructura.

Smircich (1983), Martín (1993) y Schultz (1994) realizan análisis fundamentales en la compresión del fenómeno cultural en el interior de las organizaciones: se concentran en el análisis cultural a partir del énfasis en la diferencia fundamental entre la visión de que las organizaciones tienen cultura (la cultura como variable), y la noción de que las organizaciones son cultura. 
- El primer enunciado es una perspectiva positiva que se refiere a la cultura como una variable independiente entre muchas, y la otra es percibida como un atributo instrumental que será adquirido y manipulado por los miembros de la organización.

- El segundo enunciado es un punto de vista fenomenológico que se refiere al concepto de "cultura" para entender las expresiones y los constructos humanos en las organizaciones. La organización sería una cultura en sí misma.

A partir de lo planteado por Smircich (1983), Schultz (1994) analiza las perspectivas concluyendo que la perspectiva racionalista (Deal \& Kennedy, 1982, 1999; Peters \& Waterman, 1982) y funcionalista (Schein, 1985, 1990, 1999) tratan la cultura como una variable, orientando a los funcionalistas a responder la siguiente pregunta: “¿Qué función cumple la cultura en la organización?”. Por otra parte, la perspectiva simbólica nacida a partir de los trabajos de Geertz (1973), se orienta a responder “¿Cuál es el significado de la organización para sus miembros?”.

Esto es debido, en parte, a que el estudio de la cultura se ha abordado desde los dos principales paradigmas actuales en psicología, el racionalista y el constructivista, lo que ha dificultado la confluencia de planteamientos.

\subsubsection{La cultura como variable de la organización}

Para los positivistas, las organizaciones son realidades artificiales pero reales, que existen independientemente de nosotros y son clasificables en las reacciones de causalidad que existen entre sus diferentes fenómenos y variables. Para ellos, la cultura es una característica que tienen las organizaciones, una variable que existe en ellas y que puede observarse, medirse y relacionarse con otras variables. Desde esta 
perspectiva, la cultura es una variable más en la gestión de la organización. La cultura se analizará y gestionará a través de los artefactos visibles (costumbres, mitos, símbolos) que tienen una manifestación conductual.

Peiró indica que, para los positivistas, la cultura es un medio poderoso de control implícito y el producto final de su investigación será la determinación de relaciones de contingencia que tenga aplicabilidad para quienes han de gestionar las organizaciones (Peiró, 1990). Señala que la aproximación racionalista entiende la cultura como una característica o una variable más de la organización que es posible gestionar para alcanzar la eficacia organizacional (Peters y Waterman, 1984). Según Alonso (1997), “cultura" se puede entender como una variable externa del contexto ambiental y como una variable interna de la propia organización.

Sin embargo, ambas definiciones comparten la concepción de las organizaciones como organismos que existen en un ambiente, y defienden que las organizaciones y la cultura hay que conocerlas por el estudio de las relaciones que establecen las variables internas entre sí y con el ambiente.

En el modelo de contigencia, la cultura es un elemento de la organización, del mismo modo que otros elementos del sistema organizacional como la estructura, la tecnología los sistemas de comunicación, o de los incentivos (Hofstede, 1991). De acuerdo con este modelo funcional-estructural, se conciben las organizaciones como sistemas abiertos que interaccionan con el medio ambiente por los procesos de importación, transformación y exportación. Este modelo funcional - estructural es diferente del modelo interpretativo - simbólico de la cultura, en el que la organización se entiende como cultura (Smircich, 1983; Sackmann, 1989) en cuanto que ésta refleja una 
construcción social de la realidad única para los miembros de la unidad social. Estos modelos de cultura, que son los marcos de referencia que seguiremos en esta investigación, son el de Lorsch (1985), Schein (1985), Kilmann y Saxton (1983), Rousseau (1990) y Saffold (1988).

\subsubsection{La organización como cultura: Constructivismo}

Siguiendo a Sánchez, Alonso y Palací, (1999), desde la perspectiva constructivista se contempla el mundo como pura construcción social: es nuestra forma activa de conocer. Está constituido a través del lenguaje y de los símbolos y formado por los significados compartidos mediante la interacción. La organización no tiene cultura, es cultura.

Para los constructivistas, los supuestos son diferentes: el mundo adquiere sentido y existencia en la medida en que el ser humano se los confiere; por ello se entiende que la cultura no es algo diferente de las organizaciones, sino que las organizaciones son cultura (Weick, 1985).

Según esto, las organizaciones no existen más allá de los procesos de interacción y transmisión de significados que se producen entre sus miembros y se conciben como formas expresivas, siendo analizadas y entendidas principalmente, no en términos económicos o materiales, sino en sus aspectos expresivos, ideacionales y simbólicos.

Desde este punto de vista "toda organización como tal tiene una cultura"-, el investigador ha de intentar captar su estructura profunda a través de las descripciones proporcionadas por los miembros, lo que se denomina “enfoque Eric". Desde este 
enfoque se asume que la cultura es una metáfora, una especie de lente por la que se examina la vida organizacional (Martín, 2002).

Las investigaciones sienten la necesidad de integrar ambos enfoques para seguir avanzando en el entendimiento de las influencias sociales en las organizaciones (Reichers y Schneider, 1990; Denison, 1996; Martín 2002), comenzándose a integrar los métodos cuantitativos y cualitativos.

\subsection{EVALUACIÓN DE LA CULTURA ORGANIZACIONAL.}

Para caracterizar una cultura según sus valores, lo primero que tenemos que hacer es identificar los valores relevantes, conocer cómo están relacionados y cómo se comparten entre los miembros de la organización (Saffold, 1988; O’Reilly, Chatman y Caldwell, 1988). Al examinar los significados compartidos se identifica un grupo de características que la organización valora y que captan la esencia de la cultura de la organización.

Existen muchos estudios centrados en intentar definir las dimensiones culturales que permitan comparar las diferentes culturas y también estudios que permitan establecer diferencias entre ellas.

En un estudio realizado en varias organizaciones de Estados Unidos usando el cuestionario OCP desarrollado por Saffold (1988), O'Reilly, Chatman y Caldwell (1991), identificaron siete dimensiones de la cultura: innovación, respeto por la gente, orientación del resultado, orientación del detalle, orientación del equipo y agresividad. Estas dimensiones se asemejan a las aisladas por Sackmann (1992) en una sola organización y a la de los modelos de Cameron y Freeman (1991). 
Se ha reconocido la existencia de diferentes valores según el país donde se realice el estudio: Estados Unidos se caracteriza por valores como asertividad, rapidez de decisión, innovación, riesgo en la toma de decisiones, falta de flexibilidad y énfasis en los resultados así como por el individualismo y la autonomía del individuo (Goodman, 1981). En contra, el sistema cultural japonés acentúa las virtudes del trabajo, la atención al detalle, la importancia de relaciones cercanas o la evitación del conflicto. Su cultura, por tanto, se centra en los criterios individuales y corporativos de armonía, uniformidad y subordinación al grupo, siendo importante que los empleados se identifiquen con sus organizaciones y se sientan pertenecientes a ellas, lo que dará como resultado una alta lealtad a la compañía (Holden y Gross, 1992).

\subsubsection{Modelos que comparan las diferentes culturas}

Entre los estudios que intentan comparar las diferentes culturas explicaremos los siguientes:

\subsubsection{El modelo de Hofstede}

Propone cuatro dimensiones de las culturas nacionales y seis de las dimensiones internacionales por existir diferencias entre ellas. La investigación empírica realizada por Hofstede y col. (1990) supuso un paso adelante en el estudio de la cultura: realizan un estudio de los valores y de las prácticas como componentes de la cultura, que son determinados por un modelo multidimensional. Asimismo, defienden que la cultura de una organización son las percepciones compartidas de las prácticas diarias y propusieron para cuantificar y acceder al análisis de la cultura un modelo de seis 
dimensiones definidas como prácticas comunes percibidas por los miembros de una organización y que tienen un significado específico para el colectivo.

\subsubsection{El modelo "Desfases Culturales"}

Otros autores que han desarrollado un instrumento de mediación de la cultura estudiando las normas de comportamiento han sido Kilmann y Saxton (1984). Según estos autores, aunque la cultura se manifiesta de varias formas, está sujeta, la mayoría de las veces, a valoración y cambio por medio de las normas del grupo de trabajo. Calculando las diferencias entre las normas actuales que actúan en un grupo de trabajo y las deseadas se obtienen las puntuaciones de los desfases culturales. Estos desfases se producen en cuatro áreas -apoyo a la tarea, innovación de la tarea, relaciones sociales y libertad personal-. Según estos autores, cuanto mayor son los desfases, mayor es la probabilidad de que las normas actuales estén impidiendo una buena moral y rendimiento.

\subsubsection{El perfil de Cultura Organizacional}

Siguiendo el resumen de Alonso (1997), el instrumento "El perfil de Cultura Organizacional” para medir el ajuste entre la persona y la cultura de la organización se fundamenta en el supuesto de que las organizaciones tienen culturas que son más o menos atractivas para determinados tipos de individuos. Así como la investigación ha demostrado que antecedentes, actitudes y experiencias semejantes pueden aumentar la atracción entre los individuos, del mismo modo puede suceder que las organizaciones que manifiestan y recompensan resultados y conductas diferentes serán más o menos atractivas para tipos de personas diferentes. La congruencia entre los valores del 
individuo y de la organización puede ser el elemento crucial de ajuste entre persona y cultura.

\subsubsection{Proyecto GLOBE}

Consiste en un proyecto multifase y multimodelo en el que investigadores de sesenta países examinan las interrelaciones entre la cultura societal, la organizacional y el liderazgo organizacional para desarrollar una teoría basada en datos empíricos que permita describir, entender y predecir el impacto de variables culturales específicas. La evaluación de la cultura se realiza mediante dos tipos de manifestaciones culturales -las prácticas organizacionales y los valores- en nueve dimensiones culturales que tienen como base en parte las de Hofstede.

\subsubsection{El cuestionario FOCUS}

Lo desarrollaron un grupo de investigadores internacionales que toman como base el modelo de valores de Quinn. Este cuestionario contiene dos dimensiones en polos opuestos (interno versus externo y flexibilidad versus control); de la combinación de los dos polos se obtienen cuatro orientaciones culturales -apoyo, innovación, reglas y metas-, en las cuales puntuará la organización. Dicho cuestionario consta de dos partes: una parte descriptiva en la que se miden las prácticas organizacionales y otra parte evaluativa, referida a las características de la organización. Este cuestionario se utiliza para analizar las influencias del país y del sector o departamento de la organización que se analiza en la cultura organizacional (Van Muijen et al., 1999). 


\subsubsection{Investigación cualitativa}

En la investigación cualitativa de la cultura, algunos autores han propuesto diferentes atributos para su evaluación o medida. Así, Cook y Rousseau (1988) consideran la dirección e intensidad. La dirección se refiere al contenido de la cultura, que será la manera en que los miembros representan su ambiente mostrándose en valores, normas de comportamiento y estilos de pensamiento. La intensidad es la función del grado del consenso y de la fuerza de conexiones entre las expectativas, las recompensas y conductas.

En esta línea, diversos autores han analizado la cultura mediante normas de comportamiento. Rousseau (1990) encontró tres categorías de dimensiones relacionadas con los valores culturales y normas de comportamiento: valores y comportamientos relacionados con la tarea, valores y comportamientos interpersonales y valores y comportamientos individuales.

La intensidad de la cultura se puede medir directamente por el grado de acuerdo de los miembros sobre el contenido. Un consenso que lleva un alto grado de creencias y conductas compartidas es un indicador de que deben existir fuertes conexiones entre expectativas, recompensas y conductas. Una crítica a esta postura sería que no son criterios adecuados para determinar la naturaleza social o no social de un sistema organizacional, porque se fundamentan en un contenido de naturaleza individual desde la perspectiva de identidad personal, pero no social.

La recopilación de estas ideas y el estudio analítico de los contenidos de sus instrumentos de investigación han servido para proponer una metodología de evaluación de la cultura, el método de calibrado. 
2.7.1.7. El método de calibrado

En las investigaciones de las ciencias sociales, y específicamente en la investigación de la cultura organizacional, se pueden encontrar algunas formas de calibrado distintas a las encontradas en la investigaciones cualitativas citadas previamente. Algunas investigaciones cualitativas de la cultura, como la de Hofstede, Neuijen, Ohayv, Sanders, (1990), realizan un análisis cualitativo previo para recoger información relevante en la elaboración definitiva de cuestionario. Pero este tipo de calibrado supone que cada vez que evaluáramos la cultura tendríamos que realizar previamente una investigación cualitativa para adaptar el instrumento. Por lo tanto, modificando el instrumento difícil será comparar una organización con otra.

Otra forma de calibrado es el establecimiento por parte de los participantes de un criterio de evaluación. Por ejemplo, el criterio de "cultura deseada" (Kilman y Saxton, 1983), o el criterio "perfil de cultura" (Cooke y Rousse, 1988). El interés en la investigación de Cooke y Rousseu para nuestro propósito es que estos autores encontraron un perfil cultural ideal en la organización respecto al cual se puede comparar el perfil cultural actual. No obstante, Alonso y Sánchez, (1997) encontraron que este perfil ideal no es adecuado cuando se desea establecer y analizar la cultura de sus grupos funcionales.

El principio de participación supone que el instrumento de medida establecido por el investigador recoge información sobre el estado actual y sobre el estado ideal del sistema y que se utiliza la información del estado ideal como calibrado del estado actual. Aplicando los criterios de las normas sociales a la información del estado ideal 
se establece el patrón de variables (patrón ideal de cultura), el cual se utiliza para evaluar la naturaleza de las variables del estado actual de la cultura.

Alonso y Sánchez (1997) proponen el método de calibrado; este método no presupone que las organizaciones o grupos hayan desarrollado una cultura necesariamente. Existen tres criterios que ayudan a determinar si un grupo es cultural y poder evaluar y analizar su cultura: el de conformidad, el de comunalidad y el de potencia o intensidad. La comunalidad determina si la mayoría del grupo, objetiva o estadísticamente, tiene o percibe que se da la misma norma. Este criterio coincide con el concepto de comunalidad de Katz y Kahn. La conformidad determina como apropiada o no la conducta de la norma para el grupo en su conjunto y la intensidad define el grado en que una norma es o no apropiada para el grupo en relación con otras normas sociales. Volveremos más adelante sobre ello desarrollando y explicando las dimensiones culturales que investiga.

Alonso y Sánchez (1998, 1999; Alonso, 1999) han desarrollado en España un método de evaluación de la cultura organizacional que supone una propuesta de integración de los dos grandes paradigmas, positivismo y constructivismo, y por ello la integración de metodologías cualitativas y cuantitativas. Proponen evaluar la cultura organizacional a través de las conductas normativas creando para ello el instrumento "Cuestionario de Conductas Normativas Organizacionales” (CNO) (Sánchez y Alonso, 1997,1998; El cuestionario de Conductas Normativas Organizacionales lo integran doce variables que ahora sólo citaremos y más adelante desarrollaremos: 
“Consideración, colaboración, orientación a la acción, calidad del trabajo, libertad de acción, disposición al cambio, orientación hacia la autoridad, integración del grupo, desempeño de rol, competición, tolerancia a la incertidumbre y control social de la acción”.

La evaluación de la organización a partir de estas conductas normativas características permitirá bosquejar la cultura de la organización. Serán la base de la percepción de conocimiento que tienen los miembros acerca de la organización, la forma de cómo se hacen las cosas y la manera en que se supone que los miembros deben comportarse.

Los investigadores organizacionales, aun conceptualizando la cultura de forma similar entre sí, a la hora de abordar su estudio han atendido a diferentes elementos que varían en objetividad y observabilidad. De modo que, mientras algunos autores se han centrado en los fenómenos observables, tales como los comportamientos, artefactos, ritos y rituales (Trice y Beyer, 1993; Deal y Kennedy, 1985; Martín y Saiehl, 1983) otros han enfatizado aspectos más subjetivos, como los significados, símbolos y valores compartidos por los miembros (Schein, 1985; Smircich, 1983).

\subsubsection{Metodologías diferentes: la cualitativa y cuantitativa}

A las dificultades de definir la cultura e identificar sus elementos hay que añadir el problema de utilizar metodologías distintas en el estudio de la cultura. En el terreno empírico, se observa una notable escasez de estudios en nuestra literatura. Las perspectivas constructivistas y positivistas se identifican con dos metodologías de investigación diferentes: la cualitativa y la cuantitativa, respectivamente. 
Las posturas racionalistas abogan por métodos cuantitativos que permiten extraer conclusiones generales comparando los datos de diferentes organizaciones (Louis, 1983). Siguiendo a Alonso (1997), la escuela que se identifica con la investigación cuantitativa defiende que existen elementos universales en todas las culturas. Este tipo de investigaciones utiliza métodos externos de investigación por cuanto explora un conjunto de elementos en una o varias organizaciones, imponiendo los conceptos y las categorías de cultura del investigador a los miembros de la organización. Así, los investigadores aplican una tipología o exploran un conjunto de estos elementos en una o varias organizaciones, imponiendo los conceptos y las categorías de cultura del investigador a los miembros de las organizaciones.

Por su parte, desde los planteamientos constructivistas se prefieren metodologías cualitativas con las que conocer las características propias de la organización (Ouchi y Wilkin, 1985). La escuela que se identifica con la investigación cualitativa argumenta que aceptar elementos culturales comunes es incorrecto porque les privaría del contexto que les da su significado, significa que no se puede generalizar los elementos culturales de una organización a otra (Geertz, 1973).

Esta controversia entre la investigación cualitativa y cuantitativa tiene sus raíces en las tradiciones y propósitos diferentes de la investigación antropológica, de la que los investigadores de la cultura organizacional toman sus conceptos y métodos (Trice y Beyer, 1993). Tal y como señala Alonso (1997), frente a la polémica entre la investigación cuantitativa y cualitativa existen tendencias integradoras en la metodología de la investigación de la cultura, donde destaca la utilización conjunta de ambas metodologías o una combinación de ambas: 
- Unas tendencias se centran principalmente en el contenido de la cultura (Hofstede y col., 1990; Smith y Peterson, 1988) y aplican instrumentos para recoger información cultural como material recogido por métodos cualitativos del nicho cultural para posteriormente estandarizarlo.

- Un segundo grupo utiliza principalmente técnicas estadísticas para evaluar el consenso de la cultura (intensidad e integración cultural) (Cooke y Lafferty, 1989 con el fin de establecer si los elementos culturales sobre los que se está recogiendo la información son o no comunes a la cultura de los miembros.

- Un tercer grupo de métodos parte de la metodología de evaluación del cambio (Golembiewski y col., 1976). Intenta determinar un criterio de medición que sea establecido no por el investigador, sino por los miembros que constituyen la cultura. Este criterio se utiliza como el patrón ideal de la cultura, respecto al cual se compara la cultura percibida (su estado actual) por el colectivo, proporcionando así medidas de los desajustes o desfases que existen entre ambos.

- Estamos de acuerdo con los defensores de la metodología cualitativa en que la utilización de métodos estandarizados no es adecuada para investigar los valores y los supuestos inconscientes, no por la naturaleza de estos elementos sino por las características de los procesos automáticos que intervienen en la interacción social.

Una solución en la utilización de la metodología cuantitativa es centrarnos en las normas, como elementos de la cultura que son. 


\subsection{FORMACIÓN Y CONSOLIDACIÓN DE LA CULTURA}

La implantación y mantenimiento de la cultura se produce por vías muy sutiles, creando una determinada atmósfera cultural que presiona a los miembros de la organización al ir adaptándose a determinadas formas de ver las cosas, y dificultando la discrepancia por el riesgo a la marginación.

La cultura se recibe de diferentes fuentes: superiores, compañeros, manuales de procedimiento, hábitos de funcionamiento. La cultura de una organización no está presente desde el principio de la misma, sino que se va formando gradualmente.

"Una empresa o una organización, no nace siendo una cultura, se transforma a lo largo del tiempo en una cultura, siendo esta transformación procesal" (Tavares, 1993).

La cultura se va configurando a lo largo de la historia de la organización y en ese proceso de configuración es muy importante la participación de los fundadores e iniciadores. Para su consolidación, los factores relevantes serán las circunstancias que rodean al surgimiento de la organización y el tiempo de permanencia de sus empleados, porque una empresa con rotatividad excesiva difícilmente llega a consolidar sus valores.

Una dimensión importante dentro de la cultura va a ser la cohesión del grupo, ya que una cohesión alta permite el desarrollo de la cultura, facilitando la apropiación de características comunes de actuación y valores (Rao, 2005). Como apunta Schein (1985), la formación de la cultura exige que la organización tenga una misión básica, unos objetivos derivados de ella, unas estructuras organizacionales que permiten la 
organización de estos objetivos, un sistema de información y un proceso de análisis para reparar los procesos y estructuras no compatibles con los objetivos.

En los inicios de la vida de la organización, los fundadores de la organización trasmiten su visión del mundo a la visión del mundo que tendrá esa organización. Esta influencia va a ser muy fuerte en el inicio de la vida de la organización, pero irá decayendo a medida que los diversos grupos ocupacionales adquieran experiencia y encuentren sus propias soluciones.

Como hemos apuntado en otro apartado, la cultura de una organización puede ser fuerte o débil, pero aunque sea fuerte y homogénea, no son aspectos que garanticen la eficacia de la misma, sino que tendrá que seguir consolidándose. Actualmente, debido a los constantes cambios ambientales que ocurren a nivel mundial con repercusiones en la gran mayoría de las empresas, se enfatiza la importancia de la flexibilidad y del potencial de aprendizaje e innovación de las organizaciones. La cultura nunca está formada, siempre debe existir un aprendizaje constante por parte de los miembros de la organización.

\subsection{FUNCIONES DE LA CULTURA}

El aprendizaje del grupo, especialmente ante la resolución de situaciones conflictivas, va a ir dando como resultado la formación de la cultura de ese grupo. Este proceso de aprendizaje al que se refiere Schein es social. Schein $(1985,1990,1999)$ sostiene que la base de la cultura es un conjunto de significados compartidos que definen la forma de sentir, pensar y accionar de los miembros de una organización y sostiene que "si no hay consenso, o si no hay conflicto o si las cosas son ambiguas, entonces, por definición, ese grupo no tiene una cultura en relación a esas cosas" (Schein, 1991, p. 248). 
Según Robbins (1996), la cultura desempeñará numerosas funciones dentro de la organización, destacando las siguientes:

1- Crea distinciones entre una organización y las demás.

2- Transmite un sentido de identidad a los miembros de la organización.

3- Facilita la generación de un compromiso con algo más grande, que el interés personal del individuo.

4- Incrementa la estabilidad del sistema social.

5- Proporciona los estándares sobre los que deben decir y hacer los empleados.

6- Sirve como mecanismo de control y sensatez que guía y moldea las actitudes y el comportamiento de los empleados.

Es difícil llegar a concretar una definición de cultura debido a su carácter implícito, desarrollando cada organización un grupo central de suposiciones, conocimientos, reglas implícitas que gobiernan el comportamiento en el lugar de trabajo.

Los trabajadores, cuando aprenden las reglas, son aceptados como integrantes de la organización; si se trasgreden las reglas, ya sea por parte de la empresa o de los empleados, el resultado es la desaprobación y otras repercusiones posteriores, como sanciones, motivación, ascensos o la ruptura del contrato psicológico. También puede ocurrir que la trasgresión de las reglas no sea tal, sino una percepción distinta por parte del empleado de lo que es esa cultura (es el planteamiento que vamos a desarrollar en nuestro trabajo de investigación).

La mayoría de los expertos organizacionales entienden que la cultura se desarrolla en las organizaciones para proporcionar a sus miembros un conjunto más o menos articulado de ideas y maneras específicas de expresarlas (formas culturales) con el fin 
de poder hacer frente, individual y colectivamente, a todas las incertidumbres y ambigüedades de las organizaciones (Trice y Meyer, 1993).

Las formas culturales se definen a partir de la idea de Leach (1968) de que la mayoría de las acciones humanas tienen dobles funciones: la primera será cumplir determinados fines prácticos y la segunda, expresar un conjunto de significados culturales, correspondiendo la expresión de la cultura a estas formas culturales.

La influencia de la cultura en el comportamiento de un empleado parece ser cada vez más importante. Robbins, muestra la cultura como una variable interventora en el desempeño de la organización.

Las culturas no son ni uniformes ni estáticas, ya que cambian y se van formando a lo largo del tiempo y ejercen una serie de consecuencias sobre los miembros que las comparten.

La cultura proporciona a los miembros un sentido de identidad organizacional y genera un compromiso con las creencias y valores que son mayores que ellos.

Las principales consecuencias de las culturas según Trice y Beyer (1993) se pueden resumir en:

Características: Colectivas, fuerte carga emocional, bases históricas, inherentemente simbólicas, dinámicas e inherentemente confusas.

Consecuencias: Manejo de incertidumbres colectivas, creación de orden social, creación de continuidad, creación de identidad y de compromiso colectivo, fomento del etnocentrismo, 
generación de consecuencias duales: tanto técnicas como expresivas, latentes como manifiestas y funcionales como disfuncionales.

Dos funciones fundamentales de la cultura en las organizaciones son:

- La primera, integración interna, se refiere a la identidad colectiva que desarrollan los miembros de la organización y al conocimiento que tienen de cómo poder trabajar juntos. La cultura guiará las relaciones de trabajo diario y la forma en cómo se comunica la gente en la organización, la forma en que se asignan los poderes y qué comportamientos serán aceptables.

- La segunda función es la adaptación externa, que se refiere a la forma en que los miembros de la organización cumplen las metas. La cultura ayudará a guiar las actividades diarias de los trabajadores para que alcancen su meta.

\subsection{LA TRANSMISIÓN DE LA CULTURA}

El momento en que una persona de fuera se introduce en la cultura organizacional y comienza a aprender sus diferentes matices se inicia el proceso de socialización de un nuevo miembro a la empresa. El proceso de socialización es un proceso muy significativo por contener una variada gama de material simbólico; dependiendo de la organización y de sus objetivos, se puede desarrollar una infinidad de procesos de socialización que pueden ser individuales, colectivos, formales, informales, fijos, variables.

La cultura se perpetúa porque las organizaciones tienden a atraer y a mantener individuos que parecen aceptar sus mitos, tabúes, valores y creencias. Las -68 - 
organizaciones tienen sus propios tabúes mediante los cuales se establecen límites claros en relación con lo que está permitido y con aquello con lo que no está, y mantienen sus propios ritos y ceremonias, que son de gran relevancia para la transmisión y mantenimiento de la cultura, pues gracias a ello se ayuda a la socialización de los nuevos miembros, se refuerza su lealtad, se reafirman los valores y se incrementa la identificación con la organización. Las promociones están marcadas por un conjunto de ceremonias significativas a través de las cuales el miembro promocionado manifiesta su lealtad y compromiso con el grupo y con la organización.

Este proceso de iniciación por el que a de pasar el nuevo empleado hasta llegar a ser aceptado por el grupo puede ser duro y doloroso, pero el modo en el que se desarrolle el proceso dependerá de la cultura de cada organización.

La cultura en una organización ayudará a sus miembros de una forma gradual y a través de los modelos de interacción que se establecen entre ellos, del lenguaje usado, de las imágenes y de las rutinas y de asumir como evidentes y justificados todos aquellos códigos que regulan de forma explícita o implícita los comportamientos en la organización. Smircich,(1983) desarrolla un ethos, creado y sustentado por procesos sociales, imágenes, símbolos que ejercen una influencia decisiva sobre la naturaleza de la organización y su dinámica cotidiana (Deal y Kennedy, 1985). El ethos se fomenta por numerosos rituales que tienen lugar en la vida cotidiana de la organización.

La cultura se forma y desarrolla de modo gradual como resultado de las experiencias compartidas por los individuos y por los grupos. Los miembros de un grupo y de una organización han de compartir unas normas mínimas y un lenguaje común que les 
permita establecer sus fronteras, excluir a quienes no pertenezcan a él, fortalecer la cohesión, servir de medio de identificación e incrementar la solidaridad entre ellos.

Para sobrevivir han de compartir también unos mínimos criterios a la hora de definir sus frontera, seleccionar a los nuevos miembros, asumir la autoridad, el poder, las posiciones, los recursos, los premios, las sanciones (Trice y Beyer, 1993). Asimismo, han de compartir unas normas mínimas de convivencia a fin de que las relaciones interpersonales se desarrollen de forma satisfactoria. En suma, todos los miembros han de tener una forma común de afrontar los problemas escabrosos, de enfrentarse con la incertidumbre y de adoptar decisiones. Los valores y creencias de los líderes y miembros antiguos de la organización, así como los procedimientos y métodos que se ha visto que ha funcionado con éxito, acaban por ser aceptados e interiorizados y trasmitidos a los miembros de las siguientes generaciones.

\subsection{DESFASES CULTURALES}

Para el buen funcionamiento y desarrollo de las organizaciones resulta necesario plantear la existencia de una correspondencia entre las creencias básicas, las normas y las actitudes de la mayor parte de los integrantes de la organización con los valores y las normas de ella. Schein (1988) plantea que la cultura de toda empresa esta compuesta por dos niveles esenciales:

El primer nivel, lo que se piensa de la empresa, está constituido por las creencias y supuestos básicos de los miembros de la empresa y sobre todo los valores esenciales de los que trabajan en ella. 
El segundo nivel es más explicito y observable, esta constituido por los procedimientos, conductas, organigramas, rituales y tecnología de la organización, es decir lo que la empresa hace o también lo que aparenta que es, es decir su imagen externa en general.

Si se utiliza solamente las puntuaciones de cultura percibida, como se hace en la mayoría de los procedimientos de investigación e intervención cultural, se desecha el patrón ideal como criterio, como motivador y como guía de cambio. Para el diagnóstico de la cultura organizacional se propone utilizar el estado deseado o patrón ideal propio de la organización o del grupo, porque indica cual es la cultura que desearían que existiera en esa organización o grupo, sirviendo de esta forma también como criterio con el que se puede comparar la cultura actual. El patrón ideal propio de un grupo u organización se debe utilizar para la motivación del cambio.

Si en cada grupo se compara su estado actual y su estado deseado se creará los estados de frustración (descongelación) que Lewin y Schein señalan ser necesarios para promover el cambio. Si se busca obtener los mejores resultados es necesario utilizar el patrón ideal del propio grupo porque sino el grupo no lo reconocería como propio y no se identificaría con él, y por tanto no serviría como criterio que propiciase el mecanismo de frustración o invalidación cuando se comparase con la información sobre lo que se percibe.

Por ello, el patrón ideal propio servirá de guía para orientar hacia donde debe ir el cambio al que el grupo u organización aspiran; otro patrón que no sea el suyo les guiará en una dirección contraria. 
Para facilitar el cambio se debe favorecer el grado de acuerdo del patrón real con el ideal de un grupo, por cuanto mayor consenso se estimulará una mayor motivación o descongelación para el cambio actual y se servirá de una mejor guía.

Reflexionando sobre lo anteriormente expuesto vemos la necesidad de utilizar como procedimiento metodológico para la investigación e intervención de la cultura organizacional la medición no sólo el estado actual sino también el estado deseado y no el deseado general sino el de cada grupo

En el trabajo empírico realizado por Alonso, Oscá y Palací (1994) se pone de manifiesto la importancia del estado deseado en un proceso de diagnóstico para la evaluación e intervención en la cultura organizacional. Los autores parten del modelo de cambio social propuesto por Lewin (1947) quien establece tres etapas (descongelación, movimiento y congelación) que se dan en todo el sistema social al producirse una modificación de su situación.

Las organizaciones y los grupos tienen su propio estado deseado o patrón ideal de cultura; los miembros comparten normas y expectativas que entienden que son los ideales para su organización y que son diferentes a las otras organizaciones y grupos. El estado deseado o futuro aparece explícitamente en la etapa de movimiento, ya que aquél supone el cambio a un nivel de equilibrio que desea alcanzar en el sistema.

En la interpretación que Schein (1987) hace de la etapas de cambio social que propone Lewin, el estado deseado aparece de forma explicita en la etapa de descongelación y en la de movimiento o cambio. Para Schein (1987) la etapa de descongelación va a consistir en crear motivación y disposición a cambiar. 
El modelo de cambio social aplicado a la cultura organizacional está siendo utilizado por diversos investigadores y expertos (Cooke y Rousseau, 1988; Kilmann Saxton, 1983). En sus investigaciones comparan la cultura actual con la deseada en una organización o unidad social.

Para determinar el estado actual, se pregunta a los miembros sobre las normas de comportamiento que espera de ellos la organización. Para determinar el estado deseado se pregunta a los miembros sobre las normas que debieran esperarse de los miembros para que consiguieran satisfacer sus necesidades personales y sociales y para que la organización alcanzara sus objetivos.

La comparación del estado actual con el deseado se utiliza para el diagnóstico de los desfases que se produce en la cultura organizacional, señalando de esta forma la dirección que se debe orientar el cambio para que se produzca un mejor ajuste cultural.

Kilmann y Saxton (1983) sostienen que la cultura de un grupo es una fuerza invisible que guía la conducta y determina la forma en que las declaraciones formales son interpretadas y traducidas, afecta la calidad de la toma de decisiones y de la acción, que a su vez afecta a la moral y al rendimiento del grupo de trabajo.

Aunque la cultura se manifiesta de varias formas, está sujeta, la mayoría de las veces, a la valoración y al cambio por medio de las normas del grupo de trabajo. Estas normas son reglas de juego que no están escritas y que son las que realmente cuentan para tener éxito o de forma alternativa para no tener problemas.

Con los desfases culturales se intenta calcular la diferencia entre las normas actuales que actúan en un grupo de trabajo y las normas deseadas obteniéndose unas 
puntuaciones, estas puntuaciones nos mostraran la eficacia de los equipos de trabajo según los desfases culturales; cuanto mayor sean estas puntuaciones mayor será la probabilidad de que las normas actuales estén impidiendo una buena moral y el buen rendimiento (Robinson, 1998).

Si no se tienen en cuentan los desfase culturales y no se corrigen es posible que los grupos de trabajo se opongan a cualquier intento de cambio y mejora. Los desfases se suelen materializar en una falta de disposición a adoptar nuevos métodos de trabajo e innovaciones, en la falta de apoyo a programas de mejora de calidad y la productividad.

Los desfases culturales suelen acabar con los esfuerzos de cambio y de mejora de la organización, deteriorándose la moral y el rendimiento del grupo. Solamente haciendo explicitas las normas implícitas y abriéndolas a la discusión, se puede gestionar y controlar la cultura.

Dentro de los instrumentos más utilizados para medir los desfases culturales esta "La encuesta de los Desfases Culturales de Kilmann y Saxton (1983). Según estos autores las diferencias entre las normas existentes y las deseadas, desfases culturales, se producen en cuatro áreas y el cuestionario va ha pedir información a los sujetos sobre esos cuatro tipos de normas culturales de la organización:

1. Apoyo de la tarea: Normas a favor de compartir la información de ayudar a otro en el trabajo, de preocuparse de la eficacia, etc.

2. Innovación de la tarea: Normas a favor de ser creativo, de ser premiado por ello, de hacer cosas nuevas.

3. Relaciones sociales: Normas a favor de la socialización del sujeto con el grupo de trabajo, de mezclar la amistad con los negocios. 
4. Libertad personal: Normas a favor de la expresión de uno mismo, de ejercer la liberta de decisión, de satisfacer los gustos personales.

La metodología para recoger la información sobre la cultura propone que se pase dos veces el cuestionario, una primera vez preguntando sobre las normas que actualmente perciben los sujetos y una segunda en la que se pregunta sobre lo que desearían que se dieran en la unidad para favorecer el buen rendimiento y la moral de los miembros. Así se consiguen tres tipos de información sobre la cultura de la organización: la cultura percibida o las normas que actualmente rigen la unidad, la cultura deseada o las normas que desearían los miembros que rigiesen el grupo, y los desfases culturales que son las diferencias entre las normas percibidas y las normas deseadas.

Tras el análisis de los resultados obtenidos en numerosas organizaciones productivas y no productivas con la aplicación del cuestionario de Kilmann y Saxton se pone de manifiesto diferentes patrones de desfases culturales. Por ejemplo en organizaciones muy burocratizadas, como bancos y organismos públicos, son evidentes grandes desfases culturales en libertad personal, los miembros se sienten claramente confinados y constreñidos lo cual afecta su rendimiento y su moral (Schraeder; Tears y Jordan, 2007).

La explicación se puede deber a que no todos los sujetos perciben los mismos desfases, incluso distintos equipos de trabajo en una organización pueden percibir distintos desfases culturales. Los desfases culturales más pequeños se encuentran en la alta jerarquía de la organización y los mayores desfases culturales se producen al nivel inferior de la jerarquía, en donde se revelan la alineación y la desconfianza. 
Como anteriormente hemos comentado diferentes teóricos e investigadores han argumentado y demostrado que existe no sólo una cultura dominante en las organizaciones, sino también puede existir unas subculturas propia (Cooke y Rousseau, 1988; Hofstede et al. 1990). Las culturas fuertes imponen considerables presiones a los empleados para que se adapten y limitan la gama de valores y estilos aceptables. Pero esto crea un dilema porque los individuos contratan individuos diferentes por las fuerzas alternativas que traen al trabajo, pero estas fuerzas y sus diversos comportamientos tienden a disminuir a estas culturas a medida que la gente se empeña por adecuarse. Cooke y Rousseau,1988, han puesto de manifiesto que los miembros de diferentes organizaciones comparten una creencia común en relación con las normas de comportamiento que consideran que son ideales, a este conjunto de normas y expectativas compartidas por los miembros le dan el nombre de" perfiles ideales" de cultura.

Para Alonso y Palací (1996) no sólo existe un patrón o perfil ideal de cultura común a varias organizaciones como han demostrado Cooke y Rousseau, (1998), sino que existen también patrones ideales de cultura específicos de cada organización y de cada uno de los grupos que las componen y, por lo tanto, diferencias de una organización a otra y de un grupo a otro.

Una situación no positiva se produce cuando los valores compartidos por los miembros del grupo no se corresponden con los que fomentan la empresa. Esta situación se presta a ocurrir cuando el ambiente de la organización es dinámico, cuando pasa por rápidos cambios que pueden hacer que la cultura atrincherada deja de ser apropiada. La congruencia de comportamiento es un bien para la compañía cuyo entorno es estable 
pero puede ser una carga para obstaculizar su capacidad de responder a los cambios en el medio.

En nuestro trabajo se trata de poner de manifiesto la importancia que tiene el estado deseado en la formulación y en la aplicación del modelo del proceso de cambio social y de acción- investigación. Deseamos comprobar empíricamente que las organizaciones y los grupos que se estudian tienen su propio estado deseado o patrón ideal de conducta, esto es, los miembros comparten las normas y expectativas que entienden que son ideales para que su organización o grupo proporcionándoles mayor eficacia en sus objetivos y satisfacción a sus miembros en relación a los equipos que no comparten las normas y expectativas (Robinson, 1998).

\subsection{CONCLUSIÓN}

En este capitulo se ha hablado de la cultura organizacional, uno de los conceptos más complejos de las organizaciones que cuenta con un gran auge debido al acelerado desarrollo mundial provocado, entre otros factores, por la globalización y los avances tecnológicos. Queda patente el débil consenso existente entre los investigadores del significado de cultura y como medirla pero también queda patente su importancia en las organizaciones.

En resumen, y según nuestro punto de vista, las organizaciones se consideran como sistemas abiertos que interactúan con el medio ambiente. El marco teórico de referencia que seguimos es el modelo de contingencia de culturas, donde la cultura se considera como un elemento de la organización al igual que otros elementos del sistema organizacional, tales como la estructura, los sistemas de comunicación o los incentivos. 
Departamento de Psicología Social y Antropología. Universidad de Salamanca, Facultad de Psicología

La cultura se relacionará con el rendimiento y la moral, y el resultado de esa relación está condicionada por las interacciones de la cultura con elementos no culturales 
CAPITULO 3

UNA APROXIMACIÓN TEÓRICA AL ESTUDIO DEL COMPROMISO ORGANIZACIONAL 
CAPITULO 3. APROXIMACIÓN TEÓRICA AL ESTUDIO DEL COMPROMISO ORGANIZACIONAL.

Teniendo en cuenta la contribución del capital humano en la empresa y siendo el compromiso organizacional uno de los mejores predictores del desempeño, en este capitulo revisamos el compromiso que establecen los trabajadores con la entidad en la que trabajan porque el compromiso organizacional se ha convertido en una variable fundamental de la eficacia, productividad y efectividad institucional (Morgan y Hunt, 1994).

Estudiaremos el compromiso organizacional analizando sus dimensiones y revisaremos los instrumentos de medida que se utilizan para medir el compromiso organizacional y los factores más relevantes que intervienen en su desarrollo.

Recapacitamos sobre lo importante que es encontrar indicadores que nos permitan predecir el compromiso, por ello tratamos de identificar cual es la naturaleza de cada uno de los posibles vínculos que puede establecer un empleado con su empresa y que factores o variables influyen en el desarrollo de esos vínculos. Por último determinamos la relación entre la cultura y el compromiso organizacional.

\subsection{INTRODUCCIÓN}

Una actitud que tiene una extraordinaria importancia para la constitución de las organizaciones en grupos coherentes es el compromiso que alcanzan los trabajadores con la entidad en la que ejercen sus funciones laborales, por ello, en los últimos 10 
años, el compromiso ha obtenido una gran relevancia debido a las consecuencias que tiene en el desarrollo de la organización. También ha despertado gran interés en la Psicología del Trabajo y de las Organizaciones debido a la implicación que se le atribuye en el éxito de las organizaciones, existiendo evidencia de una relación entre determinadas variables antecedentes y el compromiso y entre el compromiso y variables resultado.

El enfoque de la Teoría de los Recursos y Capacidades (Barney, 1991; Mahoney y Pandian, 1992; Peteraf, 1993) realiza un análisis estratégico de las organizaciones para tratar de identificar los recursos de todo tipo de empresas, analizar como se combinan esos recursos para generar capacidades y comprobar su efecto sobre las organizaciones.

Las ventajas que consiguen las organizaciones con sus recursos serán válidas si se pueden mantener en el tiempo. Mantenerse en el tiempo va a depender de la permanencia de los individuos en la organización y esta permanencia va a depender de la satisfacción del empleado con su trabajo porque si el empleado se encuentra satisfecho con el trabajo que desempeña realizará un mayor compromiso con la organización.

El gran reto que tienen actualmente los recursos humanos es buscar una fórmula mediante la cual el personal pueda llegar a comprometerse con los objetivos organizacionales e integrarse en la empresa, ya que el compromiso organizacional es uno de los mejores predictores del desempeño, y de la contribución del capital humano en la empresa, por ser una respuesta global y duradera en la organización. Su análisis servirá para analizar la identificación con los objetivos organizacionales, la lealtad, la vinculación de los trabajadores, el aumento del desempeño laboral, la disminución del 
asentismo laboral (Smith, 1997) citado en Mottaz, 1988, Steers, 1977), la baja rotación y menos atrasos. Se convierte en una variable fundamental de la eficacia, productividad y efectividad institucional (Morgan y Hunt, 1994).

\subsection{ANTECEDENTES CONCEPTUALES}

El desarrollo de la investigación del compromiso organizacional se remonta a los estudios de las actitudes laborales u organizacionales y sólo a partir de 1958-1960, con la formulación de Abrasom, Cutler, Kautz y Mendelson y Becker, es donde se empieza a perfilar el interés de los investigadores por precisar sus implicaciones prácticas.

En algunos estudios precursores se pueden apreciar maneras diferentes de conceptualizar el compromiso. Lodahl y Kejner (1965) lo definen como el grado que una persona se identifica psicológicamente con su trabajo. Insel y Moos (1974) lo consideran como la medida en que los empleados se interesan en sus trabajos y se comprometen con ellos.

El primer intento más sistemático por medir el compromiso organizacional se realiza en las empresas norteamericanas por Porter, Steers, Mowday y Boulian (1974) culminando con el desarrollo del Cuestionario de Compromiso Organizacional (OCP). Mowday, Porter y Steers (1979); Porte, y cols.(1974) conceptúan compromiso organizacional como la fuerza relativa de la identificación y el involucramiento de un individuo con una organización en concreto, que conlleva el deseo del trabajador de permanecer en la organización, la aceptación de valores y las metas de la organización y su voluntad para conseguirlas. 
La aproximación que realiza Meyer y Allen (1984) considerando el modelo de Porter (1974) se centra en explicar la conducta comprometida de los empleados a partir de sus cogniciones, emociones y conductas. Esta obra va a marcar el inicio de un cambio en las investigaciones de compromiso organizacional planteando la hipótesis de un único componente con dos dimensiones, afectivo y continuidad, y culminando su obra en 1990 con la incorporación de un tercer componente, el compromiso normativo, y la construcción de su escala (Allen y Meyer, 1996; Cohen, 1996).

Mathieu y Zajac (1990) en la revisión que realizan de los antecedentes, correlatos y consecuencias del compromiso organizacional encontraron que la conducta de retiro y el absentismo eran predichos mejor por el compromiso afectivo siendo evidente que el compromiso produce efectos sobre el comportamiento laboral de las personas.

En la investigación sobre Comportamiento Organizacional, Robbins (1998), se interesó en tres actitudes:

1. El compromiso organizacional: Es el grado en el cual un empleado se identifica con una organización en particular, con sus metas y desea mantenerse en ella como uno de sus miembros.

2. La satisfacción laboral: Es la actitud general de un individuo hacia su empleo.

3. Compromiso con el trabajo: el cual lo define como el grado en el cual un trabajador se identifica con su trabajo, participa activamente en él y considera su desempeño importante para la valoración propia.

Desde la postura tradicional una de las primeras divisiones que vamos a encontrar en el estudio del compromiso organizacional estará relacionada con la perspectiva desde la 
que se aborda su estudio, que puede ser una perspectiva actitudinal o perspectiva conductual.

\section{- Perspectiva actitudinal:}

Esta perspectiva se ha interesado por el estudio de los antecedentes que contribuyen al desarrollo del compromiso organizacional y por sus consecuencias. Su principal exponente son los trabajos desarrollados a partir de las propuestas de Porter y Steers (1982) que definen el compromiso organizacional con la identificación e implicación del trabajador con la organización.

Para realizarse la identificación del trabajador con la organización es necesario una fuerte aceptación de las metas y valores de la organización, la voluntad de ejercer los esfuerzos necesarios para que alcance sus objetivos y el deseo de permanecer en la organización (Smith, 2005).

La valoración de este constructo, cuya naturaleza es multidimensional, se realizó con la escala OCQ que ellos desarrollaron.

\section{- Perspectiva conductal:}

Desde esta perspectiva se centra en el análisis de las condiciones bajo los cuales la conducta de compromiso hacia la organización tiende a reaparecer y los cambios actitudinales que provoca. Su principal núcleo de investigación se refiere a la teoría side-best desarrollada por Becker (1960). Los “side-bets" son las inversiones valoradas por el individuo que serían pérdidas si éste dejara la organización.

Las consideraciones precedentes muestran que no existe un concepto simple del compromiso sino que este concepto es multifacético y que además puede estar con 
otros constructos como apoyo organizacional, satisfacción en el trabajo, consecución de metas, etc, que constituyen sus antecedentes o consecuentes pero que complementaran o ampliaran su alcance.

Nuestro estudio buscando explorar las relaciones de dependencia del compromiso con respecto a factores como cultura organizacional, desfases culturales y potencia cultural, parte de la visión del compromiso organizacional desde la perspectiva actitudinal.

\subsection{DEFINICIONES DEL COMPROMISO}

Si bien los primeros autores en estudiar el compromiso en el contexto organizacional fueron Porter et al (1974) anteriormente lo hicieron otras disciplinas como la antropología, la sociología y la psicología cognitiva.

Desde la antropología se define el compromiso como el deseo de los actores sociales de dar energía y lealtad a la organización a la que pertenecen. Kanter (1968), y Kiesler (1971), desde la psicología cognitiva, lo consideran el resultado de verse atrapado en una determinada línea de compromiso. Ambas definiciones comparten el considerar que el compromiso representa un vínculo psicológico entre las personas y las organizaciones mediatizadas por una fuerza que bajo determinadas circunstancias estabilizan el comportamiento y compromete a continuar en un curso de acción. Si no existiría esa fuerza la persona estaría tentada a cambiar su comportamiento (Bucharan, 1974; O’Really y Chatman, 1986).

Las definiciones del compromiso organizacional se han centrado principalmente en dos aspectos (Mayer y Schoorman, 1992), el primero de ellos se refiere a aquellos que consideran los aspectos relevantes para su participación y el segundo se refiere a los 
aspectos referidos a la producción, por ejemplo Hrebiniak y Alutto (1972) se centra más en el intercambio o participación y definen el compromiso como el resultado de las transacciones individuo-organización y las alteraciones en su mejor sentido o inversiones a lo largo del tiempo. Sin embargo Hall, Schneider y Nygren (1970) se centran más en las cuestiones relacionadas con los valores compartidos y definen el compromiso como "el proceso por el que los objetivos de la organización y del individuo llegan a estar cada vez más compensados y congruentes".

Resulta difícil tratar de definir qué es compromiso organizacional por los distintos planteamientos teóricos surgidos y las diferentes maneras de definirlo que aparecen en la literatura existente. Porter, Steers, Mowday y Boulian (1974) se plantean recurrir a aspectos que reflejan una actitud positiva del empleado hacia su organización por lo que lo definen compromiso organizacional como la fuerza con que un individuo se identifica e implica en una organización en particular. Hipotetizan que los individuos altamente comprometidos con los objetivos de su organización y deseos de dedicar buena parte de su energía a lograrlos, estarán más inclinados a permanecer en su organización (Shannawaz y Hazarika, 2007).

Para Porter et al (1974) la fuerza que estabiliza el comportamiento es la identificación e implicación con las metas y objetivos de la organización. A partir de las aportaciones señaladas por otras disciplinas podemos suponer que hay otras fuerzas que pueden mantener el vínculo entre una persona y su organización.

También en el intento de definirlo, Meyer y Allen (1991) definen el compromiso como un estado psicológico y como una actitud que se expresa en un vínculo psicológico del empleado hacia la organización que hace que sea poco probable que el empleado 
abandone la organización. Propusieron esta definición que refleja tres componentes: el primer componente es un deseo (compromiso afectivo), el segundo una necesidad (compromiso de continuar) y el tercer componente refleja una obligación (compromiso normativo) para mantener al empleado en la organización.

Mathieu y Zajac (1990) tras realizar una exhaustiva revisión de trabajos sobre el compromiso concluyen que las diferentes definiciones del término tienen en común el considerar que es un vínculo o lazo del individuo con la organización.

Toda esta amalgama de definiciones pone de manifiesto que el compromiso es un constructo de naturaleza multidimensional que engloba las tres dimensiones de compromiso. O'Reilly y Chatman $(1986,1990)$ y Allen y Meyer $(1990,1993))$ y Allen y Meyer (1990) van a aportar evidencia de la validez discriminante de las tres dimensiones de su escala, llevando a cabo un análisis factorial exploratorio y encontrando una estructura factorial con tres factores que coinciden con las dimensiones propuestas.

Se han realizado otros estudios factoriales para evaluar empíricamente la naturaleza del compromiso organizacional. Así Schechter (1985) tomando como base el cuestionario OCQ, desarrolló una medida de compromiso organizacional para diferenciar entre compromiso de valores y compromiso de continuar, encontró que el compromiso de continuar estaba significativamente correlacionado con intenciones de abandonar, y el compromiso con los valores estaba significativamente correlacionado con autocalificaciones de rendimiento, conductas extrarol y satisfacción.

Frutos, Ruiz y San Martín (1998), tras la revisión de las distintas propuestas teóricas existentes se propusieron delimitar las dimensiones que componen el constructo de 
compromiso obteniendo como resultado que el constructo de compromiso permite ser evaluado desde distintas perspectivas relacionadas entre sí, "dimensión afectiva, dimensión normativa y dimensión calculada“. Estos autores sitúan en la parte central a los vínculos afectivos que establece el individuo con su entorno laboral y a la percepción de una obligación normativa a continuar con la labor que desempeña dentro de la organización.

Siguiendo esta investigación, Peiro y Prieto (1996) presenta la línea que plantea la vertiente actitudinal del compromiso entendido como un estado en el que las personas se identifican con la organización y con las metas y quieren seguir siendo miembros de la misma. Como variable actitudinal presentarán un componente cognitivo, que incluye las percepciones conocimientos y creencias personales, la dimensión emocional que representará los sentimientos derivados de la relación tiene sus raíces en la propuesta de Buchanan (1974), y por último la dimensión comportamental se asentará en la manifestación del compromiso.

\subsection{DIMENSIONES DEL COMPROMISO}

Como hemos puesto de manifiesto en el apartado anterior el compromiso organizacional es una variable actitudinal que estudiaremos analizando sus tres dimensiones:

\subsubsection{Compromiso afectivo o actitudinal.}

Refleja el apego emocional, la identificación e implicación con la organización y consiste en la identificación psicológica del colaborador con los valores y la filosofía de la empresa. Mowday, Steers y Porter (1979) lo definen como "la fuerza de la 
identificación de un individuo con una organización en particular y de su participación en la misma.

Conceptualmente puede ser caracterizado por al menos tres factores: el primero es una fuerte convicción y aceptación de los objetivos y valores de la organización, la segunda es la disposición a ejercer un esfuerzo considerable en beneficio de la organización y el tercero es el fuerte deseo de permanecer como miembro de la organización.

Esta identificación con la organización se manifiesta con actitudes como la solidaridad, la preocupación por los problemas de la empresa y la preocupación por su trayectoria. El compromiso afectivo mejora o tiende a aumentar en la medida que los empleados experimentan mayor autonomía, responsabilidad e importancia del trabajo. Los empleados con alto compromiso afectivo tienden a manifestar una buena disposición al cambio implicándose en el.

El compromiso afectivo significa para Meyer y Allen $(1984 ; 1997)$ la unión emocional, la identificación e implicación del trabajador con la organización. Siendo el comportamiento más esperado por parte del trabajador la permanencia en la organización, se establece la relación entre la vinculación afectiva con la organización y ciertas consecuencias como la puntualidad, asistencia al trabajo y el desempeño de los trabajadores. Creen que este compromiso en parte es resultado de las experiencias del trabajo y de las características objetivas de la organización, de las condiciones laborales y expectativas satisfechas, al igual que esperan que existan diferencias individuales que favorezcan el desarrollo del compromiso afectivo.

Se han interesado por el estudio de los antecedentes que contribuyen al desarrollo del compromiso organizacional y sus consecuencias y el análisis de las condiciones bajo 
las cuales la conducta de compromiso hacia la organización tiende a reaparecer. Si el empleado está identificado e implicado en la organización mayor será las posibilidades de permanencia en ella.

El trabajo de Buchanan (1974) se sitúa dentro de la tradición afectiva, su conceptualización del compromiso sigue la definición de Porter y sus colaboradores, si bien, puso especial énfasis en la naturaleza eminentemente afectiva del vínculo de carácter instrumental o de intercambio.

En relación a los instrumentos de medida que se utilizan para medir el compromiso afectivo son los siguientes:

- El Cuestionario de Compromiso Organizacional (OCQ) es el instrumento de medida propuesto por Porter et al, (1974) que ha prevalecido en una buena parte de los trabajos de investigación posterior. Recoge los aspectos de investigación con la organización, implicación y lealtad. Allen y Meyer (1990) y Allen, Meyer y Smith (1993), criticaron el OCQ argumentando que algunas preguntas de lealtad estaban contaminadas por las instrucciones de abandono.

- Diversos autores han propuesto otros instrumentos en la misma línea de OCQ. O'Really y Chatman (1986) en un estudio para evaluar las consecuencias de las diferentes formas de compromiso, elaboraron una escala de compromiso con 3 componentes, los correspondientes a interacción e identificación, presentando un contenido equiparable con el OCQ.

- Penley y Gould (1988) propusieron una escala de medida para las dimensiones afectiva, normativa y calculada. Para las dimensiones afectiva y normativa se 
basaron en los ítems del OCQ de Porter et al (1974). Todos los autores informaron que la correlación con el OCQ fue significativa; Penley y Gould, 1988; O’Really y Chatman, 1986 y Allen y Meyer, 1990; Meyer, Allen y Smith, 1993).

Gran parte de los trabajos de investigación han estado orientados a identificar las variables antecedentes y las consecuencias del compromiso afectivo. Una parte de la investigación ha buscado el origen en las primeras experiencias laborales (Meyer y Allen, 1984; Buchanan, 1974), centrándose en las etapas que siguen a la entrada del nuevo empleado en la organización. Aspectos como tener una perspectiva realista del puesto, las prácticas de socialización sobre el ingreso, o la confirmación de las expectativas son lo más importante en los primeros momentos del desarrollo del compromiso. Otra parte de la investigación ha buscado los antecedentes del compromiso afectivo en el entorno laboral que rodea a la persona.

Mowday et al (1979); Steers, (1977) clasificaron los antecedentes de compromiso en dos grandes grupos; a) factores procedentes de la organización y b) los factores personales. Dentro de los factores procedentes de la organización encontramos variables que hacen referencia al contenido del trabajo, a las tensiones, las relaciones interpersonales, y la estructura de la organización y dentro de las características personales se sitúan la edad, antigüedad o la cara profesional.

\subsubsection{Compromiso de continuidad}

El compromiso de continuidad revela el apego de carácter material que el colaborador tiene con la empresa. El trabajador ira realizando diferentes inversiones en la empresa 
lo que hará que se vincule con ella en distintos grados por lo que dejarla significaría perder todo lo que ha invertido.

Desde esta teoría se define el compromiso como una línea consistente de comportamiento como resultado de la acumulación de inversiones. Será el coste asociado a la pérdida de estas inversiones acumuladas lo que conduce al trabajador a desarrollar su acción que es lo que caracteriza el compromiso organizacional.

La teoría de Becker, (1960) (side-best) sugiere la existencia de una gran variedad de vías que facilitan la acumulación de inversiones por parte de los trabajadores. Como variable influyente en la acumulación de estas inversiones tenemos la edad y la antigüedad en la organización pero también se suman el salario, la posición que se ocupa en la organización, el estado civil o percepción de alternativas. Pero esta teoría no siempre se ha confirmado empíricamente.

También se ha recurrido a la teoría de las atribuciones de Festinger (1957), Salancik, (1978); O'Really y Caldwell, 1986), sostienen que una vez que una persona ha tomado una serie de decisiones que implican inversiones en la organización, tienen la necesidad de mantenerse psicológicamente consistente con sus propias acciones. Por consiguiente expresan una actitud positiva hacia la organización (compromiso) para mantenerse consistente con las inversiones que ha realizado en la misma.

Entre las aplicaciones del compromiso de Becker esta el trabajo de Ritzer y Trice, (1969); Hrebiniak y Alutto, (1973) que interpretan el compromiso como la probabilidad de dejar la organización a cambio de incrementos salariales, el estatus, la libertad profesional o la mayor amistad entre los colegas. Según esta aplicación una persona que no quiere dejar la organización aunque consiga alguno de estos beneficios tendría un 
compromiso elevado. Esta operalización del compromiso ha recibido duras críticas, aduciendo que está más centrada en las intenciones de abandono que en el propio compromiso ( Penley y Gould, 1988).

Meyer y Allen, (1984) cuestionaron el carácter de un compromiso elevado si se ofrecen incrementos en las recompensas, que el empleado se mantenga en la organización, puede ser debido a que tenga un fuerte compromiso afectivo y no por un compromiso de continuidad permaneciendo en la organización a pesar de las tentativas externas de las recompensas. En la identificación de los antecedentes de compromiso calculado, los trabajos de investigación han dirigido su atención a las variables personales como la edad o el tiempo trabajado en la organización por su relación con las inversiones realizadas. Otras variables personales como el estado civil o el número de hijos también se han puesto en relación con el compromiso calculado porque suponen costes añadidos al abandono voluntario de la empresa. Los resultados obtenidos no son muy alentadores y ponen en tela de juicio el modelo de inversiones, aunque se puede descartar la hipótesis de que la disparidad de resultados se debe a la forma en que se ha operacionalizado el constructo del compromiso desde la perspectiva del intercambio de Becker.

Variables individuales como la edad, antigüedad, nivel educativo, capacitación, estado del mercado laboral influyen sobre el compromiso (Wang, 2006). El trabajador que mantiene unos niveles altos en esta dimensión tiende a manifestar una estabilidad laboral que puede ser puramente situacional. Esta dimensión se construye a partir de la valoración de las pérdidas para el individuo si dejara la organización (Cohen y Lowenberg, 1990), porque el individuo es consciente de que existen unos costes asociados a dejar la organización en la que trabaja (Meyer y Allen, 1991; 1997). El 
estado psicológico que surge es la necesidad, por ello los trabajadores que han desarrollado un compromiso continuo intentarán permanecer en la organización realizando las conductas que resulten imprescindibles.

Se proponen dos grupos de variables implicadas: las alternativas de trabajo y las inversiones. En referencia a las alternativas de trabajo cuando el trabajador no posee alternativas de trabajo es posible que su permanencia en la organización sea resultado del desarrollado del compromiso continuo.

En relación al segundo grupo de variables Rusbult y Farell (1983) elaboraron un modelo de compromiso calculado llamado modelo de inversiones. La propuesta describe un modelo aditivo en el que el nivel de compromiso es el resultado de la suma de recompensa procedente del trabajo menos costes asociados al mismo, a esta diferencia se añade las inversiones realizadas en las organizaciones y se le restan la existencia de alternativas factibles a la situación actual.

Según estos autores, las recompensas procedentes de la organización permanecerán constantes a lo largo del tiempo; sin embargo, el impacto de los costes de trabajo ira en aumento a medida que las expectativas del trabajo no se cumplen. La presencia de variables externas a la organización resulta novedosa, puesto que se plantea que pueden influir sobre el compromiso; según el modelo, la posibilidad de tener un trabajo alternativo reduce los niveles de compromiso.

El modelo fue contrastado empíricamente con una muestra de 88 empleados, en este estudio encontraron que el compromiso estaba asociado con grandes recompensas, bajos costes, pocas alternativas de empleo altenartivo y grandes inversiones. Oliver 
(1990) replicó el modelo y eligió la escala OCQ de Porter 1973, este autor sólo encontró soporte parcial para el modelo.

Finalmente, para intentar esclarecer la naturaleza del compromiso Frutos, Ruiz y Martín (1998) lo dividen en dos dimensiones: costes y alternativas y subrayan que esta modalidad de compromiso se caracteriza porque esta relacionada con el contenido de la tarea, el estilo de dirección, perfiles personales y conductas como intención de abandono.

\subsection{3 .Compromiso normativo}

Es la tercera dimensión y al igual que el compromiso afectivo es de naturaleza emocional. Consiste en la experimentación, por parte del trabajador, de un fuerte sentimiento de permanencia en la empresa por la sensación de deuda creada con ella. Esta dimensión es la menos desarrollada y menos estudiada empíricamente. Se crea un sentimiento de lealtad del individuo con la organización que puede deberse a presiones de tipo cultural o familiar. Este trabajador será un trabajador incondicional aunque a lo mejor no con el entusiasmo y energía del trabajador con alto compromiso afectivo.

Meyer y Allen $(1991 ; 1997)$ señalan que tienen un fuerte impacto en la conducta de los trabajadores, tanto en lo relativo a su presencia como a su desempeño y a la realización de conductas extra-rol y, que el desarrollo de este compromiso puede influir en diversos procesos vinculados con la socialización y la percepción de relaciones desequilibradas. Este compromiso normativo podría generarse por los procesos de condicionamiento y modelamiento experimentados por el trabajador tanto en el plano familiar como cultural y en la organización. Buchanan (1974) se interesa por el procedimiento mediante el que una persona se compromete con su organización y para ello recoge 
algunas definiciones procedentes de los estudios que han hecho sobre el compromiso desde otras disciplinas.

En conjunto, las experiencias laborales del individuo en el seno de la organización intervienen en el desarrollo de su actitud, se sabe poco sobre la naturaleza de estas experiencias ni su importancia relativa a la formación del compromiso. Motivados por conocer más en profundidad el desarrollo del compromiso O’Really y Chatman, (1986) buscan las bases sobre las que se establece el vínculo psicológico entre una persona y su organización. El trabajo de estos autores se puede situar en la tradición afectiva, si bien no comparten la conceptualización del compromiso con la identificación e implicación con la organización.

Según O’Really y Chatman, el vínculo psicológico no conlleva necesariamente la identificación, la implicación y el sentimiento de lealtad. El compromiso se puede entender como la identificación con un objetivo, grupo u organización, donde el grado de identificación varía al igual que las bases para el vínculo.

En el trabajo realizado por Ferrer, (2005) revela que es la categoría calculada la que obtiene una puntuación superior en valoración de los clientes, pero estos resultados discrepan con los obtenidos por Frutos et al. (1998) porque para estos autores es la dimensión afectiva la que desempeña un papel relevante en el análisis de compromiso de los empleados. Ferrer explica esa discrepancia por la falta de posibilidades de elección de los empleados, que las tienen limitadas o son pocas las opciones de elegir empleo, por lo que las personas recurren a buscar cierto sentido a su compromiso recurriendo a aspectos emotivos aunque se suponga que su trabajo le reporte pocos 
beneficios o ventajas. Por ello adquiere sentido los resultados de Frutos (1998), ser la vertiente afectiva la más influyente cuando se analiza el trabajo.

\subsection{MODELOS}

Referente a las dimensiones necesarias para explicar el fenómeno de compromiso la revisión de la literatura existente no permite un acuerdo generalizado sobre cuáles son dichas dimensiones, por este motivo algunos investigadores han realizado estudios para evaluar empíricamente la naturaleza del compromiso organizacional.

\subsubsection{El modelo de los tres componentes Meyer y Allen.}

El modelo de los tres componentes propuesto por Meyer y Allen (1991:1997) es uno de los modelos que más aceptación está teniendo. Este modelo destaca por la integración de un conjunto de investigaciones sobre compromiso organizacional que se caracterizaban por su fragmentación.

Definen el Compromiso Organizacional como estado psicológico de los trabajadores que pueden reflejar un deseo, una necesidad y/o una obligación de permanecer como miembro de la organización. Este deseo, necesidad y obligación corresponden con tres formas de vinculación del empleado con la organización que se encontrará en el trabajador en mayor o en menor medida.

Este modelo recoge los puntos que ha dominado el estudio del compromiso organizacional: la unión afectiva, los costes asociados con el abandono y el sentimiento de obligación. Su gran aportación cosiste en compendiarlos en un único constructo e intentar superar las limitaciones, sobre todo las referidas a la medición de las distintas dimensiones. 
Subrayan su naturaleza multidimensional que implica, que la identificación del trabajador con la organización será resultado de tres tipos de estados psicológicos diferentes que constituirán las dimensiones del compromiso organizacional: afectivo, continuo, y normativo. Estas dimensiones caracterizan las relaciones del trabajador con la organización y por otro lado afectan la decisión de continuar o abandonar la organización. Para Meyer y Allen estas tres dimensiones son diferentes pero no excluyentes sino que el trabajador puede experimentar las tres formas de compromiso al mismo tiempo y con distinta intensidad.

El pilar de su modelo son los instrumentos de medida elaborados pasa medir cada una de las dimensiones del compromiso organizacional, ACS, CCS, NCS.

González.y Antón, (1995), tras la revisión que realizaron de los estudios de compromiso, concluyeron que la aceptación de la propuesta realizada por Meyer y Allen debía pasar por un análisis de la validez del constructo en general, y en particular de las relaciones teóricas propuestas entre las dimensiones del compromiso organizacional y sus variables antecedentes y consecuentes.

\subsubsection{Modelo de O’Reilly y Chatman (1986)}

Basándose en los trabajos de Kelnman (1958) sobre el cambio de actitudes, O'Reilly y Chatman (1986) elaboran un modelo tridimensional del compromiso organizacional, el cual guarda paralelismo con la propuesta por Meyer y Allen (1991).

Definen tres tipos de compromiso del trabajador como respuesta a 3 procesos diferentes: sumisión (compromiso continuo), identificación (compromiso afectivo) y la internalización (compromiso normativo). En estudios posteriores sólo han identificado 
dos dimensiones concluyendo que el compromiso organizacional está integrado por dos tipos de respuesta del trabajador, el compromiso continuo que conlleva un proceso de sumisión frente a las normas y procedimientos de organización, y por otro un compromiso afectivo que engloba la respuesta de identificación e internalización del trabajador frente a la organización.

El instrumento más utilizado ha sido el Cuestionario de Compromiso Organizacional (OCQ) desarrollado por Porter, Steers, Mowday y Boulian (1974). Tomando como base el cuestionario OCQ, Schechter (1995) desarrolló una medida de compromiso organizacional para diferenciar entre lo que él llamó "compromiso con valores" "compromiso de continuar". El compromiso de continuar estaba significativamente relacionado con la intención de abandonar, el compromiso con los valores estaba significativamente correlacionado con el rendimiento y la satisfacción con la organización.

\subsection{FACTORES DETERMINANTES DEL COMPROMISO.}

Una de las primeras preguntas que debemos plantearnos es ¿Qué es lo que lleva a una persona a identificarse o implicarse con su organización?. En este punto se trata de identificar los aspectos de la organización y las características personales que pueden tener un papel relevante en el desarrollo del compromiso.

\subsubsection{Factores organizacionales determinantes del compromiso afectivo}

En el desarrollo del compromiso con la organización uno de los factores más relevantes que intervienen son las características del trabajo y experiencias vividas por una persona en su trabajo. Los empleados estarán más satisfechos cuando puedan satisfacer 
sus propias necesidades trabajando porque las condiciones del trabajo son adecuadas para ello. Existe cierto consenso en tener que considerar el contenido del trabajo como uno de los aspectos más importantes para el desarrollo del compromiso, su influencia es superior al de otros factores del entorno laboral (Buchanan, 1974; Mowday et al, 1979; Meyer y Allen, 1988).

Factores determinantes del compromiso y del abandono de la organización son el conflicto y la ambigüedad del rol (Porter y Steers, 1973: Steers y Porter, 1982). Salancik (1978), argumentó que la influencia de las tensiones del rol en el compromiso organizacional se debe a que el conflicto conduce a una disminución de la percepción de responsabilidad para la persona que ocupa el puesto que le llevará a la implicación e identificación con la organización. Del mismo modo, la percepción de ambigüedad en el rol, crea confusión en la definición de las expectativas y metas del rol por lo que será más difícil para el ocupante identificarse con las metas y por tanto decrecerá su nivel de compromiso.

El entorno social y las relaciones interpersonales que le rodea al trabajador es una parte importante de su experiencia laboral. En los procesos de socialización e integración de la persona cuando entra a formar parte de la organización el entorno social inmediato tiene un papel destacable. Posteriormente, la interacción con los compañeros de trabajo pude proporcionar el soporte y apoyo necesario para adaptarse y mantener el vínculo con la organización. Puede que incluso el grupo de trabajo influya en la formación de las actitudes del individuo hacia su organización (Buchanan, 1974: Lok; Westwood y Crawford, 2005). 
La importancia de la figura del supervisor sobre el comportamiento de los empleados se puso de manifiesto en los estudios de la universidad de Michigan y la Universidad del estado de Ohio, concluyeron que la relación del supervisor con el trabajador puede constituir un fuerte apoyo y reconocimiento facilitando la realización de su trabajo. Según el resultado obtenido en los estudios realizados por Porter y Steers (1982) la satisfacción con el supervisor era el único aspecto que diferenciaba a los empleados que permanecen en la organización de los que abandonan.

La naturaleza de la relación entre compromiso y satisfacción ha sido un punto de debate en la investigación, el motivo ha sido la ubicación temporal de las dos variables: satisfacción como antecedente de compromiso o compromiso como antecedente de satisfacción o si tienen una relación reciproca. Los resultados no son del todo concluyentes pero conocer la relación entre ambas variables es importante por las implicaciones que a nivel de intervención organizacional tiene.

Una de las primeras reflexiones a plantearse sería si el compromiso es una actitud diferente a la satisfacción y sí compromiso y satisfacción son distintos cual es la relación entre ambas:

- El compromiso con la organización expresa la relación entre el individuo y su organización en términos globales, en contraposición a la satisfacción laboral que es una actitud asociada a aspectos más específicos y tangibles del trabajo.

- La satisfacción laboral se define como "un estado emocional placentero o positivo que resulta de la evaluación del propio trabajador o de las experiencias laborales (Locke, 1975). Inicialmente, el estudio de Locke se movía en los términos de la evaluación del trabajo en términos generales, posteriormente se 
ha ido haciendo más específico analizando los elementos que componen el trabajo y la satisfacción en términos de estos elementos (contenido del trabajo, salario, promoción, reconocimiento, supervisor, compañeros y política directa)

Tanto el compromiso como la satisfacción laboral expresan actitudes hacia el trabajo, y a pesar de que existan algunos resultados contradictorios se puede concluir que existe influencia reciproca entre ambas. Esta influencia mutua se puede atribuir a que ambas actitudes vienen determinadas por aspectos comunes del entorno laboral.

Hay diversas formas o perspectivas teóricas desde las que se puede entender el compromiso, y su estudio en el contexto laboral se ha servido de estas orientaciones. Porter et al (1975) sugieren que el compromiso y la satisfacción son dos actitudes relacionadas pero discernibles:

"Cuando se habla de compromiso con la organización se piensa en términos bastante globales, necesitando el empleado más tiempo para determinar su nivel de compromiso que para determinar su nivel de satisfacción. Es posible que el nivel de compromiso sea estable y duradero. La satisfacción parece asociada a aspectos más tangibles del contexto laboral, y puede representar una respuesta afectiva que se forma rápidamente”.

\subsection{2 .Factores personales determinantes del compromiso}

Para comprender el compromiso además de atender a las circunstancias del entorno laboral hay que atender a la persona. Las características personales que con mayor frecuencia se han relacionado con el compromiso son: la edad, la educación, el género, 
el tiempo de permanencia en la organización y el puesto de trabajo, así como el nivel jerárquico dentro de la organización (Wang, 2006).

La relación de antigüedad y compromiso ha sido atribuida a que las personas que llevan menos tiempo en la empresa son menos comprometidas y abandonan la organización antes, sin embargo los más antiguos manifiestan una actitud positiva hacia la organización que justifica su permanencia en ella y la inversión realizada durante ese tiempo. De esta forma una persona que se mantiene más tiempo en su organización percibe más positivamente el lugar en el que trabaja y seguramente habrá conseguido puestos más atractivos lo que habrá derivado en un mayor nivel de compromiso hacia su organización (Salancik, 1978; Caldewell y O’Really, 1986).

También se ha mostrado relación entre el compromiso y la edad del empleado. Allen y Meyer (1993) informaron que el efecto de la edad seguía siendo significativo aunque teniendo en cuenta el efecto de la antigüedad. Los resultados muestran que las personas de más edad suelen tener mayor estabilidad en su carrera profesional y parecen que se encuentran más satisfechos en su trabajo.

En relación al nivel educativo en los estudios de compromiso se planteó que personas con mayor nivel educativo tendrían más posibilidades de realizar un trabajo intelectualmente estimulante que fomentará el compromiso con la organización. Sin embargo los resultados encontrados en diversos estudios demuestran lo contrario. La asociación encontrada entre compromiso y educación era pequeña y de signo negativo, la explicación puede ser que las personas con un nivel educativo mayor tienen una mayor expectativa sobre su trabajo y que si no están satisfechas puede conducir a un descenso en los niveles de compromiso (Mowday et al 1979). 
Buscando factores que afecten los niveles de compromiso no podemos olvidar evaluar el género como posible causa de diferenciación. A la luz de los resultados de integración no existe relación entre el género y el compromiso, dada la inconsistencia y el tamaño de relación (Aven ,1988).

Se plantea que las personas que ocupan las posiciones más altas dentro de la jerarquía de la organización tienden a mostrar mayores niveles de compromiso (Salancik, 1977; Carlopio y Gardner, 1995). Se encuentra una relación positiva y consistente aunque moderada. Los puestos superiores están relacionados con mayor estatus y reconocimiento los cuales pueden fomentar el vínculo con la organización.

\subsection{PREDICCIÓN DEL COMPROMISO}

La premisa de que un empleado satisfecho es un empleado productivo nos lleva a pensar en lo importante que es encontrar indicadores que nos permitan predecir el compromiso, para ello los investigadores tratan de identificar cual es la naturaleza de cada uno de los posibles vínculos que puede establecer un empleado con su empresa y que factores o variables influyen en el desarrollo de esos vínculos.

En los estudios revisados se ha hallado que el compromiso organizacional suele ser uno de los mejores predictores de la rotación en los puestos de trabajo. Existen evidencias que muestran como los empleados que puntúan alto en compromiso registran altos niveles de desempeño y productividad y bajos índices de asentismo. Se han encontrado resultados a favor de que la falta de compromiso puede reducir la eficacia en la organización y los trabajadores comprometidos tienen menos probabilidades de renunciar a sus trabajos y aceptar otros empleos, por lo que la organización no incurre en costos provenientes de la rotación del personal. Estos empleados comprometidos 
necesitarán menos supervisión al conocer el valor de integrar sus metas con las metas de la organización.

En los últimos años, los trabajos sobre satisfacción laboral han recibido una especial atención sobre todo por, la implicación en la calidad de vida laboral de los empleados y para explicar aspectos relevantes de la conducta laboral. A diferencia de los años $60 \mathrm{y}$ 70, que destacaron por las propuestas de nuevos modelos, estos últimos años destacan por una reconceptualización de los aspectos implicados en el proceso motivacional y las implicaciones de la satisfacción laboral. Hacia los años 80 se produce el surgimiento de constructos como implicación y compromiso organizacional (González y Antón, 1995).

La satisfacción laboral puede ser definida como un estado emocional positivo o placentero resultante de la percepción subjetiva de las experiencias laborales del sujeto (Locke, 1976), y también como la actitud del trabajador frente a su propio trabajo, dicha actitud está basada en las creencias y valores que el trabajador desarrolla de su propio trabajo. Así mismo Mowday et al. (1979) ha definido el compromiso organizacional como la fuerza de la identificación y la implicación de un individuo con una organización particular, que se caracteriza por la creencia y aceptación de las metas y valores organizacionales.

Ha sido abordada como una actitud que mantiene relaciones muy estrechas con resultados relevantes para las personas y la organización, como el absentismo, la rotación y el compromiso organizacional. Se puede establecer dos tipos de satisfacción, una la satisfacción general que es indicadora de lo que puede sentir el trabajador frente a las distintas facetas de su trabajo y la segunda la satisfacción por facetas, que 
corresponde al grado de satisfacción frente a aspectos específicos de su trabajo: reconocimiento, beneficios, condiciones del trabajo, supervisión recibida, compañeros del trabajo, políticas de la empresa.

Investigaciones empíricas previas han mostrado similares correlaciones entre las medidas de las tres variables, satisfacción laboral, implicación en el trabajo y compromiso organizacional y otras variables organizacionales, pero raramente se han incluido las tres variables en el mismo estudio o medidas simultáneamente en una sola muestra (Mowday et el., 1979, 1983). La ausencia de una teoría bien desarrollada acerca de las relaciones causales existentes entre estos constructos ha dado lugar a pensar en la posibilidad de una redundancia entre los conceptos de implicación de trabajo y satisfacción laboral y entre implicación del trabajo y compromiso organizacional (Morrow, 1983). Aunque en algunos estudios no se han realizado análisis factorial confirmatorio, los estudios correlacionales han concluido que la satisfacción laboral y la implicación en el trabajo pueden ser diferenciadas (Blau, 1985).

Brooke (1988), en su trabajo realiza un análisis discriminante mediante la técnica de análisis factorial confirmatorio de las medidas de satisfacción laboral, implicación en el trabajo y compromiso organizacional. Los resultados de su trabajo mostraban que estas tres medidas median conceptos empíricamente diferentes. Este estudio fue replicado por Lodahl y Kejner (1965) obteniendo unos resultados consistentes con ellos.

Además de la satisfacción laboral como variable que incide en la productividad seria importante encontrar respuesta a la pregunta, ¿Que factores propician el aumento de compromiso de los trabajadores con la organización?, la respuesta a esa pregunta será 
importante porque los empleados comprometidos constituyen una ventaja. Uno de los factores para lograr el compromiso e incrementar la intención de permanencia es el “Apoyo Organizacional”, es decir el hecho de que la organización les apoye en caso que necesiten ayuda. Ese posible respaldo que el empleado puede sentir se reflejará en un aumento de compromiso con la organización.

El apoyo organizacional se esperaba que constituyera un antecedente importante del compromiso porque si las personas perciben que la organización se interesa por ellas, procura su bienestar y las brinda ayuda ante sus problemas, las personas tendrán una respuesta positiva y su permanencia y desempeño será mayor, al igual que se produce cuando los trabajadores son recompensados con ascensos o incrementos en su remuneración (Eisemberger y Rileyl, 1988).

El compromiso de las personas con la organización cada vez constituye un activo importante y para elevarlo será importante conocer no solo el tipo sino también el grado de compromiso realizado. La contribución del compromiso para definir el comportamiento humano en las organizaciones hace que en 1977 Steers se plantee un modelo donde presentaba tres fuentes de compromiso: La primera fuente son las características personales, una segunda serían las características del trabajo y por último las experiencias en el trabajo. Se estudian variables como el apoyo organizacional percibido, la socialización y el reconocimiento, por tener una importancia capital para propiciar el compromiso de los miembros de la organización. Al igual que su formación se ha unido a las variables de características personales, características del trabajo categorías, experiencias en el trabajo y las características estructurales de la organización. 
Mathieu y Zajac (1990) exponen en su trabajo que las variables que determinan el grado de compromiso de un individuo con la organización en la que trabaja podría agruparse en tres categorías: las variables relacionadas con las características del individuo, las variables relacionados con el trabajo que desarrolla la persona y las variables que tienen que ver con las características de la organización o del grupo. Una de las características sería si es una organización pública o privada. En términos generales la dinámica no difiere mucho en los sectores público y privado, pues las funciones de los distintos niveles y sus aportaciones a la cultura son similares, pero si existe una diferencia de grado importante que, sin duda, marca sus respectivas identidades y sus propios modos de comportarse (Rao, 2005).

Las diferencias básicas de los resultados obtenidos por Jabes y Zussman (1989) en un estudio comparativo que realizan en Canadá sobre una amplia muestra de organizaciones públicas y privadas dedicadas a similares actividades son los siguientes:

Los autores tratan de comprobar la percepción que los empleados de ambas organizaciones tienen respecto a distintas dimensiones culturales en función de su pertenencia y experiencia vivida en ellas.

Los resultados de los estudios muestran que los empleados de organizaciones privadas perciben que identifican mejor la misión de la organización, conocen mejor las metas porque están definidas más claramente y son más realistas lográndose en una mayor proporción.

En las organizaciones públicas la misión parece definirse en relación a la política que es cambiante lo que hace que los empleados perciban la misión de la organización de forma más confusa. Las metas son derivadas de programas electorales estando por ello contaminadas de ideales. 
$>$ En la empresa privada el respeto al individuo tiende a ser percibido como una clave cultural básica en las organizaciones, teniendo una percepción más favorable en cuanto a la preocupación por desarrollar la creatividad e innovación para responder con mayor agilidad y eficacia a los cambios del entorno y de los clientes. Las empresas públicas están más jerarquizadas, burocratizadas y estructuradas.

$>$ En relación a la calidad del servicio tanto los miembros de organizaciones públicas como privadas perciben un similar grado de calidad de servicio al cliente.

Si se encuentran diferencias en cuanto a la percepción de los empleados, los miembros de organizaciones privadas perciben que son más leales y están más íntimamente vinculados con sus organizaciones que los miembros de las organizaciones públicas. Ellos perciben que a las organizaciones públicas no les importa su bienestar personal ni existe una preocupación por su desarrollo, lo que es consistente con el bajo nivel de implicación, de lealtad y de compromiso que se recogen en los resultados.

Jabes y Zussman (1989) proponen que los miembros de las organizaciones del sector privado están más satisfechos en general con los aspectos de la cultura, que consideran que inciden en su trabajo y su desarrollo profesional. En este último grupo, en las variables relacionadas con el grupo y la organización podríamos hablar de clima cultura organizacional, relaciones con el líder, cohesión del grupo, etc.....En nuestro trabajo nos centraremos en este grupo de variables porque lo que nos interesa comprobar es la relación existente entre cultura, la intensidad o potencia cultural, los desfases culturales y el compromiso organizacional de los equipos de trabajo. 


\subsection{CONSECUENCIAS DEL COMPROMISO ORGANIZACIONAL.}

Uno de los aspectos más interesantes en el estudio del compromiso organizacional ha sido su influencia en el comportamiento de los trabajadores (Griffin y Bateman, 1986), la rotación de los trabajadores, el abandono, absentismo y desempeño en el trabajo.

La unión psicológica con la organización es una de las áreas de interés más importante. Porter, Steers, Mowday (1974) conceptualizan el compromiso organizacional como la intensidad de identificación e implicación con una organización concreta que conlleva el deseo del trabajador de permanecer en la empresa, de aceptar los valores y las metas de la organización y la voluntad del trabajador para conseguirlo (Mowday, Porter y Steers, 1982; Porte, y col.,1974). En los estudios sobre contrato psicológico se comienza estableciendo una distinción entre el contrato psicológico y el legal para comprobar como una persona puede estar obligada formalmente a desempeñar una labor dentro de la organización, pero esto no significa que se ligue afectivamente a la misma, en cuyo caso si no se implica los costos emocionales y económicos se verán incrementados.

También sería importante para clarificar conceptos realizar una diferencia entre identificación y compromiso;

-Los empleados identificados con la empresa la sienten parte de sí, están en constante búsqueda de la calidad y de mejoras en los procesos, conocen y se involucran en todas aquellas áreas y actividades en donde puedan agregar su propio valor. Se sienten participes del futuro de la empresa, observan los cambios como una forma de renovarse, se sienten como parte del equipo. 
-Las personas comprometidas sienten que deben cumplir con su trabajo, internalizando que tienen que hacerlo y es razón suficiente para cumplir con la tarea, pocas veces destacan por el impulso a los cambios y las mejoras.

El compromiso organizacional ocasiona ciertas consecuencias tanto positivas como negativas para la organización algunas de ellas las mencionamos a continuación:

1-Se esperaría una intención de permanencia y el no cambio de empleo.

2-Según se incremente el compromiso se espera un mayor esfuerzo por parte del trabajador, representándose o valorándose por el tiempo dedicado al trabajo y la intensidad del mismo.

3-Su lado negativo se puede presentar porque un elevado compromiso puede significar inflexibilidad de los miembros de la organización respecto a la transformaciones en la misma, rechazo a las innovaciones y falta de adaptabilidad (Rahdall, 1987).

El compromiso ha despertado interés por las consecuencias que provoca en la forma en la que se comportan los empleados en la organización. Dependiendo de las bases sobre las que se asienta el compromiso, o de las formas de compromiso, las consecuencias van a ser diferentes.

Los teóricos de la organización a menudo han señalado que para el funcionamiento de un organización es esencial que la participación de los empleados no debería limitarse a permanecer en la organización, sino que además tendría que realizar las conductas prescritas por el rol, además de una serie de conductas espontáneas e innovadoras que van más allá de las prescripciones explicitas del rol (Katz, 1964). 
Muchos de los comportamientos en el trabajo descasan en actos de cooperación, altruismo, ayuda espontánea y no renumerada de los empleados. Es probable que para que se den estos comportamientos en el trabajo se requiere un tipo de vínculo psicológico que vaya más allá de la relación basada en la aceptación del intercambio.

\subsection{RELACIONES ENTRE COMPROMISO Y CULTURA ORGANIZACIONAL}

El compromiso organizacional ha sido examinado extensivamente en la literatura organizacional, sin embargo la relación entre cultura organizacional, subcultura y compromiso ha recibido poca atención organizacional (Price y Muller, 1981; Mottaz, 1988; Lok, Wetwood, y Crawford, 2005). Debido a la complejidad y la multifacética naturaleza de los antecedentes involucrados en el compromiso organizacional es necesario entender la dinámica de las relaciones entre estas variables. La satisfacción con el nivel de control sobre el ambiente del trabajo ha tenido alta correlación con el nivel de compromiso.

La revisión y meta-análisis analizado por Mathiew y Zajan (1990) de los antecedentes correlaciones y consecuencias de compromiso no han incluido ninguna referencia a la cultura organizacional o subcultura. Esto es significativo porque Deal y Kennedy (1982) y Waterman (1994) han sugerido que la cultura organizacional puede tener una considerable influencia en las organizaciones, particularmente en áreas tales como desarrollo y compromiso (Garr, 1998).

El estudio de Lahiry (1994) muestra solamente una débil asociación entre cultura organizacional y compromiso y autores como Brown, 1995; Martín y Saiehl, 1983; Scheneider, 1990; Sackmann, 1991 muestran que la subcultura pueden tener una mayor 
importancia que la cultura organizacional debido a que existe una mayor relación entre subcultura y compromiso organizacional que entre cultura y compromiso organizacional.

La percepción de los valores corporativos depende del sistema de valores del individuo el cual, a su vez, esta influenciado por los valores culturales. Debemos asumir que de la manera en que una persona percibe los valores corporativos (individuo-empresa) puede dar lugar a un incremento en el grado de compromiso organizacional.

La relación entre cultura organizacional y el compromiso organizacional tiene implicaciones en el aumento de la eficacia y efectividad. Angle y Perry (1981) y Garr, (1998) llevaron a cabo un estudio con el propósito de poner a prueba las consecuencias del compromiso sobre el nivel de efectividad de la organización, diferenciaron los ítems dentro del cuestionario OCQ del compromiso de continuar y compromiso con los valores y encontraron algunas diferencias en cuanto a la relación con los indicadores de la efectividad organizacional. En los resultados se muestra que las intenciones estaban asociadas negativamente con el compromiso de continuar, mientras que el compromiso que refleja la identificación con los valores mostró relación negativa y significativa con la falta de puntualidad y unas relaciones positivas con la eficacia operativa. Estos autores puntualizaron un aspecto importante, aunque el compromiso esta asociado con la permanencia en la organización no implica que la permanencia en ella signifique que vaya a trabajar. En su trabajo también concluyeron que para cada organización laboral sería beneficioso que sus miembros basen su vínculo en algo más que el simple intercambio o la aceptación. Apuntan que se puede iniciar el compromiso como un simple intercambio y a medida que pasa el tiempo el empleado se va identificando con su trabajo e ira internalizando con valores y metas de la organización. 
En nuestros estudios anteriores (Alonso, Sánchez y Tejero, 2004) hemos encontrado que la adhesión a las normas culturales del grupo se relaciona positivamente con el compromiso organizacional. Así mismo se mostraba que era importante tener en cuenta que el ajuste cultural (cultura actual-cultura deseada) se relacionaba positivamente con el compromiso con la organización y que el compromiso era más fuerte en los grupos culturales que en los grupos no culturales.

Recogiendo estos datos en nuestro estudio planteamos la siguiente hipótesis:

Hipótesis 1: La relación entre cultura y compromiso organizacional difiere según el nivel de culturalidad de los equipos de trabajo. En la medida que un equipo de trabajo sea más cultural mayor será el compromiso organizacional.

Hipótesis 2: El compromiso que establecen los equipos de trabajo con la empresa depende de la potencia cultural que tengan dichos equipos. En los equipos de trabajo que son culturales, cuanto mayor sea su potencia cultural mayor será el compromiso que establecen con la empresa.

Hipótesis 3: En la organización, cuanto menos desfases existan entre la cultura real y la cultura deseada mayor será el compromiso que los equipos de trabajo establecen con la empresa.

Hipótesis 4: Las variables control, tipo de empresa y años de permanencia en el equipo de trabajo y en la empresa, tendrán una influencia positiva o negativa en el compromiso que realizan los trabajadores así como en el tipo de compromiso que establecerán y modularan las hipótesis anteriores. 


\subsection{CONCLUSIÓN}

Uno de los problemas que ha preocupado a los teóricos de las organizaciones ha sido y sigue siendo conseguir el compromiso de los individuos que forman parte de la institución para que concentren sus esfuerzos en la consecución de metas corporativas y lograr los objetivos propuestos.

El compromiso se ha convertido en una variable fundamental en la eficacia, productividad y efectividad institucional (Morgan y Hunt, 1994). Un aspecto en el que coinciden la mayoría de las definiciones existentes de compromiso organizacional es la vinculación que establece el individuo con la organización. En este capitulo queda patente la escasez de trabajos que integran en un mismo estudio las variables cultura y compromiso organizacional y por este motivo, con objeto de poner a prueba la relación que suponemos que existe, se pone en marcha este estudio para llenar una parte del vacío existente.

En nuestro estudio hemos adoptado una visión bidimensional del compromiso y aunque los componentes que integran esas dos vertientes son diferentes existe una relación entre ellos. El interés lo centraremos en el análisis del compromiso de los trabajadores con la organización porque los trabajadores son los que mantienen viva a la organización. Seguimos una vertiente actitudinal del compromiso, estado en que las personas se identifican con la organización y con sus metas y desean seguir siendo miembros de ella, y como pretendemos demostrar en nuestro estudio sólo las personas comprometidas con los objetivos de la organización, con unos propósitos comunes y una responsabilidad compartida podrán conseguir el compromiso organizativo para sentar las bases de un buen servicio, de aquí nace la necesidad que sentimos de estudiar 
Departamento de Psicología Social y Antropología. Universidad de Salamanca, Facultad de Psicología la relación entre cultura y compromiso organizacional para comprobar la veracidad de nuestra afirmación. 


\section{ESTUDIO EMPÍRICO}


En el estudio empírico se ha comenzado con el análisis del Cuestionario de Conductas Normativas 2 (CNO 2), utilizado para el estudio de la cultura, se han realizado diversos análisis factoriales y análisis confirmatorios hasta lograr un cuestionario válido y fiable. Este cuestionario se ha pasado a los diferentes grupos en dos fases diferenciadas porque nos parece importante conocer las diferencias existentes entre el estado actual y el estado ideal de la cultura existente, porque nos permitirán conocer el grado de ajuste cultural que existe en la organización, que es lo que denominaremos "los desfases culturales. Tras dicho análisis se ha comenzado con el estudio de la cultura de los grupos que integran la muestra. Para medir la cultura de los grupos aplicamos el método de calibrado (Alonso y Sánchez, 1998).

Para el estudio de la culturalidad de los equipos de trabajo se ha utilizado el índice de fiabilidad entre jueces intragrupo (IRRJ) pero aplicando la fórmula propuestas por James.col (1984). Para constatar la importancia de la culturalidad de los equipos se ha comprobado si existen diferencias en la relación entre compromiso y cultura según sean los equipos de trabajo, culturales o no culturales.

Posteriormente se ha estudiado la existencia o no de la potencia cultural de los equipos de trabajo por ser el criterio que establecerá el grado en que una norma es apoyada por los miembros en relación con otras normas. A continuación se introduce la potencia cultural como variable independiente para comprobar su repercusión en el compromiso que se establece entre el empleado y la organización. Por último, mediante la realización de regresiones se ha examinado la fuerza global de asociación, si es o no significativa esa relación entre compromiso organizacional y las variables predictoras, índice, desfase y potencia cultural así como el tiempo en la empresa y en el equipo de trabajo. 
CAPITULO 4. METODOLOGÍA 


\section{CAPITULO 4. METODOLOGÍA}

\subsection{MUESTRA.}

La muestra se formó con el conjunto de los equipos de trabajo que participaron en la investigación, equipos de trabajo que estaban integrados por personas cuyas características se describen a continuación. Se pasaron los cuestionarios a 685 personas que pertenecían a 136 equipos de trabajo de diferentes organizaciones, públicas y privadas, de todo el territorio español y de distintos sectores laborales y distintas provincias españolas.

La mayoría de los equipos de trabajo estaban compuestos de 5 trabajadores aunque existían algunos equipos de trabajo que tenían 6 ó 7 sujetos. Los datos de las personas que participaron en la investigación se obtuvieron con todas las garantías de confidencialidad posible por ser los cuestionarios anónimos, sólo se ha pedido a los sujetos que nos proporcionaran datos sobre su edad, sexo, nivel de estudios, el tiempo en meses que llevaba trabajando en ese equipo de trabajo y si la organización donde trabajaban pertenecía al sector público o privado.

Las edades de los sujetos han oscilado entre 19 y 62 años, situándose la media de edad en los 35 años. Respecto a la antigüedad de los sujetos en su lugar de trabajo, la media se situaba en torno a los 10 años. Se ha podido apreciar que la mayoría de los sujetos, aunque las diferencias eran pequeñas, eran hombres (50.8\%) que trabajaban en empresas públicas (52.6\%) con una antigüedad de 10 años y con formación universitaria. 


\subsection{LOS INSTRUMENTOS DE MEDIDA.}

Al describir el diseño de la investigación se ha apuntado que el principal medio para medir las variables de interés ha sido un cuestionario en el que se integraban todos los instrumentos de medida, tantos los de elaboración propia como los tomados del trabajo de otros autores, de forma que los sujetos se encontrasen con un instrumento integrado y fácil de responder.

En la primera página se daba una breve explicación sobre los objetivos del cuestionario así como se hacía alusión al anonimato y a la confidencialidad de los datos que se recogieran. Los datos que se han recogido en todos los equipos de trabajo fueron los siguientes: las variables personales, cultura y compromiso organizacional, utilizando para ello distintos cuestionarios que pasamos a describir.

\subsubsection{Cuestionario de Conductas Normativas CNO2}

En este apartado se va a describir los medios utilizados para llevar a cabo este estudio comenzando por el cuestionario $\mathrm{CNO} 2$ ya que este supone la fuente de información más importante.

En el análisis de antecedentes existentes sobre el tema de cultura se ha revelado la existencia de diversos instrumentos utilizados para la medición de cultura organizacional, el Cuestionario de Kilmann y Saxton (1983); Diagnóstico de la Cultura Organizacional (Harrison y Stokes, 1992); Cuestionario de Cultura Organizacional (García, 1994); Organizacional Cultura Survey (Denison, 1999). Después de las revisiones realizadas y analizadas de la bibliografía existente, Sánchez y Alonso (1997) 
construyeron el Cuestionario de Conductas Normativas Organizacionales (CNO). En el proceso de elaboración del cuestionario siguieron los siguientes pasos:

1- Revisión de la literatura existente, especialmente de la investigación cuantitativa y de los instrumentos utilizados en esas investigaciones: Encuestas de desfases Culturales (Kilmann y Saxton, 1983), perfil de Cultura Organizacional (O’Really, Chatman y Caldwell, 1988), escalas de Clima Social (Moos, Moos y Trickett, 1987) y los trabajos de Hofstede et al.,(1990) y Reynierse y Harker(1986).

2- Un estudio analítico de los contenidos de los ítems, de las fuentes de las dimensiones culturales descritas conceptualmente.

3- Elaboración de un primer banco de datos de ítems mediante la selección de los cuestionarios revisados y la elaboración de otros que respondieran a los contenidos conceptuales no muestreados en los Ítems.

4- Obtención de una primera revisión experimental del cuestionario que fue sometido a sucesivos juicios de especialistas, a una primera aplicación y a una redacción adecuada del mismo dado el ámbito de uso a que estaba destinada.

5- Sucesivas aplicaciones que han permitido una selección y reformulación mayor de los ítems, la corrección de alguna deficiencia de la escala de medida y la unificación en la escala de las alternativas de todos los ítems bajo el mismo rasgo de 0 a 4, y por último la introducción de algunas mejoras en el muestreo de contenidos. 
En la recogida, elaboración y selección de los elementos del cuestionario se ha seguido los siguientes criterios:

1- Que fuesen conductas referidas a la interacción social y a los procesos de trabajo relacionados con la conducta social.

2- Que fuesen conductas generalizables, esto es, que se pudiesen encontrar en todos los contextos organizacionales, no solo en los contextos específicos.

3- Que fuesen conductas descriptivas, es decir, que tuviesen un contenido que las diferenciase semánticamente unas de otras.

En un principio se elaboró un conjunto de 220 ítems y tras sucesivas revisiones y reformulaciones de los ítems se fueron eliminando ítems hasta llegar a la formulación definitiva del CNO 2 que lo componía 82 ítems. En nuestra investigación para la evaluación de la cultura hemos empleado el cuestionario de Conductas Normativas Organizacionales (CNO 2) en la segunda versión experimental (Sánchez y Alonso, 1998).

\subsubsection{Descripción del cuestionario: Versión inicial del instrumento}

El CNO 2 constaba de 82 ítems recogidos en doce dimensiones que evaluaban, a partir de la información facilitada por las personas entrevistadas, los siguientes aspectos de la cultura organizacional, ampliaremos la información sobre ellas más adelante:

“Consideración, colaboración, orientación a la acción, calidad del trabajo, libertad de acción, disposición al cambio, orientación hacia la autoridad, integración del grupo, desempeño de rol, competición, tolerancia a la incertidumbre, el control social de la acción”. 
Todas estas conductas estaban referidas a conductas normativas, no eran conductas de acción sino que eran conductas que tenían para el sujeto un significado adquirido que podía llegar a ser compartido por todos los miembros del grupo; la conducta tal y como se presentaban eran puramente descriptivas, pero suponían que todos daban un significado y un valor a dicha conductas que podían ser positivas (cooperación) o negativas (sumisión o dependencia). Estas conductas podían referirse a características de las variables macroscópicas y microscópicas del proceso.

La utilización de conductas normativas para evaluar la conducta estaba justificada porque:

1-Eran de fácil acceso, ya que era suficiente con preguntar a los miembros de la organización (Kilmann y Saxton, 1983).

2-Facilitaban la participación de los miembros en la cultura a diferencia de la utilización de valores porque era difícil de determinar preguntando si eran valores actuales o son valores adoptados (Argyris, 1970; Schein, 1985).

3- Se establecieron criterios que servían para determinarlas (Katz y Kahn, 1978).

A) Las normas debían ser creencias sobre la conducta apropiada y pedida a los miembros de un grupo como miembros de él.

B) Debía darse una comunalidad de creencias objetivas o estadísticas, lo que significaba, no que cada uno de los miembros del grupo debía tener la misma idea, sino que la mayoría de los miembros activos deberían de estar de acuerdo

C) Los individuos debían tener conciencia de que existía el apoyo del grupo para una determinada creencia. 
Así, según Katz y Kahn (1978), se podría decir que existía una norma o un valor del sistema social allí donde los miembros del grupo tenían la misma creencia, eran conscientes que la mayoría la apoyaban y estaban de acuerdo en que esa creencia es adecuada para su grupo.

El problema que presentaba el planteamiento de Katz y Kahn es que tanto las normas, como los valores que regían el comportamiento del grupo, debían ser las "creencias sobre la conducta apropiada y pedida a los miembros del grupo, pero la norma podía describir la forma apropiada o inapropiada. Considerando la anterior propuesta y para mejorar este problema proponemos utilizar los siguientes criterios, comunalidad, conformidad e intensidad, que en este momento citaremos para desarrollarlos posteriormente.

Este cuestionario se pasó a los diferentes grupos en dos fases diferenciadas. En un primer momento, se recogió la información sobre conductas normativas actuales (CNO2-A) de la organización preguntando a los sujetos "en que medida dichas conducta eran características de su lugar de trabajo". Se trató de recoger información sobre las normas actuales del sistema, por ello se explicó a los miembros que sobre cada conducta tratasen de indicar el grado en que era característica de ese grupo, esto es, el grado en que entendían que los miembros del grupo apoyaban dicha conducta o también el grado en que la respetaban porque estaba sancionada por el sistema social. De esta forma se colocó a los sujetos en un marco de referencia organizacional para que nos informaran de lo característico que era dicha conducta. 
1- Al preguntar por una conducta que se daba en el contexto de la organización o del grupo se trató de colocar a los miembros en un marco de referencia colectivo o grupal.

2- Al preguntar por lo característico de la conducta se propició la información para establecer la intensidad cultural de la norma o el grado que era compartida por los miembros.

3- Al preguntar por el grado en que era característica esa conducta se facilitó el que proporcionaran información para establecer la potencia cultural o el grado en que una norma era apoyada o sostenida en relación con otras normas de la organización.

En un segundo momento (CNO2-B) se les puso a los sujetos en un escenario hipotético en el que se lograba un ambiente de trabajo colectivamente beneficioso para el bienestar organizacional y se le preguntaba "en que medida cada una de las conductas que se indicaban era característica de ese grupo”. Se trató de que los sujetos:

1-Se situasen en el escenario ideal y de futuro en que se alcanzaba un estado de bienestar, ya que nos interesaba información sobre normas de comportamiento adecuadas para alcanzar ese estado de bienestar.

2-De que los sujetos se situasen en un marco de referencia colectivo o grupal al preguntar sobre el bienestar organizacional.

3-Al preguntar por el funcionamiento de la organización en beneficio de todos los miembros se proporcionó información que respondía al criterio de intensidad cultural.

4-Al preguntar sobre la frecuencia de la conducta, daban información para determinar el criterio de potencia de cultura. 
Las respuestas se respondieron en una escala de Likert de 0 a 4 puntos, siendo el 0 un indicador de que la conducta era "nada característico" y el 4 de que era "muy característico".

\subsubsection{Revisión del instrumento}

Se inició el análisis con la revisión de la distribución de los ítems que integraban el cuestionario: media, desviación típica, curtosis y asimetría.

Para analizar la estructura empírica del cuestionario se utilizó el procedimiento sugerido por Strelau, Angleitner, Batelmann y Ruch (1990) que consiste en un proceso interactivo para determinar la pertenencia o no del ítem a su escala correspondiente en base a los siguientes criterios de eliminación:

1-Coeficiente de correlación de Pearson, entre la puntuación correspondiente y la suma de las puntuaciones en los ítems restantes es inferior a .15 .

2-Correlación del ítem con su escala menor que la correlación con otras escalas.

3-Correlación del ítem con su escala no es significativa.

Los ítems que no cumplían el primer criterio se eliminaron y el resto de los ítems se pusieron a prueba con el segundo criterio. Los que no cumplían este segundo criterio se eliminaron y el resto de los ítems no eliminados se pasaron a contrastarse con el tercer criterio, y se eliminaron aquellos que no cumplían dicho criterio. Los ítems que no se eliminaron se sometieron una vez más a los tres criterios antes señalados. Este proceso se repitió hasta que no resultó eliminado ningún ítem con en el filtro de los tres criterios dándose en ese momento por finalizado el proceso. En nuestro estudio se repitió tres veces el proceso hasta poder dar por finalizado el proceso. El cuestionario quedó 
formado, tras sucesivas revisiones, por doce dimensiones. A continuación pasamos a explicar la definición de cada una de las dimensiones.

El cuestionario de Conductas Normativas Organizacionales lo integran 12 variables:

Integración del grupo: Expresa la idea de la unificación del sistema social por medio de normas y valores compartidos (Katz y Kahn, 1978); de formar parte de un organismo, grupo, equipo, organización que tiene fines y objetivos propios. Este concepto indica, como idea básica, que los elementos actúan para conseguir realizar una tarea conjunta o alcanzar un objetivo que los miembros no podrían conseguir individualmente.

Items que la componen: $1,13,25(\mathrm{I}), 37,49,61,72(\mathrm{I}) \quad$ Alpha de Crobach $=.77$

Calidad del trabajo: Este concepto expresa la relación satisfactoria y adecuada de lo que se hace con la forma de hacerlo. Supone que la acción se puede cumplir de múltiples formas pero algunas expresan mejor que otras el carácter social y final de la acción, no sólo el instrumental. El carácter social de la acción se expresa en que las acciones ponen de manifiesto valores sociales compartidos y buscados; en la acción instrumental se expresa el carácter final y la adecuación de las acciones para conseguir los objetivos y fines propuestos.

Items que la componen: 2, 14, (I), 26, 38, 50, 62(I), 73(I) Alpha de Crobach $=.83$

Colaboración: Quiere expresar un acuerdo entre las personas para realizar acciones en una organización o grupo que llevan a alcanzar objetivos y fines que son de mutuo interés que posibilitan alcanzar los objetivos y fines personales de los constituyentes. El concepto de apoyo a las personas supone que se colabora con las propuestas y acciones de otros sin pretender con ello conseguir fines personales propios. La colaboración es 
un mutuo apoyo entre personas para conseguir algo que no tiene que ser necesariamente común.

Items que la componen: $3,15,27(\mathrm{I}), 29,51,63,70,80$ (I). Alpha de Crobach $=.73$

Consideración: Quiere recoger el reconocimiento de las personas, el respeto por lo que son, hacen y piensan. No necesitan que haya reciprocidad o correspondencia, su fundamento esta en la igualdad de la naturaleza humana y el derecho que todos los hombres tienen a ser respetados y estimado.

Items que la componen: $4,16,228.40,52,64,75$ Alpha de Crobach $=.87$

Disposición al cambio: Se intenta recoger las ganas que tiene los empleados de realizar nuevos proyectos, si buscan la innovación introduciendo nuevos métodos en el trabajo, experimentando nuevas cosas o por el contrario si se aferrará a las formas establecidas. Items que la componen: 5, 17(I), 29, 41, 53, 65(I), 76(I), 81(I). Alpha de Crobach $=.84$

Orientación a la acción: Expresa la idea de hacer cosas, de realizar proyectos, de que la acción es la expresión natural del comportamiento social y el instrumento de la realización de objetivos y fines de una organización.

Items que la componen: $6,18,30,42,54,66,77(\mathrm{I}) \quad$ Alpha de Crobach $=.65$

Orientación hacia la autoridad: Expresa la relación del sujeto con la autoridad, con los jefes, que si es positiva se sentirá apoyado a consultar sus problemas de trabajo con los jefes, sin tener grandes reparos en discutir las ideas con ellos llegando con facilidad a acuerdos para la realización de su trabajo. Esta dimensión se expresa en comportamientos de colaboración con la autoridad en cuanto se entiende que busca y 
logra la coordinación en beneficios de los objetivos e intereses de los componentes Items: 7, 19(I), 31, 43(I), 55, 67. Alpha de Crobach $=.79$

Desempeño de rol: Expresa las conductas que una persona estima apropiadas para responder a las demandas en el trabajo o que le hace su conjunto del rol del puesto laboral. En este concepto hay dos elementos principales: la respuesta de lo sujeto y las demandas o los mensajes que envían los componentes del rol. El sujeto asuma la responsabilidad del puesto siendo serio y riguroso en el cumplimento de su trabajo, haciendo lo que tiene que hacer y no desatendiendo sus obligaciones. Items que la componen: $8,20,32,44(\mathrm{I}), 56(\mathrm{I}) \quad$ Alpha de Crobach $=.78$

Competición: Es un concepto muy importante ya que recoge la superación por parte de los sujetos en sus resultados anteriores, su lucha, su afán por realizar las cosas bien incluso mejor que los demás. Se manifiesta en relación con lo que realizan los demás y busca sobresalir en las acciones, superar a otros en los resultados, en los objetivos conseguidos o en la forma de realizarlos.

Items que la componen: 9, 21, 33, 45(I), 57, 68. Alpha de Crobach $=.78$.

Tolerancia a la incertidumbre: Expresa la capacidad que tienen los sujetos para soportar los aplazamientos, retrasos en las acciones sin impacientarse demostrando tranquilidad y pudiendo esperar pacientemente los resultados de las decisiones. Items que lo componen: 10, 22, 34, 46(I), 58, 69, 78, Alpha de Crobach $=.71$

El control social de la acción: Se recoge los términos referente al control de las situaciones en las que los sujetos puede apaciguar los conflictos, se pone orden y concierto en las situaciones caóticas pero respetando las reglas establecidas. Items que la compone: $11,23,35(\mathrm{I}), 47,59(\mathrm{I}), 70,79,82$. Alpha de Crobach $=.79$ 
Libertad de acción: Se expresa la capacidad de elegir la forma de acción que se juzga adecuada para conseguir unos objetivos entre varias posibilidades. La libertad de acción admite grados, tanto en las alternativas que se ofrecen como en la capacidad de elegir que se tiene siendo consciente de los recursos con que se cuenta. Como elemento básico de la libertad de acción estaría el poder de la decisión para elegir una acción entre varias.

Items que la componen: $12,24,36,48,60,71$. Alpha de Crobach $=.57$

En los elementos señalados con una (I) se invierte su puntuación $(4=0,3=1,2=2,1=3$, $0=4)$.

Cada una de las doce dimensiones está compuesta por cinco, seis, siete u ocho ítems en una escala tipo Likert con un rango de respuesta que va de 0 a 4 según el grado de caracterización que tenga esas conductas en la organización a la que pertenece el sujeto siendo:

$0=$ Nada característico

$1=$ Algo característico

$2=\mathrm{A}$ medias característico

$3=$ Bastante característico

4= Muy característico.

\subsubsection{Cuestionario de Compromiso Organizacional OCQ}

El Cuestionario de Compromiso Organizacional OCQ es un instrumento de medida de dos dimensiones del compromiso del individuo con su organización y el resultado de adaptación de Mayer y Schoorman (1992) del original de Porter, Steers, Mowday y Boulain (1974). Estos autores han definido el compromiso como la fuerza de 
identificación del individuo con la organización y su implicación en ella, caracterizado por tres elementos psicológicos: el deseo de permanecer en ella, disposición a realizar un esfuerzo considerable en su favor y la creencia y aceptación de sus objetivos y valores.

Los estudios realizados con este cuestionario (Mayer y Schoorman, 1992) confirman que el compromiso se puede caracterizar en términos de dos dimensiones distintas las cuales conducen a distintos resultados organizacionalmente relevantes.

Este cuestionario se compone de 19 ítems que definen las dimensiones de “Compromiso de Continuar" y "Compromiso con los Valores”. Los ítems se puntúan en una escala de Likert de 1 a 7 puntos, siendo el 1 indicador de "desacuerdo total" y el 7 indicador de "acuerdo total" con lo expresado en cada uno de los ítems.

La definición de las dimensiones son:

Compromiso de Continuar: El cambio de puesto de trabajo, como resultado de dejar la organización, predice mejor este comportamiento. Los ítems que la componen son 1 , $3,5,7,9,11,13,15,17,19$.

Compromiso con los Valores: Este compromiso juega un papel fundamental en el modelo al predecir los resultados (satisfacción, rendimiento, intención de permanecer en la organización, dejar la organización, altruismo, conductas cívicas). Items que la componen: 2, 4, 6, 8,10,12, 14, 16, 18.

El ítem 11 debe llevar las puntuaciones invertidas $(1=7,2=6,3=5,4=5,5=3,6=2,7=1)$

El análisis realizado por Schechter (1985) nos ha aportado un índice de fiabilidad (alpha de Crobach) de .90 y .85 para las escalas de "compromiso con los valores" y “compromiso de continuar" respectivamente. 


\subsection{PROCEDIMIENTO}

La investigación fue diseñada de acuerdo con las siguientes características con el fin de abordar los objetivos planteados:

1. Estudiar la cultura de las empresas de distintos sectores, estamentos (públicos y privados) y distintas provincias. La elección de las empresas se realizó por parte de los alumnos que participaron en la investigación

2. Como metodología básica para contrastar la hipótesis planteadas se plantea un conjunto de cuestionarios: Cuestionario de Cultura Organizacional (CNO) Alonso y Sánchez (1998), Cuestionario para medir el Compromiso Organizacional (OCQ) Mayer y Schoorman (1992). La información sobre los cuestionarios se ampliara en los siguientes apartados.

Se contactó con empresas de diferentes provincias españolas para solicitar su colaboración en el cumplimento del cuestionario. Una vez recogidos los datos proporcionados por el paso de cuestionarios a los trabajadores de las diferentes empresas, se procedió al tratamiento de los datos recogidos mediante la inclusión en la base de datos realizada con el paquete estadístico SPSS (9.0). Desde la grabación de los datos se han realizado distintos análisis hasta llegar a la depuración del cuestionario y los resultados que más tarde mostramos.

\subsubsection{Análisis del cuestionario CNO2 inicial}

Una vez identificada las características de las distribuciones de cada ítem se procedió al análisis de la validez de estructura del constructo. Para ello se ha seguido el método de escalonamiento multidimensional (MDS), empleando el método de distancia euclídea. El escalamiento multidimensional trata de encontrar la estructura de un conjunto de 
medidas de distancia entre objetos o casos. Esto se ha logrado asignando las observaciones a posiciones específicas en un espacio conceptual (normalmente de dos o tres dimensiones) de modo que las distancias entre los puntos en el espacio concuerden al máximo con las disimilaridades dadas.

Antes de proceder al análisis factorial del cuestionario se efectuó las siguientes comprobaciones previas: la matriz de correlación (indicador del grado de intercorrelaciones); test de esfericidad de Barlett. Los valores en KMO por encima de .60 se consideraron aceptables por que si el valor resultante de KMO fuese menor de 0.50 esto indicaría que no debería usarse el análisis factorial; mientras que la prueba de esfericidad contrasta la hipótesis nula de que la matriz de correlaciones es la matriz de identidad, en cuyo caso tampoco sería pertinente el análisis.

Los resultados positivos en el test de esfericidad de Barlett y los valores en KMO nos llevaron a realizar el análisis factorial utilizando el método de Análisis de los Componentes Principales (PCA), con rotación Varimax con Kaiser.

En una segunda etapa, tratando de encontrar una estructura más viable, se realizó un análisis factorial considerando necesario el cumplimiento de tres criterios para que un ítem no fuese eliminado del cuestionario; el primer criterio sería la aceptación de coeficientes de correlación mayores de 0.40 , el segundo criterio sería la pertenencia del ítem a un solo factor y el terceto criterio sería que el índice de fiabilidad del factor fuese mayor de 0.7. Los ítems que no han cumplido con estos criterios se han eliminado del instrumento final.

Como paso previo al análisis factorial del cuestionario compuesto pos 50 ítems se obtuvo mediante el programa SPSS la medida de adecuación muestral de Kaiser- 
Meyer-Olkin y la prueba de esfericidad de Barlet, para verificar que el procedimiento era adecuado para los datos de que disponíamos.

Cumplidos los requisitos necesarios se realizó el análisis factorial exploratorio mediante el análisis de componentes principales. Para la extracción del número de factores, a parte de tener en cuenta los resultados de los estudios previos, se aplicó los anteriores criterios y se efectuó rotación ortogonal (varimax). La identificación de cada ítem en el factor correspondiente se realizó empíricamente basándonos en la mayor saturación obtenida en las correspondientes estructuras factoriales rotadas.

Con objeto de examinar empíricamente cuál de las estructuras factoriales representaba más adecuadamente al CNO-2, se llevó a cabo un análisis factorial confirmatorio, basándonos en el programa de ecuaciones estructurales AMOS 5 y para ello se utilizó el método de máxima verosimilitud. En el modelo de tres factores, los indicadores se fijaron sin permitir que los ítems saturaran en más de un factor. En la Tabla 5.3 se recoge cinco de los índices de ajuste que suelen ser empleados en la verificación de los modelos factoriales (García-Cueto, Gallo y Miranda, 1998; Rial, Varela, Braña y Lévy, 2000; Rodríguez, Arce, Seoane y Sabucedo, 1996): $\chi^{2}$, CFI (comparative Fit Index), GFI (Goodness of Fit Index), NFI (Normal Fit Index) y RMSEA (Root Mean Square Error of Approximation).

Se consideró un buen índice de ajuste un valor igual o superior a .90 en CFI (Bentler y Dudgeon, 1996). El RMSEA, proporciona una medida de discrepancia por grado de libertad y en general se ha admitido que valores de .08 o inferiores indicaban un ajuste aceptable y muy bueno cuando eran iguales o inferior a .05 (Browne y Cudeck, 1993). 
Se planteó una reespecificación del modelo propuesto al mostrar, el modelo de tres factores, índices de ajuste cercanos a la significación aunque sin llegar a los valores necesarios para considerarlos aceptables excepto en RMSEA que muestran una fuerte tendencia a la significación (valores por debajo .80 se consideran aceptables; Falces, Briñol, Sierra, Becerra y Alier, (2001). Para este fin se tuvo en cuenta la presencia de saturaciones cruzadas, los pesos factoriales y errores de medida de las variables observables.

Una vez que se dispuso de una nueva versión del CNO-2 que se ajustaba a nuestros planteamientos teóricos, era preciso comprobar si se trataba de un instrumento fiable y útil. Para estudiar la fiabilidad de la escala de 20 ítems del modelo reespecificado, así como de sus 3 componentes o variables latentes, se calculó un indicador de su consistencia interna: el coeficiente alfa de Cronbach.

Posteriormente se procedió al análisis factorial del cuestionario efectuando las siguientes comprobaciones previas: la matriz de correlación y el test de esfericidad de Barlett. Con toda la información obtenida se realizó un análisis factorial exploratorio mediante análisis de componentes principales al cumplirse los requisitos necesarios para ello. Para la extracción del número de factores, aparte de tener en cuenta los resultados de los estudios previos, se aplicó los anteriores criterios y se efectuó una rotación ortogonal (varimax). La identificación de cada ítem en el factor correspondiente se ha efectuado empíricamente basándonos en la mayor saturación obtenida en las correspondientes estructuras factoriales rotadas. 


\subsubsection{Cultura de los grupos}

Para medir la cultura de los grupos se ha utilizado el método de calibrado (Alonso y Sánchez, (1998). Este método considera tres criterios para poder determinar si un grupo es cultural y, consecuentemente poder analizar y evaluar su cultura: la conformidad cultural, comunalidad cultural y la potencia cultural

a) El criterio de conformidad cultural ha referido a las cualidades del instrumento. En nuestro caso, el instrumento $\mathrm{CNO}$ ha respondido a este criterio dado que:

1- Utiliza la información de los miembros, recogida en un segundo paso del instrumento sobre el estado ideal del grupo, como calibrador que permite la participación de los miembros en la determinación de las variables culturales, respondiendo así a la acusación de la perspectiva ética o externa de la cultura.

2- Recoge la información de la cultura que proporcionan los miembros de la unidad social al describir o evaluar las conductas desde el extremo del continuo de identidad social, respondiendo así a la acusación de la perspectiva psicológica de los individuos o del clima.

3- Utiliza las normas como elementos culturales, respondiendo así a la acusación de la perspectiva cualitativa.

b) El criterio de comunalidad se ha calculado utilizando el índice de fiabilidad entre jueces intragrupo (IRRJ), pero se ha aplicado la fórmula rwg(j), la varianza de error, tal y como propone James et al. (1984), para controlar la existencia de posibles sesgos generados por el efecto de la tendencia central, la deseabilidad social o la indulgencia de los jueces. 


$$
r_{W G(J)}=\frac{J\left[1-\left(\bar{s}^{2} \mathrm{xj} / \sigma^{2}{ }_{\mathrm{eu}}\right)\right]}{J\left[1-\left(\bar{s}^{2} \mathrm{xj}^{2} / \sigma^{2}{ }_{e u}\right)\right]+\bar{s}^{2} \mathrm{xj}^{2} / \sigma^{2}{ }_{\text {eu }}}
$$

$\bar{s}^{2} \mathrm{xj}=$ Es la media de las varianzas observadas

$\sigma_{\text {eu }}^{2}=(\mathrm{A} 2-1 / 12)$.Es la varianza esperada del error

$J=$ Es el $n^{0}$ de ítems de la escala

El punto de corte elegido fue de $r_{\mathrm{WG}} \geq 0.70$

c) El criterio de potencia cultural ha establecido el grado en que una norma es apoyada por los miembros en relación con otras normas. Este criterio se ha aplicado a las variables que han quedado seleccionadas según los criterios anteriores.

Definidas cada una de las variables de cada grupo con los criterios de comunalidad y conformidad cultural el siguiente paso ha sido determinar que grupos se pueden considerar como grupos culturales siendo necesario para ello establecer el patrón mínimo de cultura.

El patrón cultural mínimo es el número mínimo de variables en que se cumplen los criterios de comunalidad cultural En la literatura sobre cultura organizacional se ha venido utilizando diferente número de variables para evaluar la cultura. Kilmann y Saxton (1993) utilizan cuatro, Schein (1985) propone cinco dimensiones, Rousseau (1990) se limita a tres categorías. En nuestro caso se ha realizado una clasificación donde se ha propuesto tres dimensiones, la dimensión 1 "no cultural" y tienen 0 ó 1 factor cultural, la dimensión 2 "normal cultural" tiene dos factores culturales y la dimensión 3 “muy cultura”tendrá 3 factores. Este criterio de patrón cultural mínimo 
lo aplicamos a la información recogida sobre la cultura del estado actual para clasificar los grupos de la muestra.

\subsubsection{Categorización de los equipos de trabajo según su nivel cultural}

Según la primera hipótesis se ha planteado que la relación existente entre compromiso y la cultura de los equipos de trabajo será mejor cuanto más culturales sean los grupos, por tanto se ha procedido a analizar el nivel de cultura en los equipos de trabajo siguiendo la propuesta de Alonso y Sánchez (1998). Para calcular la comunalidad cultural de los equipos se ha utilizado el índice de fiabilidad entre jueces intragrupo (IRRJ) pero se ha aplicado la fórmula propuestas por James, Demaree y Wolf (1984). Después de determinar el índice de comunalidad de los tres factores en cada uno de los equipos de trabajo el siguiente paso ha sido determinar que grupos se podían considerar grupos culturales para lo que se ha establecido el patrón cultural mínimo. Valorados cada uno de los factores en cada equipo de trabajo con los criterios de comunalidad, se ha determinado que grupos se pueden considerar culturales o no y los que son culturales en que grado.

Siguiendo a Alonso (1998), con la utilización del método de calibrado y después de la aplicación de los criterios de comunalidad y potencia para poder evaluar la cultura del sistema social se ha puesto de manifiesto que pueden existir al menos tres clases de grupo en las organizaciones relativos a la cultura:

A- Grupos de trabajo, son grupos que no han formado un patrón mínimo de cultura ni en el estado actual ni en el ideal, son grupos que no perciben un patrón mínimo de normas compartidas. Los grupos con estas características 
suelen ser grupos de reciente creación o con tareas independientes, grupos que no tienen funciones claras y específicas ni tareas coordinadas.

B- Grupos sociales, son los que si han formado un patrón mínimo de cultura sólo en el estado actual o sólo en el estado ideal. Son grupos capaces de desarrollar cogniciones compartidas pero únicamente en un estado. Posiblemente son grupos con tareas individuales de los miembros cuya formación o creación como grupo no responde a una función grupal u organizacional suficientemente explicita pero cuyos miembros tienen un conocimiento adecuado de la naturaleza de la función social y de su función en el sistema organizacional.

C- Grupos de la organización, son los grupos que han sido capaces de desarrollar un patrón mínimo de normas compartidas, tanto en su estado actual como en su estado ideal. Se puede pensar que sean grupos antiguos, que conocen su función de organización, con tareas grupales que buscan responder a sus funciones.

\subsubsection{Cultura actual}

Se ha realizado un primer análisis de la cultura de los equipos de trabajo, los datos obtenidos con la aplicación del cuestionario CNO-2 se ha analizado según la culturalidad de los grupos utilizando el índice de calibrado, rwg de James et al (1999). Previo a la contrastación de la hipótesis se ha distribuido a los equipos de trabajo en grupos según su culturalidad. Una vez que se ha clasificado a lo equipos de trabajo en tres grupos se ha comprobado la correlación de cultura y de compromiso organizacional. 


\subsubsection{Cultura deseada}

El patrón ideal de cultura está formado por las variables que cumplen los criterios de cultura y que los miembros consideran que deberían formar parte de la cultura de la organización para que el grupo funcione en beneficio del conjunto del sistema.

\subsubsection{Potencia cultural}

Se ha definido potencia cultural como el grado en que las normas son apoyadas por los miembros de un equipo y que estos reconocen como propias de su grupo, esta potencia se puede referir tanto al estado actual como al estado ideal.

Al utilizar un anclaje que va desde Nada característico"(0) a "Muy característico" (4), el acuerdo entre los miembros del equipo puede estar en cualquiera de los 5 puntos de la escala. Se habla de potencia cultural cuando el equipo de trabajo supera los 3 criterios siguientes en cada factor:

El primero es que el índice de acuerdo tenga un valor mayor o igual a .70, el segundo es que la media tenga un valor igual o mayor de dos y el tercer es que la desviación típica sea menor o igual a uno.

En esta investigación se ha planteado el estudio de la intensidad de potencia cultural porque aunque el índice de acuerdo es el estadístico correcto para expresar el consenso de la percepciones de un grupo, ese grupo puede ser consistente pero sin estar cercano a la media. Para analizar la cultura de los equipos de trabajo se ha aplicados el método de calibrado para hallar la potencia cultural de cada equipo de trabajo. 


\subsubsection{Desfases culturales}

Se ha denominado desfase cultural a las diferencias existentes entre el estado actual y el estado ideal de su cultura. Esas diferencias nos han permitido conocer el grado de ajuste cultural que existe en la organización.

Para hallar los desfases culturales se ha calculado las diferencias significativas de las medias mediante el estadístico de Wilcoxon de pares asociados para grupos pequeños. Una vez se ha hallado los desfases culturales existentes en los equipos de trabajo nos planteamos cual sería su influencia en el compromiso organizacional que establece el empleado pero teniendo también en cuenta la potencialidad de los equipos de trabajo.

\subsubsection{Regresión}

Comprobada la relación existente entre el compromiso y la cultura posteriormente se ha querido estudiar en que medida influye la cultura sobre el compromiso, porque a lo largo de esta exposición teórica se ha manifestado el interés en estudiar esa relación existente pero no de quedarnos en la simple descripción de la relación sino de interesarnos en buscar alguna relación causal entre la cultura y el compromiso así como la dirección de esa influencia y el grado de la misma.

La cultura y el compromiso organizacional son constructos que se han consideran claves en el funcionamiento de la organización y que se han correlacionado con otras variables organizacionales surgiendo influencias reciprocas. Se ha elegido para realizar este estudio las variables predictoras de culturalidad, la potencia cultural y los desfases culturales de los equipos de trabajo. 
CAPITULO 5. RESULTADO 


\subsection{CUESTIONARIO DE CONDUCTAS NORMATIVAS ORGANIZACIONALES 2.}

\subsubsection{Análisis del instrumento inicial.}

El objetivo de esta tesis ha sido dilucidar hasta qué punto las dimensiones de la cultura de los equipos de trabajo pueden ayudar a determinar el compromiso organizacional en las empresas españolas. Para lograr dicho objetivo en el estudio empírico se comenzó con el análisis del Cuestionario de Conductas Normativas 2, (CNO 2), realizándose diversos análisis factoriales y análisis confirmatorios hasta lograr un cuestionario válido y fiable. Una vez identificada las características de las distribuciones de cada ítem se procedió al análisis de la validez de estructura del constructo siguiendo el método (MDS).En el siguiente gráfico se muestra la configuración de los estímulos obtenidos.

Grafico 5.1 Modelo Euclideano variables culturales.

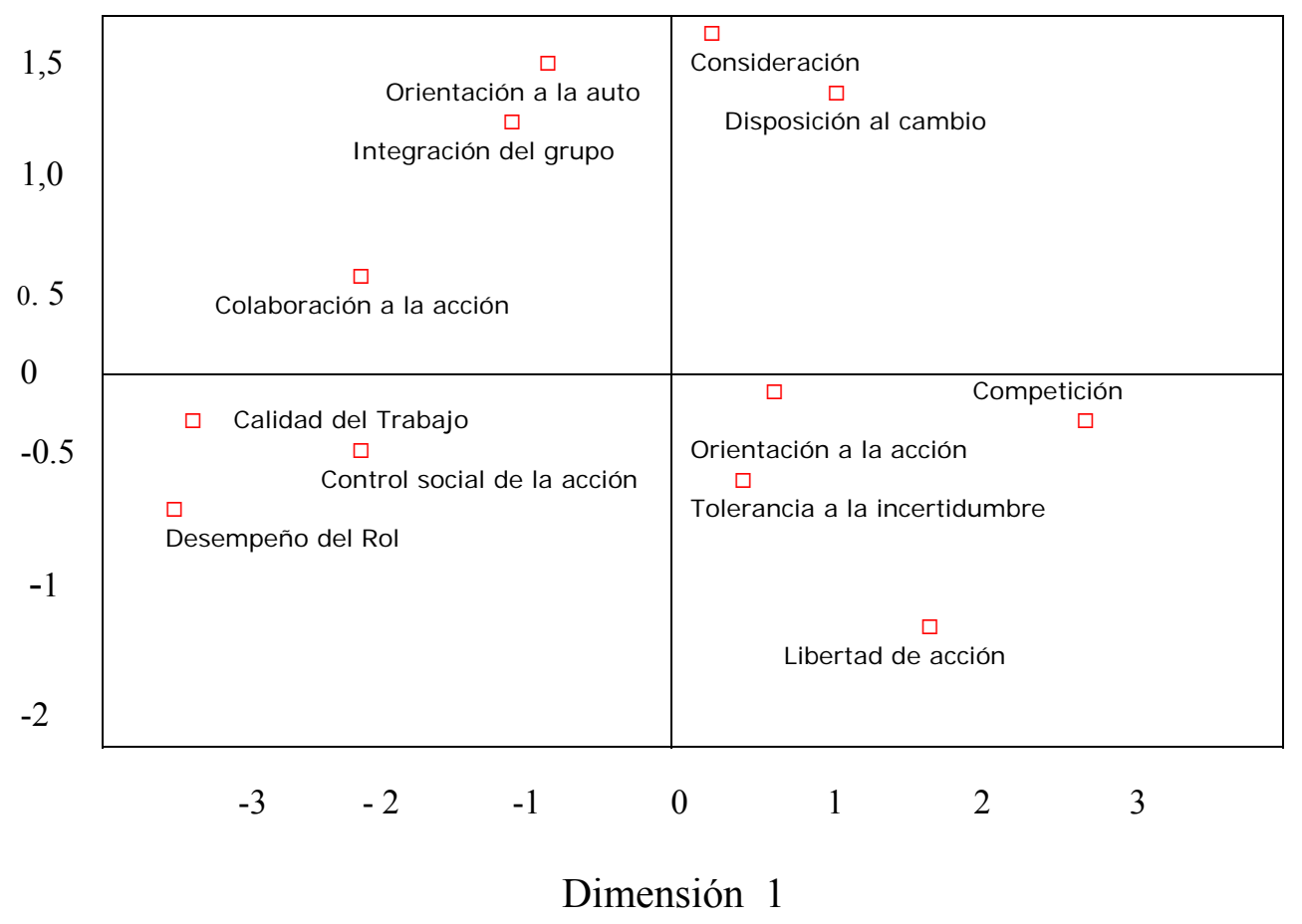


A través de una revisión visual se pudo observar la agrupación de las doce escalas que componían el cuestionario en tres grupos, hipotetizando una estructura factorial del cuestionario y procediendo a evaluar su grado de ajuste a los datos muestrales empleando el análisis factorial. El test de esfericidad de Barlett reveló un $\chi^{2}$ aproximado de 31.064 ( $3321 \mathrm{gl}$.), significativo a .000; y finalmente un índice KMO de Káiser- Mayer- Olkin de .953. Esta información nos permitió tomar la decisión de realizar el correspondiente análisis factorial por cumplirse los requisitos necesarios para ello. En el análisis factorial se obtuvieron doce componentes que explicaban un 58,8 \% de la varianza total y que se presentan en la tabla 5.1 .

En un primer análisis de los resultados se comprobó la existencia de una estructura tendente a la unifactorial, todos los ítem que componían el cuestionario saturaban de forma elevada en el factor 1, como se ha mostrado en el gráfico de sedimentación 5.2, no correspondiendo la distribución de los ítem en los factores igual que la distribución de los ítem en las escalas del cuestionario

Tabla 5.1. Varianza Total Explicada

\begin{tabular}{|c|c|c|c|c|c|c|c|c|c|}
\hline \multirow{3}{*}{$\frac{\text { Componente }}{1}$} & \multicolumn{3}{|c|}{ Autovalores iniciales } & \multicolumn{6}{|c|}{$\begin{array}{l}\text { umas de las saturaciones al cuadrado de la Suma de las saturaciones al cuadrado de la } \\
\text { extracción } \\
\text { rotación }\end{array}$} \\
\hline & \multirow{2}{*}{$\frac{\text { Total }}{26,539}$} & \multicolumn{2}{|c|}{$\%$ de la varianza $\%$ acumulado } & \multirow{2}{*}{$\frac{\text { Total }}{26,539}$} & \multicolumn{2}{|c|}{$\%$ de la varianza $\%$ acumulado } & \multirow{2}{*}{$\frac{\text { Total }}{12,596}$} & \multicolumn{2}{|c|}{$\%$ de la varianza $\%$ acumulado } \\
\hline & & 32,365 & 32,365 & & 32,365 & 32,365 & & 15,361 & 15,361 \\
\hline 2 & 4,566 & 5,568 & 37,933 & 4,566 & 5,568 & 37,933 & 5,430 & 6,622 & 21,983 \\
\hline 3 & 2,824 & 3,443 & 41,376 & 2,824 & 3,443 & 41,376 & 5,096 & 6,215 & 28,198 \\
\hline 4 & 2,527 & 3,082 & 44,458 & 2,527 & 3,082 & 44,458 & 4,886 & 5,958 & 34,156 \\
\hline 5 & 1,904 & 2,322 & 46,780 & 1,904 & 2,322 & 46,780 & 3,421 & 4,173 & 38,329 \\
\hline 6 & 1,677 & 2,045 & 48,825 & 1,677 & 2,045 & 48,825 & 3,406 & 4,154 & 42,482 \\
\hline 7 & 1,653 & 2,016 & 50,841 & 1,653 & 2,016 & 50,841 & 2,611 & 3,184 & 45,667 \\
\hline 8 & 1,414 & 1,724 & 52,565 & 1,414 & 1,724 & 52,565 & 2,417 & 2,948 & 48,615 \\
\hline 9 & 1,370 & 1,671 & 54,236 & 1,370 & 1,671 & 54,236 & 2,348 & 2,864 & 51,478 \\
\hline 10 & 1,326 & 1,617 & 55,853 & 1,326 & 1,617 & 55,853 & 2,252 & 2,746 & 54,224 \\
\hline 11 & 1,250 & 1,525 & 57,377 & 1,250 & 1,525 & 57,377 & 2,047 & 2,496 & 56,721 \\
\hline 12 & 1,200 & 1,463 & 58,840 & 1,200 & 1,463 & 58,840 & 1,738 & 2,120 & 58,840 \\
\hline
\end{tabular}

Método de extracción: Análisis de Componentes principales 


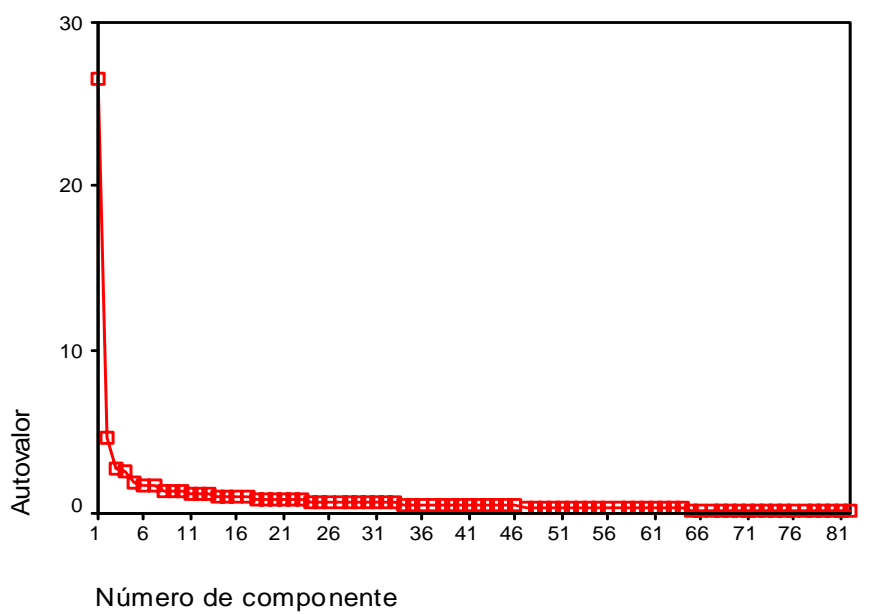

La interpretabilidad de la estructura factorial obtenida hizo reflexionar sobre la posibilidad de buscar una estructura más viable.

En una segunda etapa, se realizó un análisis factorial en el cual 32 ítems, un 39,02\%, no cumplían los tres criterios propuestos para que un ítem no fuese eliminado del cuestionario; de esta manera se eliminaron los ítems 4, 6, 9, 12 , 13, 15, 19, 19, (33,45,48,51,52,57,61,63,64,65,68,74,78,79,80,81), quedando el cuestionario formado por 50 ítems. En esa fase, el análisis de fiabilidad (Alpha de Crobach) fue de .96 lo que se estimó muy buena y superior a la obtenida en la fase anterior de su construcción.

\subsubsection{Análisis del instrumento reformulado}

Los resultados de la medida de adecuación muestral de Kaiser-Meyer-Olkin y la prueba de esfericidad de Barlet fueron, $\chi^{2}=18592.790, \mathrm{gl}=1540, \mathrm{p} \leq .001$; $\mathrm{y}$ el del índice de KMO .954, se consideraron muy buenos y nos verificaban que era adecuado realizar el análisis factorial. 
Tras el análisis de los componentes principales se obtuvieron 3 factores que estaban integrados por los ítems:

Factor 1: 1,3,5,7,16,29,31,33,37,40,41,49,53,55,67,70,75,7

Factor 2: 2,8,10,11,20,26,30,32,34,42,47,50,54,58,69,71,82

Factor 3: 14,17,25,27,35,44,46,56,59,60,62,66,72,73,76.

El porcentaje explicado por cada factor era el factor 1-15,799\%, por el 2-15,799\% y por el (3)-12\% y la fiabilidad de los tres factores era aceptable, del factor 1: .9119; la del factor 2: .9276 y la del factor 3: .79

Tabla 5.2. Varianza total explicada.

\begin{tabular}{lrrrrrr} 
& & & & \multicolumn{3}{c}{ Suma de las saturaciones al cuadrado de la } \\
& & \multicolumn{3}{c}{ Autovalores iniciales } & & \multicolumn{3}{c}{ rotán } \\
\cline { 2 - 7 } Componente & Total & \% de la varianza & \% acumulado & Total & \% de la varianza \% acumulado \\
\hline 1 & 18,845 & 33,652 & 33,652 & 8,848 & 15,799 & 15,799 \\
2 & 3,290 & 5,876 & 39,528 & 8,845 & 15,795 & 31,594 \\
3 & 2,277 & 4,067 & 43,594 & 6,720 & 12,000 & 43,594 \\
4 & 1,634 & 2,919 & 46,513 & & & \\
\hline \hline
\end{tabular}

Método de extracción: Análisis de Componentes principales.

\subsubsection{Análisis factorial confirmatorio}

El análisis factorial confirmatorio se realizó aunque la magnitud del estadístico $\chi^{2}$ era muy elevada y significativa, lo cual nos indicaba que los datos no se ajustaban al modelo propuesto, pero siguiendo a autores como Byrne (1989), Medsker, Williams y Holahan (1994), o Kelloway (1998), se consideró de manera complementaria otros índices de ajuste. En primer lugar se probó un modelo que hipotetizaba una estructura de 3 factores, correspondientes a las dimensiones de orden superior. Se tomó como variables exógenas observables los 53 ítems del cuestionario obteniendo un ajuste a los 
datos bastantes pobres $(\chi 2=4433: \mathrm{gl}=323 ; \mathrm{p}=.00 ; \mathrm{CFI}=803 ; \mathrm{NFI}=.73 ; \mathrm{RMSEA}=.062)$. Cabe señalar, no obstante que los resultados obtenidos tampoco fueron los esperados, lo que refuerza la idea de que los datos no se ajustaban al modelo inicial. La estimación de cargas factoriales y de los errores de medida de las variables observables del modelo de tres factores se muestra en Grafico 5.3. 
Gráfico 5.3. Análisis confirmatorio modelo CNO2

\begin{tabular}{|c|c|c|}
\hline$\delta$ & $\mathrm{X}$ & $\lambda$ \\
\hline .059 & cnol & .702 \\
\hline .050 & cno3 & .686 \\
\hline .055 & cno5 & .671 \\
\hline .052 & cno 7 & .578 \\
\hline .078 & cno16 & .581 \\
\hline .055 & cno29 & .695 \\
\hline .053 & cno31 & .689 \\
\hline .061 & cno40 & .700 \\
\hline .051 & cno41 & .754 \\
\hline .055 & cno49 & .592 \\
\hline .055 & cno53 & .745 \\
\hline .047 & cno55 & .599 \\
\hline .053 & cno67 & .429 \\
\hline .050 & cno 77 & .606 \\
\hline .099 & cno 70 & .471 \\
\hline .053 & cno 75 & .681 \\
\hline .053 & cno33 & .552 \\
\hline .054 & $\mathrm{cno} 37$ & 370 \\
\hline .065 & cno 2 & .683 \\
\hline .062 & cno8 & .720 \\
\hline .057 & cno 10 & .426 \\
\hline .062 & cnol1 & .602 \\
\hline .063 & cno 20 & .613 \\
\hline .063 & cno23 & .669 \\
\hline .056 & cno26 & .724 \\
\hline .113 & cno56 & .560 \\
\hline .074 & cno30 & .533 \\
\hline .058 & cno32 & .732 \\
\hline .063 & cno34 & .646 \\
\hline .060 & cno42 & .735 \\
\hline .053 & cno47 & .469 \\
\hline .057 & cno50 & .746 \\
\hline .065 & cno51 & .677 \\
\hline .061 & cno54 & .799 \\
\hline .057 & cno58 & .539 \\
\hline .065 & cno71 & .572 \\
\hline .052 & cno82 & .591 \\
\hline .105 & cno14 & 518 \\
\hline .104 & cno17 & .556 \\
\hline .131 & cno25 & .576 \\
\hline .102 & cno27 & .621 \\
\hline .105 & cno35 & .532 \\
\hline .110 & cno44 & .730 \\
\hline .104 & cno46 & .656 \\
\hline .113 & cno56 & .657 \\
\hline .105 & cno59 & .641 \\
\hline .100 & cno60 & -.363 \\
\hline .123 & cno62 & .650 \\
\hline .105 & cno65 & .510 \\
\hline .132 & cno66 & -.666 \\
\hline .129 & cno 72 & .775 \\
\hline .121 & cno73 & .640 \\
\hline .642 & cno76 & .331 \\
\hline .054 & cno37 & .370 \\
\hline
\end{tabular}

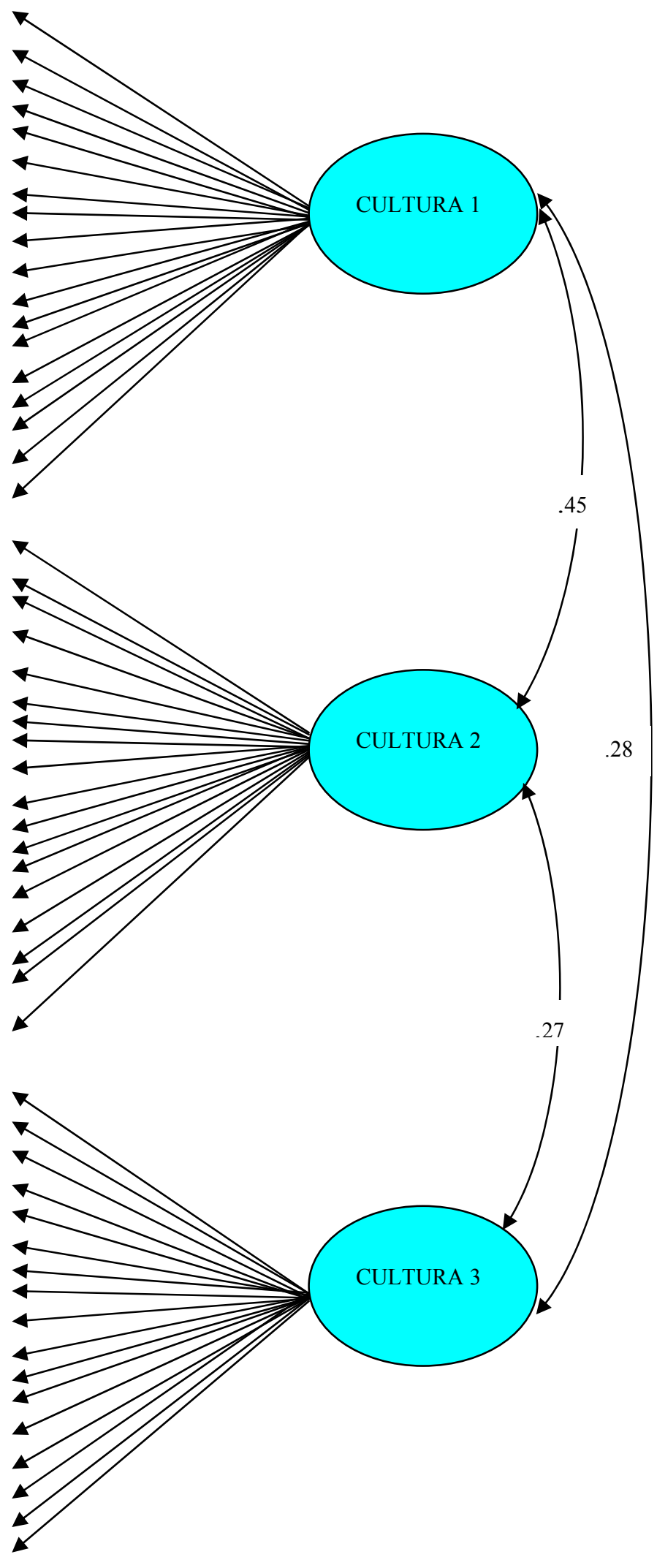




\subsubsection{Modelo final del instrumento}

En la reespecificación del modelo propuesto la estimación de cargas factoriales y los errores de medida obtenidos de las variables observables se muestra en el Gráfico 5.4.

\section{Gráfico 5.4 Análisis confirmatorio modelo reespecificado}

\begin{tabular}{|c|c|c|}
\hline$\delta$ & $\mathrm{X}$ & $\lambda$ \\
\hline .053 & cno8 & .734 \\
\hline .058 & cnolo & .434 \\
\hline .056 & cnoll & .632 \\
\hline .067 & cno30 & .501 \\
\hline .052 & cno32 & .722 \\
\hline .049 & cno47 & .474 \\
\hline .053 & cno69 & .565 \\
\hline .059 & cno 71 & .596 \\
\hline .701 & cno82 & .603 \\
\hline .056 & cno37 & .367 \\
\hline .057 & cno75 & .680 \\
\hline .053 & cno77 & .602 \\
\hline .058 & cno49 & .580 \\
\hline .059 & cno29 & .682 \\
\hline .065 & cno16 & .585 \\
\hline .059 & cno5 & .702 \\
\hline .063 & cnol & .687 \\
\hline .151 & cno14 & .518 \\
\hline .152 & cno62 & .693 \\
\hline .150 & cno 73 & 695 \\
\hline
\end{tabular}

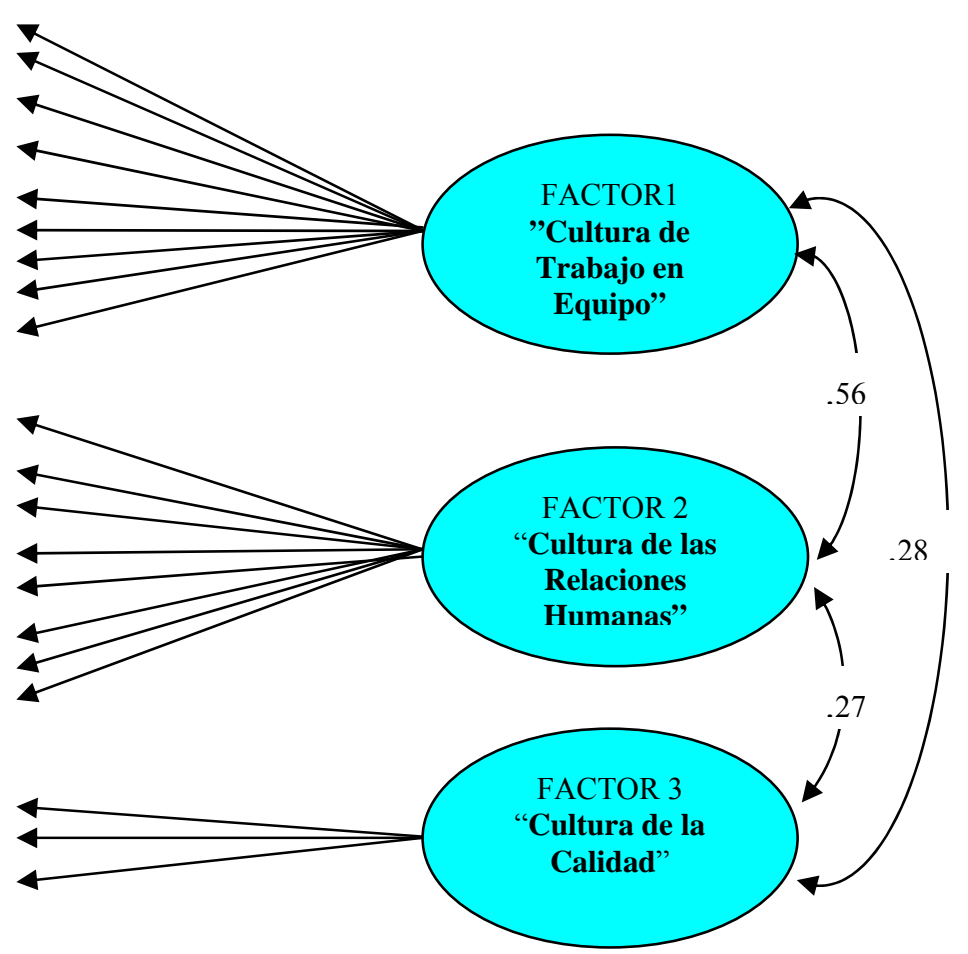

Dicho modelo reespecificado continua contemplando la estructura factorial de tres factores aunque cuenta sólo con 20 ítems:

Factor (1): 1, 5, 16, 29, 37, 49, 75, 77.

Factor (2): 8, 10, 11, 30, 32, 47, 69, 71, 82.

Factor (3): 14, 62, 73.

Realizando un estudio de los ítems que componen cada factor se pueden identificar con tres tipos de culturas diferentes pero complementarias englobadas en la cultura organizacional:

El factor 1 se podría identificar como "Cultura del Trabajo en Equipo", el factor 2 se 
identificaría con "Cultura de Relaciones Humanas" y el factor 3 se enfoca hacía una “Cultura de la Calidad”.

Como se observa en el Tabla.5.3 los índices de ajuste obtenidos con el modelo reespecificado son altamente satisfactorios.

Tabla 5.3. Comparación entre los índices de ajuste

\begin{tabular}{|lrrrrrrr|}
\hline & $\boldsymbol{X} \mathbf{2}$ & $\boldsymbol{P}$ & $\boldsymbol{D F}$ & $\boldsymbol{G F I}$ & NFI & RMSEA \\
\hline MODELO CNO 2 INICIAL & 4433 & .000 & 3.536 & .809 & .753 & .061 \\
MODELO REESPECIFICADO & 675 & .000 & 2.884 & .923 & .890 & .046 \\
\hline
\end{tabular}

Resumiendo los datos anteriores, podemos decir que se ha alcanzado una medida más parsimoniosa del constructo y que se ajusta mucho mejor a la concepción teórica que defendemos de la implicación, entendida como un proceso.

\subsubsection{Consistencia interna}

Se calculo un indicador de la consistencia interna de la escala de 20 ítems del modelo reespecificado: el coeficiente alfa de Cronbach. En primer lugar cabe decir que la fiabilidad del CNO-2 fue alta (con un $\alpha=.90$ ). A pesar de su reducido número de ítems, se obtuvieron también valores aceptables para cada uno de sus tres componentes por separado factor 1: $\alpha=.85$, factor 2: $\alpha=.80$, factor 3 con un $\alpha=.67$, si bien los peores resultados se obtuvieron en el tercer factor con un $\alpha=.67$. Una posible explicación de la baja puntuación obtenida en el factor(3) podría ser un número reducido de ítems, 3 ítems solamente. En la tabla 4.6 se muestra también la media y desviación de los tres factores. 
Tabla 5.4. Estadísticos descriptivos de los tres factores

\begin{tabular}{|c|c|c|c|c|c|c|}
\hline & \multicolumn{2}{|c|}{$\mathrm{N}$} & \multirow[b]{2}{*}{ Media } & \multirow[b]{2}{*}{ Desv. típ. } & \multirow[b]{2}{*}{ Mínimo } & \multirow[b]{2}{*}{ Máximo } \\
\hline & Válidos & Perdidos & & & & \\
\hline FACTOR1A & 135 & 1 & 1,9469 & ,8273 &, 00 & 3,88 \\
\hline FACTOR2A & 133 & 3 & 2,4214 & ,6749 & ,33 & 4,00 \\
\hline FACTOR3A & 135 & 1 & 2,9031 & ,8829 & , 00 & 4,00 \\
\hline
\end{tabular}

Posteriormente procedimos al análisis factorial del cuestionario efectuando las siguientes comprobaciones previas: la matriz de correlación; test de esfericidad de Barlett, que revela un Chi cuadrado aproximado de 3.964,202 (171 gl.), significativo a .000; y finalmente, el índice KMO de Káiser- Mayer- Olkin que fue de .926

Esta información nos permitió tomar la decisión de realizar el correspondiente análisis factorial por cumplirse los requisitos para ello. El análisis factorial se realizó utilizando el método de Análisis de los Componentes Principales (PCA), con rotación Varimax con Kaiser se obtuvieron 3 componentes que explican un 48,341\% de la varianza total y que presentamos en la tabla 5.5.

Tabla 5.5. Varianza total explicada de los tres factores

\begin{tabular}{|c|c|c|c|c|c|c|c|c|c|}
\hline \multirow[b]{2}{*}{ Componente } & \multicolumn{3}{|c|}{ Autovalores iniciales } & \multicolumn{3}{|c|}{$\begin{array}{l}\text { Sumas de las saturaciones al cuadrado de la } \\
\text { extracción }\end{array}$} & \multicolumn{3}{|c|}{$\begin{array}{l}\text { Suma de las saturaciones al cuadrado de la } \\
\text { rotación }\end{array}$} \\
\hline & Total & $\%$ de la varianza & $\%$ acumulado & Total & \% de la varianza & $\%$ acumulado & Total & $\%$ de la varianza & $\%$ acumulado \\
\hline 1 & 6,501 & 34,217 & 34,217 & 6,501 & 34,217 & 34,217 & 3,508 & 18,462 & 18,462 \\
\hline 2 & 1,516 & 7,981 & 42,197 & 1,516 & 7,981 & 42,197 & 2,980 & 15,683 & 34,145 \\
\hline 3 & 1,167 & 6,144 & 48,341 & 1,167 & 6,144 & 48,341 & 2,697 & 14,196 & 48,341 \\
\hline 4 & 989 & 5,204 & 53,545 & & & & & & \\
\hline 5 & 931 & 4,899 & 58,444 & & & & & & \\
\hline 6 & ,787 & 4,145 & 62,588 & & & & & & \\
\hline 7 & ,747 & 3,932 & 66,520 & & & & & & \\
\hline 8 & ,710 & 3,737 & 70,257 & & & & & & \\
\hline 9 & ,662 & 3,482 & 73,739 & & & & & & \\
\hline 10 & ,637 & 3,355 & 77,094 & & & & & & \\
\hline 11 & ,609 & 3,205 & 80,299 & & & & & & \\
\hline 12 &, 549 & 2,888 & 83,187 & & & & & & \\
\hline 13 &, 540 & 2,840 & 86,027 & & & & & & \\
\hline 14 &, 521 & 2,744 & 88,772 & & & & & & \\
\hline 15 & ,483 & 2,541 & 91,313 & & & & & & \\
\hline 16 & 450 & 2,370 & 93,682 & & & & & & \\
\hline 17 & ,421 & 2,214 & 95,896 & & & & & & \\
\hline 18 & ,395 & 2,080 & 97,976 & & & & & & \\
\hline 19 & .385 & 2,024 & 100,000 & & & & & & \\
\hline
\end{tabular}


En un primer análisis de los resultados se comprobó la existencia de una estructura donde todos los ítems que componían el cuestionario saturaban de forma elevada en 3 factores, como se muestra en el gráfico de sedimentación.

Gráfico 5.5. Grado de sedimentación

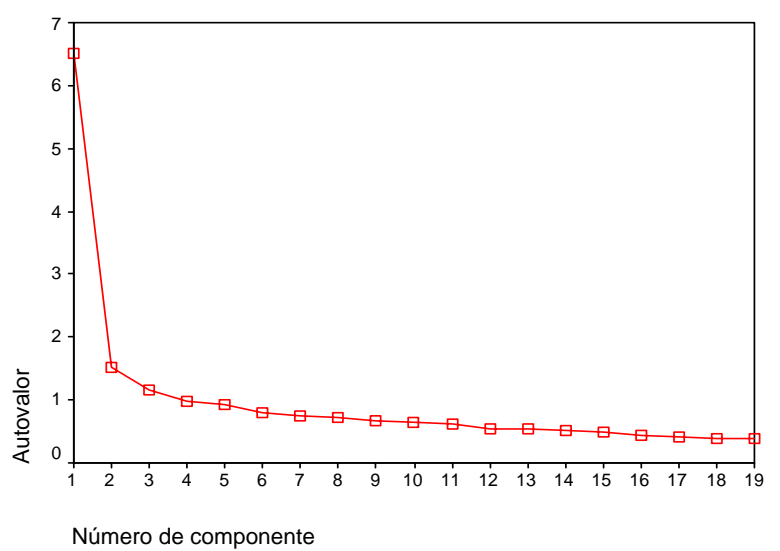

Con esta información realizamos un análisis factorial tras el análisis de los componentes principales se obtuvieron 3 factores que están integrados por los ítems que nos confirmaba el análisis factorial confirmatorio realizado con el programa Amos.

Tabla 5.6. Matriz de componentes rotados

\begin{tabular}{llll} 
& \multicolumn{3}{c}{ Componente } \\
\cline { 2 - 4 } CNO1A & 1 & 2 & 3 \\
CNO5A &, 649 &, 548 \\
CNO8A &, 691 &, 745 \\
CNO10A & &, 660 \\
CNO11A & & \\
CNO14A & & \\
CNO16A &, 421 &, 594 \\
CNO29A &, 690 & \\
CNO30A & &, 481 \\
CNO32A & & \\
CNO37A &, 609 &, 540 \\
CNO47A & & \\
CNO49A &, 435 & \\
CNO62A & &, 490 \\
CNO71A & & \\
CNO73A & & \\
CNO75A &, 623 &, 736 \\
CNO77A &, 674 & \\
CNO82A & & \\
\hline \hline
\end{tabular}

Método de extracción: Análisis de componentes principales.

Método de rotación: Normalización Varimax con Kaiser.

a. La rotación ha convergido en 5 iteraciones. 
Una vez realizados todos los análisis pertinentes y de acuerdo con los resultados obtenidos se puede afirmar que la adaptación realizada del CNO-2 posee las garantías suficientes para su aplicación

\subsection{CUESTIONARIO DE COMPROMISO ORGANIZACIONAL (OCQ) de Mayer y Schooman (1992).}

Con referencia al cuestionario OCQ elegido para el estudio del compromiso del individuo con su organización se realizó el análisis factorial del cuestionario pero efectuando las comprobaciones previas, la matriz de correlación; test de esfericidad de Barlett, que revela un $\chi^{2}$ aproximado de 7439,682 (171 gl.), significativo a .000; y el índice KMO de Káiser- Mayer- Olkin que fue de .939, para comprobar que se cumplían los requisitos para ello. El análisis factorial se realizó utilizando el método de Análisis de los Componentes Principales (PCA), con rotación Varimax con Kaiser y se obtuvieron 2 componentes que explicaban un 54,671\% de la varianza total.

\begin{tabular}{|c|c|c|c|c|c|c|}
\hline \multirow[b]{2}{*}{ Componente } & \multicolumn{3}{|c|}{ Autovalores iniciales } & \multicolumn{3}{|c|}{$\begin{array}{l}\text { Suma de las saturaciones al cuadrado de la } \\
\text { rotación }\end{array}$} \\
\hline & Total & $\%$ de la varianza & $\%$ acumulado & Total & $\%$ de la varianza & $\%$ acumulado \\
\hline 1 & 8,725 & 45,921 & 45,921 & 6,957 & 36,616 & 36,616 \\
\hline 2 & 1,663 & 8,750 & 54,671 & 3,430 & 18,055 & 54,671 \\
\hline 3 & 1,127 & 5,929 & 60,600 & & & \\
\hline 4 &, 890 & 4,685 & 65,285 & & & \\
\hline 5 & ,822 & 4,325 & 69,609 & & & \\
\hline 6 &, 752 & 3,959 & 73,569 & & & \\
\hline 7 & ,698 & 3,672 & 77,241 & & & \\
\hline 8 & ,581 & 3,059 & 80,300 & & & \\
\hline 9 & ,507 & 2,671 & 82,971 & & & \\
\hline 10 &, 470 & 2,475 & 85,445 & & & \\
\hline 11 & ,454 & 2,390 & 87,835 & & & \\
\hline 12 & ,403 & 2,119 & 89,954 & & & \\
\hline 13 & ,374 & 1,970 & 91,925 & & & \\
\hline 14 & ,338 & 1,780 & 93,705 & & & \\
\hline 15 & ,292 & 1,539 & 95,244 & & & \\
\hline 16 & ,280 & 1,471 & 96,715 & & & \\
\hline 17 & ,218 & 1,145 & 97,860 & & & \\
\hline 18 & ,213 & 1,122 & 98,983 & & & \\
\hline 19 &, 193 & 1,017 & 100,000 & & & \\
\hline
\end{tabular}

Método de extracción: Análisis de Componentes principales. 


\subsection{CATEGORIZACIÓN DE LOS EQUIPOS DE TRABAJO SEGÚN SU NIVEL CULTURAL}

Siguiendo la clasificación que realizó Alonso (1998) de los equipos de trabajo que existen en las organizaciones según la cultura que poseen, agrupamos nuestros equipos en grupos o equipos de trabajo, organización o sociales como recogemos en la tabla 5.8 .

Tabla. 5.8 Distribución de los equipos de trabajo en los distintos grupos formados.

\begin{tabular}{|l|c|c|c|}
\hline & $\begin{array}{c}\mathbf{N}^{0} \text { de grupos } \\
\text { Organización }\end{array}$ & $\begin{array}{c}\mathbf{N}^{\text {o }} \text { de grupos de } \\
\text { Trabajo }\end{array}$ & $\begin{array}{c}\mathbf{N}^{\mathbf{0}} \text { de grupos } \\
\text { Sociales }\end{array}$ \\
\hline TOTAL & 105 & 13 & 18 \\
\hline
\end{tabular}

Analizando los resultados comprobamos una distribución mayoritaria de los equipos en la casilla de grupos o equipos de la organización, es decir equipos que han sido capaces de desarrollar un patrón mínimo de normas compartidas tanto en su estado actual como en su estado ideal. Para ratificar la primera hipótesis donde planteábamos que la relación existente entre compromiso y la cultura de los equipos de trabajo sería mejor cuanto más culturales fuesen los grupos procedimos a analizar el nivel de cultura en los equipos de trabajo siguiendo la propuesta de Alonso y Sánchez (1998). Según los resultados obtenidos en nuestros análisis como se muestra en la Tabla 5.9, distribuimos a los 136 equipos de nuestra muestra en tres grupos según su nivel de culturalidad.

Tabla 5.9 Distribución de los equipos de trabajo según su nivel de culturalidad.

\begin{tabular}{|l|c|}
\hline & $\mathbf{N}^{\mathbf{0}}$ de Equipos de Trabajo \\
\hline No culturales & 20 \\
\hline Cultural & 18 \\
\hline Muy Cultural & 98 \\
\hline \multicolumn{1}{|c|}{ TOTAL } & 136 \\
\hline
\end{tabular}

$-155-$ 


\subsubsection{Cultura actual}

Una vez clasificados lo equipos de trabajo en tres grupos se comprueba la correlación de cultura actual y el compromiso organizacional según el nivel de culturalidad de los equipos de trabajo. Los resultados se muestran en las tablas 5.10., 5.11

Tabla 5.10.Correlación entre cultura y compromiso organizacional en los equipos no culturales

Correlaciones $^{a}$

\begin{tabular}{llrr}
\hline \hline & & $\begin{array}{c}\text { compromiso } \\
\text { con valores }\end{array}$ & $\begin{array}{c}\text { compromiso } \\
\text { con continuar }\end{array}$ \\
\hline FACTOR1A & Correlación de Pearson &, 277 &, $548^{\star}$ \\
& Sig. (bilateral) &, 250 &, 015 \\
& $\mathrm{~N}$ & 19 & 19 \\
\hline FACTOR2A & Correlación de Pearson &, 031 &, 334 \\
& Sig. (bilateral) &, 896 &, 150 \\
& $\mathrm{~N}$ & 20 & 20 \\
\hline FACTOR3A & Correlación de Pearson &,- 008 &, 177 \\
& Sig. (bilateral) &, 973 &, 470 \\
& $\mathrm{~N}$ & 19 & 19 \\
\hline \hline
\end{tabular}

*. La correlación es significante al nivel 0,05 (bilateral).

a. INDICJAM $=, 00$

Tabla 5.11.Correlación entre cultura y compromiso organizacional en los equipos muy culturales

Correlaciones $^{a}$

\begin{tabular}{llrr}
\hline \hline & & $\begin{array}{c}\text { compromiso } \\
\text { de continuar }\end{array}$ & $\begin{array}{c}\text { compromiso } \\
\text { con los valores }\end{array}$ \\
\hline FACTOR1A & Correlación de Pearson &, $384^{\star \star}$ &, $613^{\star \star}$ \\
& Sig. (bilateral) &, 000 &, 000 \\
& $\mathrm{~N}$ & 98 & 98 \\
\hline FACTOR2A & Correlación de Pearson &, $391^{\star \star}$ &, $550^{\star \star}$ \\
& Sig. (bilateral) &, 000 &, 000 \\
& $\mathrm{~N}$ & 97 & 96 \\
\hline FACTOR3A & Correlación de Pearson &, $255^{\star \star}$ &, $428^{\star \star}$ \\
& Sig. (bilateral) &, 000 &, 000 \\
& $\mathrm{~N}$ & 98 & 99 \\
\hline \hline
\end{tabular}

**. La correlación es significativa al nivel 0,01 (bilateral).

a. INDICJAM $=3,00$ 
Observamos que la correlación entre cultura actual y compromiso organizacional difieren según el nivel de culturalidad de los equipos de trabajo, en los equipos donde la culturalidad es alta la correlación existente es mayor que en los equipos de trabajo que no se consideran culturales. En los equipos no culturales la única correlación significativa existente es en el factor1 en la dimensión de compromiso con valores.

Cuando la culturalidad en los equipos de trabajo es alta la correlación es significativa en las dos dimensiones siendo mayor en la dimensión de compromiso con los valores. Este resultado está relacionado con el compromiso que se crean los trabajadores con la empresa cuando coincide la cultura de la empresa y la cultura de los trabajadores que trabajan en ella.

\subsubsection{Cultura deseada}

Los valores de la correlación entre la cultura deseada y el compromiso organizacional teniendo en cuenta el nivel de culturalidad de los equipos de trabajo se encuentran recogidos en las siguientes tablas.

Tabla 5.12.Correlación entre cultura y compromiso organizacional en los equipos no culturales

\begin{tabular}{llrr}
\hline \hline & & $\begin{array}{c}\text { compromiso } \\
\text { de continuar }\end{array}$ & $\begin{array}{c}\text { compromiso } \\
\text { con los valores }\end{array}$ \\
\hline FACTOR1B & Correlación de Pearson &, 272 &, 142 \\
& Sig. (bilateral) &, 260 &, 561 \\
& $\mathrm{~N}$ & 20 & 20 \\
\hline FACTOR2B & Correlación de Pearson &, 169 &, 030 \\
& Sig. (bilateral) &, 488 &, 903 \\
& $\mathrm{~N}$ & 19 & 19 \\
\hline FACTOR3B & Correlación de Pearson &,- 403 &,,$- 651^{\text {** }}$ \\
& Sig. (bilateral) &, 087 &, 003 \\
& $\mathrm{~N}$ & 20 & 19 \\
\hline \hline
\end{tabular}

**. La correlación es significativa al nivel 0,01 (bilateral).

a. INDICJAM $=, 00$ 
Al igual que en los resultados obtenidos en la cultura actual la correlación existente en los equipos en los que el índice de culturalidad es nulo sólo es significativo en la dimensión de compromiso de valores en el factor 3, sin embargo cuando la culturalidad de los equipos es alta la correlación es significativa en los tres factores en las dos dimensiones siendo menor e inversa en el factor 3.

Tabla 5.13 Correlación entre cultura y compromiso organizacional en los equipos muy culturales.

\begin{tabular}{llrr}
\hline \hline & & $\begin{array}{c}\text { compromiso } \\
\text { de continuar }\end{array}$ & $\begin{array}{c}\text { compromiso } \\
\text { con los valores }\end{array}$ \\
\hline FACTOR1B & Correlación de Pearson &, $117^{\star \star}$ &, $162^{\star \star}$ \\
& Sig. (bilateral) &, 010 &, 000 \\
& $\mathrm{~N}$ & 98 & 98 \\
\hline FACTOR2B & Correlación de Pearson &, $254^{\star \star}$ &, $258^{\star \star}$ \\
& Sig. (bilateral) &, 000 &, 000 \\
& $\mathrm{~N}$ & 98 & 98 \\
\hline FACTOR3B & Correlación de Pearson &,$- 106^{*}$ &,$- 140^{\star \star}$ \\
& Sig. (bilateral) &, 018 &, 002 \\
& $\mathrm{~N}$ & 99 & 99 \\
\hline \hline
\end{tabular}

\subsection{POTENCIA CULTURAL}

Realizados los análisis correspondientes se comprobó que el número de equipos que superan los tres criterios para considerarlos que tenían potencia cultural fueron 116 equipos distribuyéndose según el nivel de potencia alcanzado en el siguiente orden.

Tabla 5.14. Número de equipos que cumplen los 3 criterios de potencia cultural

\begin{tabular}{|l|c|}
\hline \multicolumn{1}{|c|}{ Nivel de potencia } & $\mathbf{N}^{\mathbf{0}}$ de Equipos \\
\hline Máxima potencia (3 factores) & 46 \\
\hline Potencia normal (2 factores) & 36 \\
\hline Poca potencia ( 1 factor $)$ & 34 \\
\hline Sin potencia $\quad$ ( factores) & 20 \\
\hline
\end{tabular}


Se obtiene como resultado que el factor que alcanza una puntuación mayor es el de “máxima potencia", aunque se observa una distribución bastante uniforme entre las cuatro categorías. Una vez hallada la potencia cultural de cada equipo de trabajo, se introduce potencia cultural como variable independiente para comprobar la repercusión en el compromiso que se establece entre el empleado y la organización mostrándose los resultados en las siguientes tablas.

Tabla 5.15. Correlación entre cultura y compromiso organizacional en equipos sin potencia cultural

Correlaciones a

\begin{tabular}{llrr}
\hline \hline & & $\begin{array}{c}\text { compromiso } \\
\text { de continuar }\end{array}$ & $\begin{array}{c}\text { compromiso } \\
\text { con los valores }\end{array}$ \\
\hline FACTOR1A & Correlación de Pearson &, $420^{*}$ &, $407^{*}$ \\
& Sig. (bilateral) &, 037 &, 039 \\
& $\mathrm{~N}$ & 15 & 16 \\
\hline FACTOR2A & Correlación de Pearson &, 088 &, 076 \\
& Sig. (bilateral) &, 674 &, 711 \\
& $\mathrm{~N}$ & 15 & 16 \\
\hline FACTOR3A & Correlación de Pearson &, 359 &, $518^{*}$ \\
& Sig. (bilateral) &, 078 &, 007 \\
& $\mathrm{~N}$ & 15 & 16 \\
\hline \hline
\end{tabular}

*. La correlación es significante al nivel 0,05 (bilateral).

**. La correlación es significativa al nivel 0,01 (bilateral).

a. $\mathrm{JAM}_{\mathrm{N}}=0$

Tabla.5.16. Correlación entre cultura y compromiso organizacional en equipos con potencia cultural

Correlaciones a

\begin{tabular}{llrr}
\hline \hline & & $\begin{array}{c}\text { compromiso } \\
\text { de continuar }\end{array}$ & $\begin{array}{c}\text { compromiso } \\
\text { con los valores }\end{array}$ \\
\hline FACTOR1A & Correlación de Pearson &, $313^{* *}$ &, $526^{\star *}$ \\
& Sig. (bilateral) &, 000 &, 000 \\
& $\mathrm{~N}$ & 80 & 80 \\
\hline FACTOR2A & Correlación de Pearson &, $413^{* *}$ &, $489^{* \star}$ \\
& Sig. (bilateral) &, 000 &, 000 \\
& $\mathrm{~N}$ & 80 & 80 \\
\hline FACTOR3A & Correlación de Pearson &, $320^{* *}$ &, $424^{\star *}$ \\
& Sig. (bilateral) &, 000 &, 000 \\
& $\mathrm{~N}$ & 80 & 80 \\
\hline \hline
\end{tabular}

**. La correlación es significativa al nivel 0,01 (bilateral).

a. JAM. $=3$ 
El compromiso que establece el equipo de trabajo con la empresa es mayor cuanto mayor es la potencia cultural del equipo de trabajo. Si el equipo tiene una potencia cultural baja (0) la correlación es significativa en el factor 1 en las dos dimensiones del compromiso organizacional analizadas y en el factor 3 en el compromiso con valores. Cuando el equipo de trabajo tiene una potencialidad alta la correlación es significativa en las dos dimensiones en los tres factores.

Se confirma nuestra hipótesis donde se planteaba la potencia cultural como variable independiente que influía en la relación que se establece entre el compromiso y la cultura organizacional.

\subsection{DESFASES CULTURALES}

Una vez calculados los desfases culturales que nos permiten conocer el ajuste cultural que existe en la organización se extraen el número de equipos que tienen desfase cultural en 1, 2 o en tres factores y los desfases existentes en los tres factores como se muestran en las siguientes tablas.

Tabla 5.17. El número de desfases que tienen los equipos

\begin{tabular}{|c|c|}
\hline Factores & $\mathbf{N}^{\mathbf{0}}$ de equipos \\
\hline Con desfase en un factor & 38 \\
\hline Con desfase en $\mathbf{2}$ factores & 19 \\
\hline Con desfase en 3 factores & 27 \\
\hline Sin desfase & 52 \\
\hline
\end{tabular}


Tabla 5.18. El número de desfases que tienen los equipos en cada factor.

\begin{tabular}{|l|c|}
\hline \multicolumn{1}{|c|}{ Factores } & $\mathbf{N}^{\mathbf{0}}$ de equipos \\
\hline Factor 1. "C. de Trabajo en equipo" & 49 \\
\hline Factor 2. "C. de las Relaciones Humanas" & 28 \\
\hline Factor 3. "C. de Calidad" & 59 \\
\hline
\end{tabular}

Se percibe que el factor 2 "Cultura de las Relaciones Humanas" tenía un número muy bajo de desfases, 28 y que tan sólo 19 equipos de trabajo tienen desfases en dos factores y 52 equipos no tienen desfases lo que muestra una gran concordancia entre la cultura actual en la organización y la cultura deseada en nuestros equipos de trabajo.

Una vez hallados los desfases culturales existentes en los equipos de trabajo nos planteamos cual sería su influencia en el compromiso organizacional que establece el empleado pero teniendo también en cuenta la potencialidad de los equipos de trabajo. En la tabla siguiente se muestra los valores obtenidos cuando tenemos en cuenta como variables independientes la potencia cultural y los desfases culturales.

Tabla 5.19. Correlación entre cultura y compromiso en equipos con desfase cultural con potencia cultural alta

\begin{tabular}{llrr}
\hline \hline & & $\begin{array}{c}\text { compromiso } \\
\text { con los valores }\end{array}$ & \multicolumn{2}{c}{$\begin{array}{c}\text { compromiso } \\
\text { continuar }\end{array}$} \\
\cline { 1 - 2 } & Coctrelación de Pearson &, $288^{\star *}$ &, $488^{* *}$ \\
& Sig. (bilateral) &, 010 &, 000 \\
& $\mathrm{~N}$ & 36 & 36 \\
\hline FACTOR2A & Correlación de Pearson &, 123 &, $282^{*}$ \\
& Sig. (bilateral) &, 274 &, 010 \\
& $\mathrm{~N}$ & 36 & 36 \\
\hline FACTOR3A & Correlación de Pearson &, 055 &, $345^{\star *}$ \\
& Sig. (bilateral) &, 627 &, 001 \\
& $\mathrm{~N}$ & 36 & 36 \\
\hline \hline
\end{tabular}

\footnotetext{
${ }^{* *}$. La correlación es significativa al nivel 0,01 (bilateral).
}

*. La correlación es significante al nivel 0,05 (bilateral). 
Cuando existe desfase cultural pero el equipo de trabajo tiene una potencialidad alta la correlación entre cultura y compromiso de trabajo solamente es significativo en la dimensión de compromiso continuar para los tres factores y en el factor 1 en compromiso con los valores.

\subsection{REGRESIÓN}

Para seguir profundizando en esta relación vamos aplicar una regresión múltiple para poder concluir la existencia de evidencia suficiente para afirmar que existe una verdadera relación entre las variables predictoras y de criterio. Lo resultados obtenidos se muestran a continuación.

Tabla 5.20. Análisis de regresión siendo variables predictoras, la culturalidad, la potencia cultural y los desfases culturales en los equipos de trabajo.

\begin{tabular}{|l||c|c|c|c|c||c|c|c|c|c||}
\hline \multicolumn{1}{|c|}{} & \multicolumn{4}{|c|}{ C. CONTINUAR } & \multicolumn{5}{c||}{ C. VALORES } \\
\cline { 2 - 12 } & & Sig & $\beta$ & Beta & t & & Sig & $\beta$ & Beta & T \\
\hline Culturalidad & &, 07 &, 13 &, 08 &, 05 & &, 00 & .22 &, 12 & 2,99 \\
\hline Potencia & &, 00 &, 27 & 5,40 &, 00 & &, 00 & .47 &, 38 & 9,03 \\
\hline Desfase & &, 04 &, 00 &,- 52 &, 59 & &, 05 & -.19 &,- 07 & $-1,93$ \\
\hline $\boldsymbol{R}^{n}$ &, 04 &, 00 & & & &, 12 &, 00 & & & \\
\hline $\boldsymbol{F}$ & 9,91 &, 00 & & & & 32,1 &, 00 & & & \\
\hline
\end{tabular}

En la dimensión de compromiso con continuar el 4,2 \% de la varianza de la variable compromiso está predicha por la variables Culturalidad, Desfase cultural y Potencia cultural

Existe una relación significativa ente Compromiso Continuar y Potencia cultural $\mathrm{F}(3,679)=9,91 \mathrm{p}<0,000$. Se comprueba que cuanto mayor puntuación en Potencia, mayor puntuación en Compromiso con Continuar en la empresa. No existe una relación significativa entre índice de culturalidad y desfase cultural con Compromiso con Continuar. En la dimensión de Compromiso con los Valores el 1,2 \% de la varianza de la variable compromiso está predicha por la variables culturalidad, desfase cultural y 
potencia cultural. Existe una relación significativa ente Compromiso con Valores y desfase cultural $\mathrm{F}(3,679)=32,18 \mathrm{p}<0,000$ y Compromiso con Valores y potencia cultural $F(3,679)=32,18 p<0,003 F(3,679)=9,91 p<0,000$. Se comprueba que cuanto mayor puntuación en Potencia, mayor puntuación en Compromiso con los Valores de la empresa y que cuanto mayor desfase cultural en los equipos de trabajo menor compromiso con los valores de la empresa. No existe una relación significativa entre índice de culturalidad y el compromiso con valores de la organización.

Estudiando la relación entre la variable criterio tipo de empresa, pública o privada, y la variable predictora, culturalidad, desfase cultural y potencia cultural de los equipos de trabajo los resultados obtenidos son los mostrados en la siguiente tabla 5.21.

Tabla 5.21. Análisis de regresión siendo variables predictoras, la culturalidad, la potencia cultural y los desfases culturales en los equipos de trabajo teniendo en cuenta el tipo de empresa.

\begin{tabular}{|c|c|c|c|c|c|c|c|c|c|c|}
\hline & \multicolumn{10}{|c|}{ EMPRESA PÚBLICA } \\
\hline & \multicolumn{5}{|c|}{ C. CONTINUAR } & \multicolumn{5}{|c|}{ C. VALORES } \\
\hline & & Sig & B & Beta & $\mathbf{t}$ & & Sig & B & Beta & $\mathbf{T}$ \\
\hline Culturalidad & &, 07 &, 17 &, 10 & 1,07 & & ,29 &, 11 & ,06 & 1,0 \\
\hline Potencia & &, 00 &, 31 &, 06 & 4,75 & &, 00 &, 48 & ,39 & 6,7 \\
\hline Desfase & &, 04 &,- 26 &,- 11 & $-2,03$ & & ,92 &,- 00 &, 00 & ,09 \\
\hline$R^{2}$ & ,06 &, 00 & & & & ,12 &, 00 & & & \\
\hline \multirow[t]{4}{*}{$F$} & 8,2 &, 00 & & & &, 00 & & & & \\
\hline & \multicolumn{10}{|c|}{ EMPRESA PRIVADA } \\
\hline & \multicolumn{5}{|c|}{ C. CONTINUAR } & \multicolumn{5}{|c|}{ C. VALORES } \\
\hline & & Sig & 及 & Beta & $\mathbf{t}$ & & Sig & 及 & Beta & $\mathbf{T}$ \\
\hline Culturalidad & & ,09 &, 17 &, 11 & 1,6 & &, 00 &, 41 & ,24 & 3,6 \\
\hline Potencia & &, 00 &, 25 &, 23 & 3,3 & &, 00 &, 51 & ,40 & 6,2 \\
\hline Desfase & &, 27 &,- 15 &,- 06 & $-1,0$ & &, 01 &, 40 &,- 14 & $-2,6$ \\
\hline$R^{2}$ &, 03 &, 00 & & & &, 12 &, 00 & & & \\
\hline$F$ & 4,5 & ,00 & & & & 16,6 &, 00 & & & \\
\hline
\end{tabular}

Se comprueba que en referencia a la potencialidad de los equipos los resultados son significativos tanto en la empresa privada como en la pública en las dos dimensiones de 
compromiso organizacional En la empresa pública los desfases culturales son significativos en Compromiso con Continuar $\mathrm{p} \leq .043$ pero no es significativo en Compromiso con Valores $\mathrm{p} \leq$.96), por ello a mayor desfase cultural menor Compromiso de Continuar en la empresa pública, pero en la empresa privada si son significativos los resultados obtenidos en Compromiso con valores $\mathrm{p} \leq .011$ y no son significativo en compromiso de continuar $\mathrm{p} \leq .277$, manifestado la diferencia de compromiso que establecen los equipos según su nivel de desfase cultural que exista en los equipos de trabajo (con desfase o sin desfase o baja) y el tipo de empresa en la que trabaja.

La culturalidad de los equipos de trabajo es sólo significativa en el Compromiso con los Valores que establece los equipos de trabajo en la empresa privada $p \leq .000$. Los equipos con potencia cultural alta realizan en la empresa privada un mayor Compromiso con sus Valores que los equipos cuya potencia cultural es baja no obteniendo los mismos resultados en la empresa pública.

Tabla 5.22. Compromiso de los trabajadores en la empresa pública y privada según su potencialidad

\begin{tabular}{|c|c|c|c|c|c|}
\hline EMPRESA & COMPROMISO & $t$ & Sig & POTENCIA & $\overline{\bar{x}}$ \\
\hline \multirow{4}{*}{$\begin{array}{c}\text { EMPRESA } \\
\text { PÚBLICA }\end{array}$} & \multirow{2}{*}{ C. CONTINUAR } & \multirow{2}{*}{-3.89} & \multirow{2}{*}{00} & Sin potencia & 3,11 \\
\hline & & & & Mucha potencia & 3,80 \\
\hline & \multirow{2}{*}{ C. VALORES } & \multirow{2}{*}{$-6,15$} & \multirow{2}{*}{00} & Sin potencia & 2,91 \\
\hline & & & & Mucha potencia & 4,15 \\
\hline \multirow{4}{*}{$\begin{array}{c}\text { EMPRESA } \\
\text { PRIVADA }\end{array}$} & \multirow{2}{*}{ C. CONTINUAR } & \multirow{2}{*}{-3.35} & \multirow{2}{*}{00} & Sin potencia & 3,03 \\
\hline & & & & Mucha potencia & 3,68 \\
\hline & \multirow{2}{*}{ C. VALORES } & \multirow{2}{*}{$-4,51$} & \multirow{2}{*}{, 00} & Sin potencia & 3,15 \\
\hline & & & & Mucha potencia & 4,13 \\
\hline
\end{tabular}

Revisando los datos obtenidos en la empresa pública, en referencia a la relación entre el compromiso organizacional y el tiempo que llevan trabajando en el equipo y en la 
empresa comprobamos que solo existe una la correlación negativa entre el tiempo que llevan trabajando en el equipo y el compromiso con los valores que a mayor tiempo en el equipo menor es el compromiso con los valores.

Tabla 5.23. Relaciones entre tiempo que lleva trabajando en el equipo, en la empresa y el compromiso organizacional en la empresa pública

\begin{tabular}{llrr}
\hline \hline & & $\begin{array}{c}\text { compromiso } \\
\text { de continuar }\end{array}$ & $\begin{array}{c}\text { compromiso } \\
\text { con los valores }\end{array}$ \\
\hline Tiempo Trabajando & Correlación de Pearson &, 003 &,- 136 \\
en el equipo & Sig. (bilateral) &, 953 &, 015 \\
& $\mathrm{~N}$ & 135 & 134 \\
& Correlación de Pearson &, 036 &,- 058 \\
Tiempo trabajando & en la empresa &, 519 &, 301 \\
& Sig. (bilateral) & 136 & 134 \\
\hline \hline
\end{tabular}

*. La correlación es significante al nivel 0,05 (bilateral).

a. EMPRESA $=$ Pública

Analizando en la empresa privada comprobamos que la única correlación existente entre el tiempo que llevan trabajando en la empresa y el compromiso con los valores, a mayor tiempo trabajando en la empresa menor el compromiso organizacional que establecen los trabajados.

Tabla 5.24. Correlaciones entre tiempo que lleva trabajando en el equipo y en la empresa y el compromiso organizacional en la empresa privada

\begin{tabular}{llrr}
\hline \hline & & $\begin{array}{c}\text { compromiso } \\
\text { de continuar }\end{array}$ & $\begin{array}{c}\text { compromiso } \\
\text { con los valores }\end{array}$ \\
\hline Tiempo Trabajando & Correlación de Pearson &, 019 &,- 079 \\
en el equipo & Sig. (bilateral) &, 735 &, 157 \\
& $\mathrm{~N}$ & 135 & 134 \\
\hline Tiempo trabajando & Correlación de Pearson &,- 061 &,$- 142^{*}$ \\
en la empresa & Sig. (bilateral) &, 277 &, 011 \\
& $\mathrm{~N}$ & 136 & 134 \\
\hline \hline
\end{tabular}

\footnotetext{
*. La correlación es significante al nivel 0,05 (bilateral).

a. EMPRESA $=$ Privada
} 


\begin{tabular}{|ll|r|r|}
\hline & & \multicolumn{2}{c|}{$\begin{array}{c}\text { compromiso } \\
\text { con los } \\
\text { valores }\end{array}$} \\
\hline Tiempo Trabajando & de continuar &,$- 814^{\star *}$ \\
en el equipo & Correlación de Pearson &,- 220 &, 000 \\
& Sig. (bilateral) &, 366 & 19 \\
\hline Tiempo trabajando & $\mathrm{N}$ &,$- 460^{*}$ &,$- 715^{\star \star}$ \\
en la empresa & Correlación de Pearson &, 048 &, 001 \\
& Sig. (bilateral) & 19 & 19 \\
\hline
\end{tabular}

**. La correlación es significativa al nivel 0,01 (bilateral).

*. La correlación es significante al nivel 0,05 (bilateral).

Tabla 5.25. Correlaciones entre tiempo que lleva trabajando en el equipo y en la empresa.

\subsection{CONCLUSIÓN}

Con los resultados obtenidos en nuestro estudio podemos confirmar las hipótesis que planteabamos al comienzo de nuestra investigación.

El índice de culturalidad de los equipos de trabajo será una variable independiente importante en la relación que establece entre compromiso y cultura organizacional de los equipos de trabajo.

Que la potencialidad cultural es una potente variable independiente que modula la relación entre la cultura de la organización y el compromiso que realizan los equipos de trabajo con la organización en la que trabajan. Los equipos de trabajo con una potencia cultural alta establecen un mayor compromiso con continuar y con los valores de la empresa donde trabajan que los equipos con potencialidad baja.

Los desfases culturales existentes van a dar lugar a un peor compromiso con la empresa.

Existencia de variables como si la empresa es pública o privada, el tiempo que llevan trabajando en el equipo de trabajo o en la empresa van 
a tener una relación significativa positiva o negativa en el compromiso que se establezca con la empresa.

Comentados los resultados obtenidos en nuestra investigación y después de repasar nuestras hipótesis en el siguiente capítulo se recogerá las conclusiones principales de la presente tesis doctoral. 
CAPITULO 6

DISCUSIÓN Y CONCLUSIONES 


\section{CAPITULO 6. DISCUSIÓN Y CONCLUSIONES}

En este último capítulo se pretende resumir las conclusiones a las que se ha llegado respecto a la relación entre cultura y compromiso organizacional y su influencia en el desarrollo de la organización, así como señalar tanto las limitaciones como las aportaciones del trabajo que hemos realizado. Nos proponemos referir algunos hallazgos no previstos que se han presentado a lo largo del proceso de investigación. Finalmente se sugerirán algunas implicaciones de los resultados obtenidos para la planificación de investigaciones futuras y la práctica de un buen desarrollo organizacional.

\subsection{INTRODUCCIÓN}

El impacto sobre la gestión organizacional de la cultura y el compromiso organizacional queda patente en los múltiples estudios realizados sobre estos dos constructores complejos desde distintas vertientes. Este impacto también ha llevado a observar y estudiar estos dos constructos en el ámbito práctico de la empresa. Los estudios realizados sobre la cultura y el compromiso organizacional son amplios cuando estos fenómenos se han estudiado separadamente, pero son pocos los trabajos empíricos existentes que han estudiado la asociación o relación entre ambos conceptos.

Con el presente trabajo pretendemos realizar algunos avances que mejoren la compresión de la relación existente entre cultura organizacional y compromiso, pese a la dificultad de encontrar fundamentación teórica, y trabajos que aborden su estudio de manera empírica, nosotros consideramos que es el camino más adecuado a seguir en un 
futuro. Así, en este último capitulo sintetizaremos los resultados obtenidos en nuestra investigación, expondremos las conclusiones generales a que hemos llegado con el análisis de resultados y por últimos expondremos las implicaciones que consideramos que pueden tener dichos resultados en investigaciones futuras.

\subsection{RESUMEN DEL PLANTEAMIENTO TEÓRICO.}

El objetivo de nuestra tesis ha sido analizar empíricamente el análisis de la relación entre cultura y compromiso organizacional teniendo en cuenta la influencia de variables como la culturalidad, los desfases culturales y la potencia cultural de los equipos de trabajo.

Se ha partido del concepto de "organización", y se ha tenido que salvar la existencia de múltiples definiciones para precisar una definición de "organización" y asumir que aunque la organización sea un sistema de significados no implica que sean compartidos y que estos significados puedan diferir de una organización a otra.

A continuación, tras revisar las conceptualizaciones básicas existentes sobre "cultura", se ha analizado sus elementos, las metodologías de investigación, y los modelos planteados y se ha profundizado en los distintos estudios que se han realizando sobre este constructo.

Siguiendo un modelo funcional estructural se ha considera la cultura como un elemento de la organización. El constructo de cultura -refiriéndonos a valores compartidos y creencias personales que comparten los miembros de un grupo social- que se ha utilizado en este estudio especifica el concepto de cultura organizacional en dos aspectos: uno referido al núcleo de la cultura que lo forman los valores compartidos por 
un grupo social, los entendimientos comunes y patrones de creencias y expectativas (Rousseau, 1990); y el segundo aspecto, las manifestaciones culturales, que serán la forma de expresión de la cultura como, por ejemplo, los mitos, leyendas, rituales y normas de comportamiento.

Los equipos con los que se ha trabajado son equipos reales que dentro de la organización tienen una trayectoria propia, han vivido experiencias juntos y han desarrollado unas normas sociales y creencias compartidas, es decir, que poseen una cultura organizacional. Se ha considerado las características culturales de los equipos de trabajo por creer que la influencia del equipo sería decisiva en el proceso de compromiso organizacional.

Como ha afirmado Van Maanen (1985) también nosotros creemos que dentro de la misma organización se constituyen muchas subculturas que conviven. Cada una de ellas tiene un espacio singular, el de un equipo de trabajo específico, que es el contexto inmediato en el que las personas funcionan cotidianamente. A la vez todas estas subculturas cuando se las compara entre sí son distintas.

En relación con las percepciones de las personas acerca de la cultura de su trabajo, hemos indagado si resultaban influidas por la cultura real de los grupos de trabajo, es decir, si las personas dentro de un grupo de trabajo organizan sus percepciones basándose en los rasgos objetivos del ambiente laboral o lo hacen en torno a constructos mas significativos, como sus valores o sus necesidades. Si se produjese la selección selectiva de la información sería posible admitir que una experiencia compartida (índice de culturalidad), y consensuada (potencia cultural) se vinculará con un mejor rendimiento y eficacia en las tareas. 


\subsection{RESUMEN DE RESULTADOS.}

A continuación expondremos los resultados obtenidos en nuestro estudio confirmando las hipótesis que planteábamos tras el análisis de los estudios empíricos existentes y la revisión bibliográfica realizada.

De los resultados obtenidos comenzamos señalando que la investigación presentada aporta evidencia empírica de la importancia de la cultura como un prerrequisito para el compromiso organizacional de los equipos de trabajo.

Dentro de la división de los equipos de trabajo en "Grupos de la Organización, Sociales o de Trabajo" según el patrón mínimo de cultura que han podido desarrollar tanto en el estado ideal como en el real. En nuestra muestra existe un número mayor de "Grupos de Organización" (105 equipos de trabajo), reuniéndose mayoritariamente en el factor 2, "Cultura de la Relaciones Humanas", los "Grupos de Trabajo" (13 equipos) y los "Grupos Sociales" (18 equipos) en los que predomina el tercer factor, "Cultura de Calidad"-.

Según estos resultados, los equipos con los que trabajamos al pertenecer mayoritariasmente a "Los Grupos de la Organización” son equipos antiguos, es decir el tiempo que hace que trabajan en la empresa y el tiempo que hace que los empleados forman parte de ese equipo es superior a cuatro años.

Nuestros planteamientos e hipótesis parten de la idea de que la cultura de la organización está relacionada con el rendimiento y dicha relación entre ellos puede depender de otros elementos de la organización (Wang, 2006). 
Hipótesis 1: La relación entre cultura y compromiso organizacional difiere según el nivel de culturalidad de los equipos de trabajo. En la medida que un equipo de trabajo sea más cultural mayor será el compromiso organizacional.

Cuando analizamos la cultura actual y deseada comprobamos que el nivel de culturalidad de los equipos de trabajo es decisivo para desarrollar mayor o menor compromiso con la organización.

El nivel de culturalidad de los 136 equipos de trabajos estudiados es muy alto solamente 20 equipos no son culturales, es decir, no superan el índice de acuerdo intrajueces del .70 .

Tras analizar los resultados obtenidos en la cultura actual se comprueba que los equipos no son culturales, la única relación significativa se establece en la dimensión de Compromiso con Continuar y solamente en el factor 1 "Cultura del trabajo en equipo". Parece ser que aunque no comparten la cultura de la empresa y no se sienten identificados con ella sí desean continuar en ella. Si los equipos son muy culturales los resultados conseguidos son significativos en los tres factores en los dos tipos de compromiso.

Cuando se estudian los resultados obtenidos en la cultura deseada nos señalan que en los equipos que no son culturales la única relación significativa que establecen con la empresa es entre Compromiso con los Valores y el factor 3 "Cultura Calidad", pero esta relación es negativa.

Sin embago en los equipos muy culturales se encuentra un mayor compromiso con la organización en sus dos dimensiones, siendo mayor en la dimensión de "Compromiso 
con los Valores" de la empresa que en la dimensión de "Compromiso de Continuar" trabajando en ella, ya que, al ser los equipos muy culturales, se identifican con la empresa y aceptan su cultura.

Hipótesis 2: El compromiso que establecen los equipos de trabajo con la empresa depende de la potencia cultural que tengan dichos equipos. En los equipos de trabajo que son culturales, cuanto mayor sea su potencia cultural mayor será el compromiso que establecen con la empresa.

Para el estudio del análisis del consenso existente en un equipo de trabajo sobre la cultura de la empresa se ha visto la necesidad de ir más allá, en un principio se estudio a través del índice de acuerdo de James posteriormente se ha planteando el estudio de la potencia cultural. Los resultados nos indican que de los 116 equipos de trabajo que son culturales 82 equipos tienen una potencia cultural alta y establecen un mayor compromiso con la organización que los equipos en los que no existe potencia cultural. Cuanto mayor es la potencia cultural, es decir, cuanto mayor sea el consenso sobre lo que entienden por cultura los equipos de trabajo y ese consenso se sitúe en torno a las puntuaciones medias o superiores a ellas, el compromiso que establecen esos equipos de trabajo con la empresa es mayor.

Queda patente la importancia de la variable potencia cultural para establecer el compromiso, tanto de continuar como con los valores de la empresa, de los equipos de trabajo con la empresa (Hause, 2001). 
Hipótesis 3: Cuanto menos desfases existan entre la cultura real y la cultura deseada existente en la organización mayor será el compromiso que los equipos de trabajo establecen con la empresa.

Estudiamos los desfases culturales por pensar que se interrelacionarían de forma negativa y significativa con el compromiso laboral. Esto significa que cuanto mayor sea el desfase, es decir cuanto mayor sea el desequilibrio entre la cultura existente en la empresa y la deseada por el equipo de trabajo, menor será el compromiso del equipo con la organización, como se propone en la hipótesis (Garr,1998).

Los equipos de trabajo estudiados se distinguen por tener pocos desfases en los tres factores, solo hay 59 equipos que tengan desfases en los tres factores. En el factor donde existen más desfases es en el factor 3 "Cultura de Calidad" y el factor en que menos desfases se registran es el factor 2, llamado "Cultura de Relaciones Humanas".

Se puede deducir por estas características que son organizaciones con muchos años de trayectoria, en las que los equipos llevan bastante tiempo trabajando juntos y poseen una cultura consolidada, con un alto grado de identificación y aceptación de la cultura de la empresa, que les lleva a no desear cambios significativos. Sin embargo, en algo tan novedoso y reciente como es el tema calidad los equipos de trabajo no se sienten identificados con la cultura que la empresa implanta. Es bastante normal la aparición de discrepancias entre la empresa y los trabajadores en la conceptuación de qué es y qué implica la calidad, puede ser por el desconocimiento por parte de los trabajadores de lo que abarca la implantación de la calidad y el miedo a ser evaluados por ello.

En los equipos de trabajo en los que no existen desfases se halla una identificación mayor con los valores de la empresa y se adaptan mejor a los cambios existentes en 
ella. Cuando existen desfases aunque la potencia cultural sea alta no es significativo la relación que se establece con el "Compromiso de Continuar". Ese compromiso de continuidad puede ser debido al coste y pérdidas que supondría dejar ese trabajo, pero no está basada en la aceptación de la cultura de la empresa, aceptación que se produce cuando no existen desfases.

Frente a la idea de que es necesario un acatamiento por parte de los trabajadores de las normas de la organización para un correcto desempeño de las mismas, surgen con fuerza conceptos como el compromiso organizacional y la implicación con los objetivos de la organización, destacando el componente actitudinal y motivacional del comportamiento del trabajador.

Si relacionamos las variables "desfases" y "potencia cultural" y reflexionamos sobre su influencia en el compromiso que realizan los equipos con la empresa, los resultados muestran que cuando existe desfase entre la cultura percibida y la cultura deseada la variable independiente determinante del establecimiento de un mayor compromiso es la potencia cultural existente en esos equipos, ya que en los equipos en los que existe un alto consenso, potencia cultural alta, y existe desfase, existe un mayor compromiso que en los equipos que existe desfase pero tienen una potencia cultural baja. Esta relación es mas significativa en la dimensión de compromiso con continuar que con compromiso con los valores. La interpretación de estos resultados es que aunque existe desfase cultural, es decir no están de acuerdo con la cultura de la empresa, existe un alto consenso en lo que entiende el equipo de trabajo por cultura, siendo por ello un equipo fuerte lo que le lleva a comprometerse a continuar en la empresa pero no comprometerse con los valores de la empresa. 
El bajo compromiso organizacional puede ser la señal de bajos niveles de satisfacción en el trabajo y del bajo apoyo organizacional percibido. Los empleados que no están satisfechos con su trabajo y que no perciben un apoyo suficiente por parte de la organización generan un bajo nivel de Compromiso Afectivo, de Continuación y Normativo en comparación con el personal que sí está satisfecho y por ello decide permanecer en su organización.

El modelo propuesto es el resultado de la revisión de la literatura existente y de seguir un marco teórico que establece que la rotación voluntaria esta influida por la baja intención por permanecer en la organización por parte del personal (intención) y por el deseo de encontrar un empleo en otra organización debido a un bajo apego emocional con la organización donde está (compromiso afectivo). El bajo apego se produce porque las pérdidas que el personal sufriría con la separación serían relativamente bajas (compromiso de continuar), y porque no se sienten obligados moralmente a continuar en su empleo (compromiso normativo), Mobley (1982).

La rotación en el trabajo entra en relación con diferentes componentes de satisfacción en el ámbito laboral, pero especialmente con la satisfacción del contenido que dicho trabajo proporciona (Mobley, Griffith, Hand, y Meglino, 1979). La rotación se predice por la intención que tiene el trabajador de dejar el empleo, intención que a su vez se predice por la baja satisfacción; pero la satisfacción laboral, aunque es una variable muy importante, no es la única variable que genera rotación (Mobley y otros, 1979).

Hipótesis 4: En referencia a las variables control, tipo de empresa y años de permanencia en el equipo de trabajo y en la empresa, tendrán una influencia positiva o 
negativa en el compromiso que realizan los trabajadores así como en el tipo de compromiso que establecerán y modularan las hipótesis anteriores.

Al igual que Rousseau (1990); Scharaeder (2007) y Rao (2005), que en sus estudios sobre la relación de la cultura con el rendimiento encontraron diferencias en los resultados según el tipo de normas con las que se trabajaba y estas variaban de la empresa pública a la empresa privada, nosotros hemos constatado que existen diferencias en los resultados obtenidos según el tipo de empresa, pública o privada, en la que se trabaja.

El nivel de culturalidad de los equipos es mayor en las empresas privadas que en las públicas, y cuanto mayor es el tiempo que llevan trabajando en la empresa, el nivel de culturalidad de los equipos de trabajo es mayor; sin embargo, no hemos encontrado una relación directa entre el tiempo que el equipo llevan trabajando juntos y el nivel de culturalidad.

Los resultados obtenidos en nuestra investigación apoyan las conclusiones que se plasman en los trabajos de Jabes y Zussman (1989) y Rao (2005) en referencia al compromiso que realizan los sujetos según trabajan en empresa pública o privada. Los resultados de su estudio comparativo muestran que los empleados de las organizaciones privadas identifican mejor la misión de la organización y conocen mejor las metas porque están definidas más claramente y son más realistas que los empleados de organizaciones públicas. También se muestra que estos empleados son más leales y están más vinculados con sus organizaciones. A los empleados de las organizaciones públicas parece ser que nos les importa el desarrollo de su empresa y mantienen un bajo nivel de implicación, de lealtad y de compromiso con ella. Jabes y Zussman (1989) proponen que los miembros de las organizaciones del sector privado están más 
satisfechos en general con los aspectos de la cultura que consideran que inciden en su trabajo y su desarrollo profesional.

Revisando los datos obtenidos en nuestro estudio con la empresa pública en referencia a la relación entre el compromiso organizacional y el tiempo que llevan trabajando en el equipo y en la empresa comprobamos que sólo existe una correlación negativa entre el tiempo que llevan trabajando en el equipo y el compromiso con los valores, es decir, que a mayor tiempo en el equipo, menor es el compromiso con los valores. Parece existir un desgaste en los trabajadores por causas que para nosotros resultan desconocidas pero que provoca un menor compromiso con la organización.

Retomando la reflexión de Jabes y Zussman (1989) sobre la empresa pública, sólo quedaría la implicación con el equipo de trabajo, implicación que parece ser que sufre un gran desgaste con el tiempo, siendo un reflejo de la baja implicación que mantienen con la empresa.

En referencia a la empresa privada comprobamos que la única correlación existente entre el tiempo que llevan trabajando en la empresa y el compromiso con los valores es que a mayor tiempo trabajando en la empresa, menor es el compromiso organizacional que establecen los trabajadores. Parece ser que en estos resultados se puede estar reflejando los desfases que surgen con el paso del tiempo una vez que estás integrado en la empresa, conoces y participas de su cultura. Al surgir los desfases se verá afectado el compromiso con los valores de la empresa que realizan los empleados.

Con respecto a los equipos que son culturales, comprobamos que el nivel de culturalidad de los equipos de trabajo está relacionado con el tiempo que llevan 
trabajando en la empresa, el tiempo que llevan trabajando en el equipo en el que estaban en el momento de contestar al cuestionario.

Un dato curioso y a tener en cuenta en futuros análisis son los resultados obtenidos en los missing o casos perdidos ya que existe correlación inversa entre el tiempo que lleva trabajando en el equipo del que forman parte y el compromiso con los valores, y también entre el tiempo que lleva trabajando en la empresa y el compromiso con los valores. Esto quiere decir que grupos jóvenes, que hace poco tiempo que trabajan juntos o que hace poco tiempo que trabajan en la empresa, establecen un alto compromiso con los valores de la empresa. Los sujetos que llevan más tiempo trabajando en la empresa y hace más tiempo que forman parte de ese equipo realizan un bajo compromiso con los valores de la empresa.

Estos serían los equipos que impiden el desarrollo y evolución de la empresa, así como los que siembran una insatisfacción con la organización siendo bueno para el desarrollo organizacional identificarlos para poder eliminarlos.

Como conclusión con los distintos análisis realizados hemos comprobado que el índice de culturalidad, los desfases culturales y la potencia cultural tienen un poder predictivo en el compromiso que realizan los equipos de trabajo con la organización. Este compromiso se ve favorecido por un alta culturalidad y alta potencia cultural en los equipos y con un bajo desfase cultural entre la cultura que tienen y la cultura que desean. Por ello concluimos que las tres variables tienen una influencia significativa pero difieren en la forma y en el grado de influencia. 


\subsection{APORTACIONES Y LIMITACIONES.}

Una de las más importantes aportaciones de este trabajo es el intento de estudiar un campo casi inexistente, la relación entre cultura y compromiso organizacional. Como hemos comentado anteriormente, los estudios realizados sobre la cultura y el compromiso organizacional son amplios cuando estos fenómenos se han estudiado separadamente, pero son pocos los trabajos empíricos existentes que hayan estudiado la asociación o relación entre ambos conceptos; sin embargo, pese a la dificultad de encontrar fundamentación teórica y abordar su estudio de manera empírica, éste es el camino que nosotros consideramos necesario a seguir en un futuro para su mejor desarrollo.

El impacto sobre la gestión organizacional de la cultura y el compromiso organizacional queda patente en los múltiples estudios realizados sobre estos dos constructos complejos desde distintas vertientes. Este impacto también ha llevado ha observar y estudiar estos dos constructos en el ámbito práctico de la empresa.

En esta tesis se ha tratado de reflejar los enfoques teóricos de los autores que han destacado en el análisis de cultura y compromiso organizacional tanto a nivel individual como en estudios que tratan de integrar ambos constructos. Con el presente trabajo también se ha pretendido afianzar resultados obtenidos en otras investigaciones así como realizar algunos avances que mejoren la compresión de la relación existente entre cultura organizacional y compromiso con el trabajo. 
Hemos trabajado en una dirección tan novedosa como son:

Los índices de acuerdo intragrupo (James, 1984) para obtener el consenso de los miembros del equipo de trabajo en referencia al concepto que tienen sobre cultura organizacional.

La potencia cultural del equipo de trabajo, una variable que se ha analizado por parecernos relevante en este estudio, su importancia se debe a dos factores, primero a la escasez de estudios existiendo sólo algunas referencias en trabajos internacionales y por la comprobación empírica que hemos obtenido de su influencia en la relación que se establece entre la cultura y el compromiso organizacional.

En esta investigación se ha trabajado con un concepto muy poco desarrollado, los desfases culturales, y se ha comprobado cómo la existencia o no de desfases entre la cultura que la empresa ofrece y cultura que desea el grupo va influir en el compromiso que establece el trabajador con la empresa. Por lo tanto, si ajustamos los desfases existentes, podríamos conseguir un mayor compromiso.

Esta tesis doctoral supone una contribución al campo de desarrollo organizacional en el ámbito del estudio y cambio de la cultura organizacional para un desarrollo mayor de la empresa. Una vez conocida la relación que se establece entre cultura y compromiso hemos identificado algunas de las variables que influyen en la constitución de una relación fuerte o débil entre ellas y que contribuirán al desarrollo y éxito de la empresa.

Una contribución importante por la característica de la recogida de la muestra de estudio es la realización del estudio empírico en todo el contexto español, con empresas pertenecientes a distintos sectores y tanto públicas como privadas. 
6.4.1. Limitaciones de esta investigación.

- Amenazas a la validez de nuestros resultados provienen de que la mayoría de las medidas se han obtenido son por autoinforme, lo cual puede dar origen a que las relaciones observadas se hallen mediadas por la tendencia de las personas a responder de forma no consistente.

- Reticencia de participantes a cumplimentar algunas variables como población, nivel de estudios, sector de la empresa, debido a lo cual no se ha tenido la posibilidad de realizar análisis que hubieran aportado riqueza al estudio.

- También apuntamos como limitación los pocos estudios realizados con el Cuestionario de Conductas Normativas CNO 2 con el que hemos trabajado, hecho que nos lleva a tener la necesidad de validación de los resultados con otras investigaciones futuras $\mathrm{y}$ con estudios transculturales que tenemos previstos.

\subsection{LINEAS DE INVESTIGACIÓN FUTURA.}

La investigación que presentamos puede ser considerada como punto de partida para el estudio y el trato empírico, con las limitaciones anteriormente señaladas, de un tema escasamente estudiado como ha quedado demostrado en la revisión bibliografía revisada. Es necesario una mayor profundización teórica buscando vías de conexión entre los marcos teóricos surgidos en torno a los estudios de cultura y compromiso organizacional. 
Para estudiar sus relaciones se ha integrado en un modelo coherente para estudiar sus relaciones variables señaladas como esenciales en otros estudios sobre compromiso organizacional, aunque quedan por resolver interrogantes como los bajos índices de regresión obtenidos.

El estudio de la cultura organizacional se ha realizado desde el nivel grupal, por considerar que es la verdadera medida en la cultura. Partiendo de este punto proponemos estudios posteriores en la misma línea y estudios transculturales para validar el cuestionario de Conductas Normativas para enriquecer los resultados encontrados.

\subsection{IMPLICACIONES PRÁCTICAS.}

La justificación del presente estudio se sustenta en que, a diferencia de otros comportamientos que ocurren en el entorno laboral, la rotación voluntaria del personal se manifiesta como una ruptura definitiva de la relación laboral entre individuos y organizaciones. Por dicha razón, es fundamental señalar que la separación repercute en costos de reclutamientos, de selección y capacitación, así como una baja moral de los empleados que permanecen Estos costos son aún más serios cuando la organización pierde empleados valiosos, aunque sí hay que señalar que la rotación de personal no siempre es indeseable pero en ciertas organizaciones puede llegar a ser disfuncional.

La presente investigación plantea determinar las variables que anteceden a la rotación del personal porque conociendo estas variables conoceríamos las causas que han producido la ruptura del contrato apareciendo el desfase cultural y una falta de compromiso organizacional del empleado con la organización. Estos resultados nos mostrarían dónde poder actuar para crear o restablecer el equilibrio entre la 
organización y los empleados y producir un desarrollo organizacional positivo. El compromiso se ha convertido en una variable fundamental en la eficiencia y productividad empresarial. La clave para conseguir un compromiso organizativo y sentar las bases de un servicio es la implicación de los trabajadores. Dicha implicación se refleja en la aceptación y creencia de las metas y valores organizacionales. Solamente las organizaciones integradas por las personas comprometidas con sus objetivos y que compartan propósitos pueden desarrollarse hacia estructuras más adaptadas y evolucionadas.

Esta investigación abre una puerta a futuras investigaciones y deja entrever la gran repercusión que tiene el compromiso de los trabajadores en el desarrollo organizacional. Será motor para impulsar más trabajos que puedan ofrecer a las organizaciones claves que garanticen la estabilidad del trabajador y que repercutan en un incremento del desarrollo organizacional. Los resultados apoyan nuestra hipótesis de que en los equipos de trabajo con máxima culturalidad, alta intensidad cultural (consistencia media interna con mínima variabilidad) y mínimos desfases culturales es mayor el compromiso con la organización. 


\section{REFERENCIAS BIBLIOGRÁFICAS}

Alonso, E. (1994). La cultura organizacional de los centros asistenciales. Universidad Nacional Educación Distancia. Madrid.

Alonso, E. (1996). Formación e intervención en las organizaciones. Universidad Nacional Educación Distancia. Madrid.

Alonso, E. (1997). Aplicación el método de calibrado en la evaluación y análisis de la cultura de una muestra de 22 grupos de trabajo. Presentado en el VI Congreso Nacional de Psicología Social. San Sebastián.

Alonso, E. (1999).El método del calibrado en la evaluación de la cultura. Trabajo presentado en 8th European Congreso on Work and Organizacional Psychology, Verona, Italia.

Alonso, E., Oscá. A. y Palací D. F.(1993). Una tipología de la cultura organizacional en los centros de salud de la Comunidad de Madrid. Psicología del Trabajo y de las Organizaciones. Universidad Nacional Educación Distancia. Madrid.

Alonso E., Oscá. A. y Palací D. F.(1994). La cultura organizacional de los equipos de atención primaria y los centros de atención a drogodependientes. Universidad Nacional Educación Distancia. Madrid.

Alonso, E., Oscá. A. y Palací D. F. (1994). El patrón ideal de la cultura organizacional. Universidad Nacional Educación Distancia. Madrid.

Alonso, E. y Sánchez, J. (1997). La evaluación de la cultura: el cuestionario de conductas normativas organizacionales. Presentado en el VI Congreso Nacional Psicología Social. San Sebastián. 
Alonso, E., y Sánchez, J.C. (1998). El método de calibrado en la evaluación de la cultura. Trabajo presentado al IV Congreso Nacional de Psicología del Trabajo y de las Organizaciones. Valladolid.

Alonso, E. Sánchez, J.C. y Palací, F.J. (2000). Evidencia de la validez de constructo de la versión revisada del C.N.O (Cuestionario de Conductas Normativas de la Organización). Trabajo presentado al VII Congreso Nacional de Psicología Social, Oviedo.

Alonso, E. Sánchez, J.C., y Tejero, B. (2004). La potencia cultural de los equipos de trabajo y sus relaciones con el compromise organizacional. Trabajo presentado al IX Congreso Nacional de Psicología Social, A Coruña.

Alvesson, M. y Berg, P.O.(1992). Corporate culture and organizational symbolism. Walter de Gruyter \& Co. Studies in Organization.

Allaire, Y. y Firsirotu, M.E. (1984). Theories of organizational cultures. Organization Studies 5/3.

Allen, N.J.(1991). Three components model of organizational commitment. Journal of Applied Psychology, 79, 15-23.

Allen, N.J. y Meyer, J.P. (1990). The measurement and antecedents of affective, continuance and normative commitment on the organization. Journal of Occupational Psychology, 63 (1), 1-18.

Allen, N.J., Meyer, J.P.y Smith, C.A. (1993). Organizational commitment: Evidence of career stage effects?. Journal of Business Research, 26, 49-61.

Allen, N.J. y Meyer, J.P. (1996). Affective, continuance, and normative commitment to the organization: An examination of construct validity. Journal of Vocational Behavior, 49, 252-276. 
Andrade, H. (1991).El proceso de cambio cultural en la organización. Management Today en Español.

Angle, H.L. y Perry, J.L. (1981). An empirical assesment of organizational commitment and organzational effectives. Administrative Science Quaterty, 26,1-4.

Argyris, C.(1970). Intervention theory and method. Reading Ma. Addison-Wesley.

Argyris, C.(1976). Increasing leadership effectiveness. New York: Wiley.

Argyris, C. y Schon, D.A. (1978). Organizational learning: A theory of action Perspective, Addison- Wesley, Reading.

Ashforht, B. y Mael, F. (1989). Social identity theory and the organization. Academy of management Review, 14, 20-39.

Ashkanasy, N.H. y Jackoson, C.R.A (2001). Organizational culture and climat. En N. Anderson, D. S. Ones, H.K. Sinangil y C. Viswewvaran (eds), Handbook of industrial, Work \&Organizational Psychology. Volume 2: Organizational Psychology (pp.398-415). Thousand Oaks, CA: Sage.

Aven, F.F.,Jr. (1988). A methodological examination of the attitudinal and behavioural components of organizational commitment. Unpublished doctoral dissertation. University Colorado. Boulder.

Avolio, B.J. y Bass, B.M. (1988). Carisma and beyond: Research findings on transformational and transactional leadership. Emerging Leadership Vistas. Boston: MA, Lexington.

Ayestarán, S. (1999). Formación de equipos de trabajo, conductas de manejo de conflicto y cambio cultural en las organizaciones. Rev. De Psicología General y Aplicada, 52(2-3), 203-217. 
Baker, E.L. (1980). Managing organizational culture. Management review, 69.

Barney, J.B. (1991). Firm Resources and Sustained Competitive Advantage, Journal of Management, 17, pag.99-120.

Barley, S.R. (1983). Semitics and the study of ocupational and organizational cultures. Administrative Science Quaterty,36, 350-372.

Barley, S.; Meyer, G.W. y Gash, D.(1988). Culture of culture: Academics, practitioners, and the pragmatics of normative control. Administrative Science Quarterly, 33 (1).

Bass, B, M. y Stodgill. (1990). Handbook of Leadership. New York, The Free Press,

Bass, B. M. (1985). Leadership and perfomance beyond expectations. New York, The Free Press.

Bass, B. M. y Avolio, B.J. (1990). Transformational Leadership Development: Manual for the Multifactor Leadership Questionnaire Palo Alto, Consulting Psychologists Press.

Becker, H.S.(1960). Notes on the concepts of commitment. American Journal of Psychology, 66, 32-62.

Bentler, P.M., y Dudgeon, P. (1996). Covariance structure analysis: Statistical practice, theory, and directions. Annual Review of Psychology, 47, 541-570.

Bernard, L.(1995). Examining the organizational culture and organizational performance link. MCB University Press Limited.

Beres, M.E. y Postwood, J.D. (1981). Sociocultural influences on Organizations. An Análisis of Recent Research. En England, G.W., Negandhy, A.R. y Wilpert, B. (eds). The functioning of complex Organizations (pp.337-350). Cambridge: Verlag Anton Hein. 
Blau, G.J. (1985). A multiple study investigation of the dimensionality of job involvement. Journal of Vocational Behavior, 27, 9-36.

Bonavia, T. y Quintanilla, I. (1996). La cultura en las organizaciones y sus efectos sobre la participación de los empleados. Psicología del Trabajo. Universidad de Valencia.

Brewer, M. (1979). In-Group bias in the minimal intergroup situation. A cognitivemotivational analysis. Psychologyal Bulletin, 86,393-400.

Brooke, P., Russell, D., y Price, J. (1988). Discriminant validation of measures of Job Satisfaction, job Involvement and Organizational commitment. Journal of Applied Psychology, 73,n², pg 139-145.

Brown, A. (1995). Organizational Culture, Pitman, London.

Brown, M., y Cudeck,R. (1989). Single sample cross-validation indices for covariance structures. Multivariate Behavioral Reserch, 24, 445-455.

Brown, M., y Cudeck, R. (1993). Alternative ways of assessing model fit. In K. A. Bollen \& J.Long (Eds.), Testing structural equation models (pp. 136-162). Newbury Park, CA: Sage.

Buchanan, B. (1974). Building organization commitment: The socialization of managers in workers organizations. Administrative Science Quarterly, 19, pg 533-546.

Burke, W. (1989). Organization development. A process of learning an changing. Addison-Wesley Publishing Company

Burke, W.(1988). Desarrollo organizacional: punto de vista normativo. México: Addison-Wesley Iberoamericana.

Burns, J.M. (1978). Leadership. New York: Harper and Row. 
Bryk, A. y Raudenbush, S. (2002). HLM: Hierarchical Linear and nonlinear modeling. London: Sage.

Byrne, B. (1989). A primer of LISREL: Basic applications and programming for confirmatory factor analytic models. New York: Springer.

Byrne, B. (2001). Structural equation modelling with Amos. Londres. Erlbaum Asociados.

Cameron, K. S. y Freeman, S. J. (1991).Cultural congruence, strength, and type: Relation ships to effectiveness. Management Science, 32, 539-553.

Carlopio, J. y Gardner, D. (1995) Perceptions of work and workplace: Mediators of the relationship between job level and employee reactions. Journal of Occupational and Organizational Psychology, 68, 321-326.

Chatman, J. (1991). Matching people and organizations: Selection and socialization in public accounting firms. Administrative Science Quarterly, 36.

Cialdini, R., Kallgren, C. y Reno, R.(1991). A focus theory of normative conduct: A theoretical refinement and revaluation of the role of norms in human behavior. in Experimental Social Psychologya, 24,201-234.

Cohen, A. (1996). On the discriminant validity of the Meyer and Allen measure of organizational commitment: How does it fit with the work commitment construct?, Educational and Psychological Measurement, 56,494-503.

Cohen. A y Lowenberg, G. (1990). A re-axamination of the side- bet Theory as Applied to organizational commitment. Human Relations, pp 1015-1050.

Cook, K.S. y Emerson, R.M. (1978). Power, equity and commitment in ex-change networks. American Sociological Review, 43 (5), 721-739. 
Cooke, R. y Rousseau, D.(1988). Behavioral norms and expectations: A quantitative approach to the assessment of organizational culture. Group and Organization Studies. 13, September.

Cooke, R. y Lalferty, J. (1989).Organizational culture inventory. Human Synergistic Plymouth, Michigan.

Deal, R.E. y Kennedy, A.A. (1982). Corporate culture, Addison Wesley, Reading, Massachusetts.

De Frutos, B., Ruiz, M. y San Martín, R. (1998). Análisis factorial confirmatorio de las dimensiones del compromiso con la organización. Psicológica,19, 345-366.

Del Cerro, A. (1991). El psicólogo y la organización. Barcelona: PPU.

Denison, D. R. (1984). Bringing corporate culture to the bottom line. Organizational Dynamics 13(2), 5-22.

Denison, D, R. (1996). What is the difference between organizational culture and organizational climate? A native's point of view on a decade of paradigm wars. Academy of Management Review, 21( 3),619-654.

De White, K. y Van Mujien, J. J.(1999). Organizational Culture: Critical questions for researchers and practitioners. European Journal of Work and Organizational Psychology, 8, 583-595.

Dunlap, W.P., Burke, M. Y Smith- Crowe, K. (2003). Accurate test of statistical significance for $r_{\mathrm{wg}}$ and average deviation interrater agreement indexes. Organizational Research Methods, 5, 159-172.

Dyer, W. G. (1984)._The Cycle of cultural evolution in Organizations. Unpublished Paper, en Kilmann R.H et al (eds). Gaining Control of the Corporate Culture. San Francisco, Ca., Jossey, Bass Inc.,pp200-229. 
Eisemberger, E. M., y Riley, P.(1988).Organizational symbols and sensemaking. In G.M Goldhaber y G.A. Barnett (Eds.). Handbook of organizational communication. Norwood, N.J. Ablex.

Erez, M., y Grati, E. (2004). A dynamic, Multi-Level Model of Culture: From the Micro Level of the Individual to the Macro Level of a Global Culture. Applied Psychology: An International Review, 53(4). 583-598.

Falces, C., Briñol, P., Sierra, B., Becerra, A., y Alier. E. (2001). Validación de la escala de necesidad de cognición y su aplicación al estudio del cambio de actitudes. Psicothema, 13(4), 622-628.

Festinger, L. (1957). A theory of cognitive dissonance. Evanston III., Row Peterson.

Fernández, N. (1999). Dirección de equipos de trabajo en las organizaciones. Ed. Civitas.

Fernández-Ríos, M. y Sánchez, J. C. (1998). Valoración de puestos de trabajo; Ed.Díaz de Santos.

Ferrer, C. (2005). Validez predictiva de los componentes del compromiso del cliente y su relación con la satisfacción. Anuales de psicología, 21, $n^{\circ}$ 2(diciembre), 316-322.

Franklin, J.L. (1975). Power and commitment-empirical assessment. Human Relations, 28 (8), 737-753.

Freitas, M.E. (1991). Cultura Organizacional: forma, tipología e impacto. Sao Paulo, SP. Makron, McGraw-Hill.

Frost, P. J; Moore, L. F y Louis, M. R.(1985). Organizational culture. Beverly Hills: pp, 13-29. 
Frutos, B. (1997). El constructo del compromiso con la organización como predictor del abandono: Un modelo causal. Tesis doctoral. Universidad Autónoma de Madrid.

Frutos, B. de, Ruiz, M. A. y San Martín, R. (1998). Análisis factorial confirmatorio de las dimensiones del compromiso con la organización. Psicología, 19, 345366.

García, F. (1994). Jerarquía de Valores y Cultura Organizacional. Trabajo de Grado. Valencia, Estado Carabobo.

Garcia-Cueto, E., y Gallo, M. (1998). Bondad de ajuste en el análisis factorial confirmatorio. Psicothema., 10, 3: 717-724.

Garmendia, J.A. (1988). La cultura de la empresa: una aproximación teórica práctica. R.E.I.S., 41, 724.

Garr, M.C. (1998). Organizational culture as a predictor of organizational commitment. Tesis Doctoral, UM:AAM9803774

Ghiselli, E.E. y Porter, L. (1966). Managerial Thinking: An international study. New York John Wiley.

Gibson, J. (1999). Las organizaciones; Ed. McGraw Hill Irvin.

Geertz, C. (1973). The interpretation of cultures. Basic Books. New York.

González-Romá, V., Espejo, B. y Hernández, A. (1994). Validez discriminante de dos medidas de compromiso organizacional e implicación en el trabajo. Psicológica, 15, 343-350.

González- Romá, V., Peiró, J. M., Lloret, S. y Zornoza, A. (1999). The validity of collective climates Journal of Occupational and Organizational Psychology, $72,25-40$ 
González, L. y Antón, C. (1995). Dimensiones del compromiso organizacional. En L. González, A. de la Torre y J. de Elena (Eds), Psicología del Trabajo y de las Organizaciones. Gestión de Recursos Humano y Nuevas Tecnologías. Salamanca. España. Eudemas.

Goodman, L.A. (1981), “Criteria for Determining Whether Certain Categories in a Cross-Classification Table Should be Combined, with Special Reference to Occupational Categories in an Occupational Mobility Table," American Journal of Sociology, 87, 612-50

Goodman, P.S., Ravlin,E. y Schminke, M. (1987). Understanding groups in organizations. En L.L Cummings y .M.Staw(eds.), Rearch in Organizational Behavior, 9,121-173. Greenwinch, CT:JAI Press.

Goofman, E. (1967). Interaction ritual. Hawthorne, New York: Aldine.

Golembieswski, R. (1985). Humanizing public organizations. Mount Airy. MD: Lomond.

Guest, D.(1995). Human resource management, trade unions and industrial relations. En J.Storey (Eds). Human resource management, A critical text. London. Routledge.

Griffin, F. y Bateman, T.S. (1986). International Review of Industrial and Organizational Psychology. London: J. Wiley and Sons.

Griffith, J. (2002). Multilevel Analysis of Cohesion's relation to Stress, Well- being, Identification, Disintegration and Perceived Combat Readiness. Military Psychology, 14 (3), 217-239.

Hall, D.T., Schneider,B y Nygren, H.T.(1970). Personal factos in organizational identification . Administrative Science Quaterty, 17, 555-572. 
Hannan, M.T., y Freeman, J. (1977). The population ecology of organizations. American Journal of Sociology, 82, 929-964.

Haire, M., Ghiselli, E.E. y Porter, L.W. (1966). Managerial Thinking: An international study. New York: John Wiley.

Haire, M., Ghiselli, E.E. y Porter. L.W. (1971). Actitudes de los directivos. Madrid. Marova.

Harrison, R. y Stokes, H. (1992). Diagnosing Organizational Culture. Pfeiffer \& Co. San Francisco.

Hause, OR.Jr.(2001). Relationships between organizational culture strength and organizational effectiveness in an electrical utility company. Tesis Doctoral, UM:AAI9994100

Hemmelgarn, A., Glisson, C. y James, L. (2006). Organizational Culture and Climate : Implications for Services and Interventions Research. Clinical Psychology: Science and practice. 13(1), 73-89.

Hrebiniak, L.G., y Alutto, J.A. (1972). Personal and role-related factors in the development of organizational commitment. Administrative Science Quarterly, 17, 555-573.

Hofstede, G. (1991). Culture's Consequences: Software of the Mind. McGraw-Hill.

Hofstede, G. (1990) Measuring organizational cultures: a quantitative study across 20 cases. Administrative Science Quarterly, 35, 286.

Hofstede, G., Neuijen, B., Ohayv, D.D. y Sanders, G. (1990). Measuring organizational cultures; A qualitative and quantitative study across twenty cases. Administrative Science Quarterly, 35(2), 286-316.

Holden, T. y Gross, N. (1992). Japan Just May Be Ready to Change its Ways, 
“Business week, 3249 (Janary 27), 30.

Husenman, S. (1987).Prólogo a la edición española. En Schein, E.(Eds). La cultura empresarial y liderazgo. Barcelona: Plaza y James Editores.

Insel , P.M., y Moss, R.H. (1974). Clima social. Madrid: TEA, Ediciones.

Jabes, J. y Zussman, D.(1989). La cultura de las organizaciones en las burocracias públicas. Rev Internac. De CC. Administrativas, 56, 1.

James, L.R, Demaree, R.J y Wolf, G. (1984). Estimating within group interrater reliability with and without response bias. Journal of Applied Psychology, 69, $85-98$

Katz, D. (1964). The motivation bias of organizational behavior. Behavioral Science, 9, $131-146$.

Katz, D. y Kahn, R.L.(1978). Psicología Social y de las Organizaciones. México: Trillas

Katz, D., y Kahn, R.L. (1978). The social psychology of organizations ( $2^{a}$ ed). New York: Yohn Wiley y Son.

Kanter, R.M. (1968). Commitment and social organization. A study of commitment mechanisms in utopian commumities. American Sociologial Review, 33, 499517.

Kanter, R.M. (1983).Change masters and the intricate architecture of corporate culture change, Management Review, 72.

Kanter, R.M. (1968). Commitment and social organization. A study of commitment mechanisms in utopian commumities. American Sociologial Review, 33, 499517.

Kiesler, C.A. (1971). The psychology of commitment: Experiments linking behavior to belief . NuevaYork: Academic Press. 
Kelnman, H. C. (1958). Compilance, identification, and internalization, three processes of attitude change. Journal of Conflict Resolution, 2, 51-60.

Kelloway, E.K. (1998). Using LISREL for structural equation modeling: A researcher's guide. Thousand Oaks, CA: Sage.

Kiesler, C.A. (1971). The psychology of commitment: Experiments linking behaviour to belief. New York: Academic Press.

Kilmann, R. (1986). Five Steps for Closing Culture-Gaps. Gaining Control of the Corporate Culture.

Kilmann, R.H., y Saxton, M.J. (1983). The Kilmann y Saxton culture- gap survey Organizational Desing Consultans, Pittsburgh, Pennsylvania.

Kilmann, R.H., Saxton, M.J. y Serpa, R. (1986). Issues in Understanding and Changing Culture. California Management Review, 2 Winter.

Koberg, C.S. y Chusmir, L.H. (1987). Organizational culture relation ships with creativy and other job-related variables, Journal of Bussiness Research,15, 397-409.

Kotter, J.P. y Heskett, J.L. (1992). Corporate culture and performance. New York: Free Press.

Lahiry, S. (1994). Building commitment through organizational culture. Training and Development,3.50-2.

Lammers, C.J. y Hickson, D. (1978). Organizations alike and unlike. London. Routledge y Kegar Paul.

Lawrence, P.R. y Lorsch, J.W. (1967). Differentiation and integration in complex organization. Administrative Science Quarterly, 12,1-47.

Leach, E (1968). Ritual. International Encyclopedia of the Social Sciences. 
Lewin, K. (1947). Frontiers in group dynamics. Human Relations, 1, 5-41.

Lewin, K. (1951). Field theory in the social science. New Cork: Harper.

Lewin, K. (1988). Canales de la vida del grupo: Planificación social y acción investigación, Revista de Psicología Social, 3, 201-2.

Lodahl, T. y Kejner, M. (1965). The definition and measurement of job involvement. Journal of Applied Psychology, 49, pg 24-33.

Locke, E.A.( 1969). What is job satisfaction?. Organizational behaviour and Human Performance, 4,309-336.

Locke, E.A.(1975). Personnel attitudes and motivation. Annual Review of Psychology, 26.

Locke, E. (1976). The nature and causes of job satisfaction. In M..D. Dunnette (Ed) Hanbook of Industrial and Organizational Psychology. Chicago: Ran McNally.

Lok, P. y Crawford, J. (2002). Antecedents of Organizational commitment and the mediating role job satisfaction. Journal of Managerial Psychology. 16(8), 594-613

Lok, P., Westwood, R. y Crawford, J. (2005). Perceptions of Organizational Subculture and their significance for Organizational Commitment. Applied Psychology. 54(4), 490-514.

Lorsch, J.W. y Morse, J.J. (1974). Organizations and their Members. A Contingency Approach. New York: Harper \&Row.

Lorsch, J.W. (1985). Managing Culture: The Invisible Barrier to Strategic Change. Califo: Management Review, 2.

Louis, M.R. (1981).“A cultural perspective on organizations”. Human Systems Management 2, 246-258. 
Luthans, F. y McCaul, H.S (1985). Organizational commitment: a comparison of American, Japanese, and Korean employees. Academy of Management Journal, 28, 21-219.

Mahoney, J., y Pandian, JR. (1992).The Resource-Based View within the Conversation of Strategic Management, Strategic Management Journal, 13,pag.363-380.

March, J.C. y Shapira, Z.(1989). Behavioral decision theory and Organizational decision theory. Decision marking: An interdisciplinary inquiry. Boston. Kent.

Marcone Trigo, R. y Martín del Buey, F. (2003). Construcción y validación de un inventario de cultura organizacional educativa (ICOE). Psicothema, 15 (2), 292299.

Martin, J. (2002). Organizational Culture. Mapping the Terrain. Thousand Oaks, CA: Sage.

Martin, J. (1993). Cultures in Organizations: Three Perspectives. New York: Oxford Universty Press.

Martín, J. y Saiehl, C. (1983). “Organizational Culture y Counterculture: An Uneasy Symbiosis "Organizational Dynamics12, Autumn 52-64.

Mathieu, J. E., y Zajac, D. (1990). A review and meta-analysis of the antecedents, correlates, and consequences of organizational commitment. Psychological Buletin, 108, 171-194.

Mayer, R. C. y Schoorman, F. D. (1992). Predictig participation and production outcomes through a two dimensional of organizational commitment. Academy of Management Journal, 35(3), 671-684. 
Medsker, G.J., Williens.L.J. y Holahan,P.J. (1994). A review of current practices for evaluating causal models in organizational behaviour and human resources management research. Journal of management 20,439-464.

Meyer, J. P y Allen, N. J. (1984). Testing the side-bet theory of organizational commitment: Some methodological consideration. Journal of Applied Psychology, 69, 372-378.

Meyer, J. P y Allen, N. J. (1991). A Three-Component Conceptualization of Organizational Commitment. Human Resource Management Review, 1, 6189.

Meyer, J. P. y Allen, N. J. (1997). Commitment in the workplace. London: Sage.

Meyer, J. P.; Allen, N. J., y Smith C. A. (1993). Commitment to Organizations and Occupations: Extension and test of a three-component conceptualization. Journal of Applied Psychology, 78, 538-551.

Mobley, W.H. (1982). Employee Turnover: Causes, Consequences and Control. Reading, Mass.: Addison-Wesley.

Mobley, W.H., Griffith, R., Hand, H. y Meglino, B. (1979). “A review and conceptual analysis of the employee turnover process". Psychological Bulletin, 62, 493-522.

Moos, R.H., Moos,B.S., y Trickett, E.J.(1987). Escalas de clima social: familia, trabajo, instituciones penitenciarias, centro escolar. Madrid: TEA

Morgan, G. (1986). Images of Organization. Jossey-Bass. Beverly Hills, CA.

Morgan, G. y Hunt, S.D.(1994).The commitment trust theory of relationship marketing. Journal of marketing, 58(3), 20-38.

Mottaz, J.(1988)."Determinants of Organizational Commitment," Human Relations, 4,467-482.Morris, J. H. y Sherman, J.D.(1981). Generalizability of an 
organizational commitment model. Academy of Management Journal, 24,512526.

Morrow, P., (1983). Concept redundancy in organizational research: The case of work commitment. Academy of Management Review, 8, 486-500.

Mowday, RT, Porter, LW, \& Steers, RM (1979). The measurement. of organizational commitment. Journal of Vocational Behavior,. 14, 224-247.

Munduate, L. (1997). Psicología Social de la Organización. Las personas organizando. Madrid: Pirámide.

Odom, R.y. Box, W.R. y Dunn (1990). Organizational cultures, commitment, satisfaction, and cohesion. Public in Organizational Behavior,14, 224-247.

Oliver, C. (1990). Determinants of Interorganizational Relationships: Integration and future directions. Academy of Management Review, 15, 214-265.

O'Relly, C.A., Chatman, J. y Caldwell, D.F. (1991). People and organizational culture: A profile comparison approach to assessing person- organization fit. Academy of Management Journal, 34, 487-516.

O’Really, C., y Chatman, J. (1986). Organizational commitment and pshycological attachment: The effects of compliance, identification, and internalization on prosocial behavior. Journal of Applied Psychology, 71, 492-499.

O’Relly, C.A. y Caldwell, D.F (1986). Organizational commitment and psychological attachment: the effects of compliance, identification and internalization on prosocial behavior. Journal of Applied Psychology,71.

Ouchi, W. G. y Wilkin, A. I. (1983).Efficient cultures: exploring the relationship between culture and organizational performance, Administrative Science Quarterly, 28. 
Ouchi, W. G. y Wilkin, A. I. (1985).Organizational Culture. Annual Review of School, $11,457-483$.

Peiro, J. Ma (1985).Evaluación psicológica de las Organizaciones. Evaluación psicológica. Psychological Assement 1,184-239.

Peiro, J. Ma . (1990). Organizaciones: nuevas perspectivas psicológicas. Barcelona. Biblioteca Universitaria de Ciencias Sociales. Serie Menor.

Peiro, J. Mª (1999). Psicología de la Organización. Madrid: UNED.

Peiro, J. Ma. (1999).Organizaciones: Nuevas perspectivas psicosociológicas. Barcelona: PPU.

Peiro, J. Ma. y Prieto, F. (1996). Tratado de Psicología de Trabajo. 2, 65-100. Madrid. Síntesis.

Penley, L. E. y Gould, S. (1988). Etzioni's model of organizational involvement: A perspective for understanding commitment to organizations. Journal of Organizational Behavior, 9, 43-59.

Peter, T. J. (1993). Reinventando la excelencia. El management liberador, Ediciones B, Barcelona.

Peter, T. J, Waterman, Jr. R. H. (1982). En busca de la excelencia. Barcelona. Plaza y Janés.

Peteraf, M. A. (1993). The Conerstones of compeititve Advantage: a resource - based view, Strategic Management Journal,14, 179-192.

Pettigrew, A.M. (1979). On studying organizational cultures. Administrative Science Quarterly, 24, 570-581.

Pheysey, D.C. (1993). Organizational cultures. Types and transformations. Londres: Routledge.

Pierce, J. L., \& Dunham, R. B.(1987). Organizational commitment: Preemployment propensity and initial work experiences. Journal of Management, 13,163-178. 
Pondy, L.R. (1977). Effectiveness: A thick description, en P.S. Goodman y J.M. Pennings(eds.),New Perspectives on Organizational Effectiveness (pp.227234).San Francisco, CA:Jossey-Bass.

Pondy, L.R. (1978). Leadership is a language game. En McCall , M y Lombardo, M. (Eds). Leadership: Where Else can we go?. Durham, NC Duke Univ. Press.

Porter, L,W.y Steers, R. M.,(1982). Organizational Linkage: The psychology of commitment, Absenfeeism and Turnover, Academic Press, New York.

Porter, L.W., Lawler, E.E. y Hackman, J.R. (1975). Behavior in Organizations. New York: Prentice-Hall.

Porter, L, W., Steers, R. M., Mowday, R. T. y Boulian, P. V.(1974).Organizational commitment, job satisfaction, and turnover among psychiatric technicians. Journal of Applied Psychology, 59, 603-609.

Price,L., y Muller,C.W.(1981). A causal model of turnover for nurses. Academy of Management Journal, 24: 543-565

Pulliam, H.R. y Dunford,C. (1980). Programmed to learn: An Essay, on the evolution of Culture. New York. Columbia University Press.

Quijano, S. (1984). Análisis Psicosocial del modelo japonés de relaciones laborales. Revista de psiquiatría y psicológica humanista. Tema monográfico: Psicología Humanista y Empresa. 6. Marzo1984, 3-22.

Quijano, S. (1993). La psicología en las Organizaciones. Fundamentos. PPU. Barcelona.

Quinn, R.E. y Spreitzer, G.M.(1991). The psycometrics of the Competing Values Culture Instrument and an analysis of the impact of organizational culture on quality of life(pp.115-142). En R.W. Woodman y W.A. Pasmore (eds.), 
Research in organizational change and development. Vol.5, Greenwich, CT: JAIPress.

Randall, D.M. (1987). Commitment and the organization: the organization man revisited. Academy of Management Review, 12, 460-471.

Randall, M. L., y O’Driscoll, M.P (1997). Affective versus calculative commitment: Human resource implications. Journal of Social Psychology, 137, 606-617.

Rao,T. (2005). Employee Empowerment: Differential Influences of Organizational Culture Across the Public and Private Sector Organizations. Social Science International. 21(2), 3-14.

Reichers, A. E. (1985). A review and reconceptualization of organizational commitment. Academy of Management Journal, 10, 465-476.

Reichers, A.E. y Schneider, B. (1990). Climate And Culture: An evolution of constructs. En B. Schneider (ed), Organizational Climate and Culture (pp. 539). San Francisco: Jossey-Bass.

Reynierse, J.H., y Harker, J.B. (1986). Measuring and managing organizational culture, Human Resource Planning, 9(1), 1-8.

Rial, A., Varela, J., y Rojas, A.J. (2001). Depuración y análisis preliminares de datos en SPSS. Madrid: Ra-ma.

Rial, A., Varela, J., Braña, T., y Lévy, J.P. (2000). El valor de la marca a partir de la relación con el consumidor. Psicothema, 12(2), 247-254.

Ritzer, G. y Trice, H.M. (1969). An empirical study of Howard Becker's side-bet theory. Social Forces, 47, 475-479.

Robbins,S. (1987). Comportamiento organizacional. Conceptos, controversias y aplicaciones, $3^{\text {a }}$ edición, Ed Prentice- Hall Hispanoamericana S.A. México.

Robbins, S. (1994). Comportamiento organizacional. Prentice Hall Hispanoamericana, México. 
Robbins,S. (1996).Fundamentos del comportamiento organizacional. Mexico.PrenticeHall.

Robbins,S. (1998). Comportamiento organizacional. Conceptos, controversias, aplicaciones ( $6^{\circ}$ ed). México: Prentice-Hall.

Robbins,S., Water-Mash,T.(1981).Organizational concepts, controversials and applications: Australia and New Zealnd, Prentice-Hall, Sydney.

Robinson, P.J. (1998). The influence of value congruence upon the effectiveness of work teams. Tesis Docroral. UM:AAM9803008

Rodriguez, A. (1993). La cultura de las organizaciones públicas y privadas. Psicothema, 5, 237-260.

Rodríguez, M.S., Arce, C., Seoane, G., y Sabucedo, J.M. (1996). Cuestionario para evaluación de edificios. Psicothema, 8, 247-254.

Rousseau, D.(1990). Quantitative assessment of organizational culture: The case for multiple measures. Organizational climate and culture (pp153-192). San Francisco,: Jossey-Bass.

Rusbult, C. y Farell, D.(1983). A longitudinal test of the investment model: The impact on job satisfaction, job commitment, and turnover of variations in rewards, costs, alternatives, and investments, Journal of Applied Psychology, 68, pg $429-438$

Sackmann, S.A. (1991). Cultural Knowledge in Organizations: Exploring the collective mind. Newbury Park, CA: Sage. Publications.

Sackmann, S.A., Phillips, M.E., Kleinberg, M.J. y Boyacigiller, N.A. (1997). Single and Multiple Cultures in international Cross- Cultural Management Research: Overview. En S.a. Sackman(ed) Cultural complexity in organizations (pp. 1448). T housand Oaks, CA: Sage. Publications. 
Saffold, G.S. (1988).Culture traits, strength and organizational perfomance: moving beyond strong culture. Academy of Management Review, 3( 4 ),546-558.

Salancik, G.R. (1978). A social information processing approach to job attitudes ad task design. Administrative Science Quarterly, 23, 224-252.

Salvador, C.M. (2005). Validez predictiva de los componentes de compromiso del cliente y su relación con la satisfacción. Anales de psicología, 21,( 2),316322.

Sánchez, J. C y Alonso, E. (1998). Análisis de las escalas del cuestionario de Conductas Normativas Organizacionales (CNO-2). Trabajo presentado al IV Congreso de Psicología del Trabajo y de las Organizaciones, Valladolid.

Sánchez, J.C., Alonso, E. y Palací, P. (1999).El concepto de Cultura Organizacional, sus fundamentos teóricos e investigación en España. Revista de Psicología General y Aplicada, 52 (2-3), 287-299.

Shannawaz,M.G. y Hazarika,N.(2007). Organizacional commitment and organizacional cultura: A study of two hospitals in Asma. Journal of the Indian Academy of Applief Psychology. 30(1-2.), 124-130.

Schechter, D.S. (1985). Value and continuance commitment: A field test of a dual conceptualization of organizational commitment: Unpublished master's thesis. University of Maryland, College Park.

Schein, E. (1985). Organizational culture and leadership. San Francisco: Jossey-Bass.

Schein, E. (1988). La cultura empresarial y el liderazgo. Barcelona. Plaza Janés (original 1985).

Schein, E. (1990). Organizational Culture. American Psychologist.45(2),112-115.

Scheneider, B. (1990). Organizational climate and culture. San Francisco: Jossey-Bass. 
Scholz, C. (1987). «Corporate culture and strategy -the problem of strategic fit». Long Range Planning. 20 ( 4), 78-87.

Schraeder, M., Tears, R. y Jordan, M.(2007). Organizacional cultura in public sector organizations: Promoting change through training and leading by example. Leadership and Organization Development Journal. 26(6), 492-502.

Schultz,M. (1994). On Studying Organizational Culture Diagnosis and Understanding. Walter de Gruyter. Berlin.

Seren,S. y Baykal,U. (2007). Relationships between change and organizacional cultura in hospitals. Journal of Nursing Scholarship. 39(2),191-197

Silva, M. (1992). El clima en las Organizaciones. Teoría, método e intervención. Barcelona: EUB.

Smircich, L. (1983). Concepts of culture and organizational analysis. Administrative Science Quartely, 28, 339-358.

Smircich,L. (1985). Is the concept of culture a paradigm for understanding organizations and ourselves. En Frost, P.J, Moore,L.F., Louis,M.R., Lundberg,C.C. y Martin,J.(eds.), Organizational culture: the meaning of life in the workplace,.Sage Publications.

Smith,C.A.(1995) Human resource practices and polices as antecedents of organizational commitment. Unpublished. 
Smith, J.M. (2005). The relationship between critical dimensions of organizational culture and employee commitment. Tesis doctoral, UM:AAI3144875

Smith, P.B.(1997). New forms of work organizations. Annual Review of Sociology, 23, $315-339$.

Smith,P.B. y Paterson, M. (1988). Leadership in context: A cultural analysis of organizational behaviour. London: Sage, London.

Steers,R.M. (1977). Organizational E ffectiveness: A behavioural view. Pacif Palisades, CA: Goodyear.

Stevens, J.M. y Beyer, J.M.(1978). Assessing personal, role, and organizational predictors of managerial commitment. Academy of Management Journal, 21, 380-396.

Strealau, J., Anglitner, A., Batelmann, J., y Ruch, W. (1990). The Strealau temperament inventory-revised (STI-R): Theoretical considerations and scale development. European Journal of Personality, 4,209-235.

Svyantek, D. y Bott, J. (2004). Organizatinal cultura and organizacional climate measures: An integrative review. Comprehensive handbook of psychological assessment, 4. En Industrial and organizacional assessment. 507-524. Hoboken, NJ., John Wiley \& Sons Inc, 545pp.

Topa Cantisano, G., Lisbona, A, Palací, F. y Morales, F. (2003). Percepción de ruptura de contrato psicológico y burnout en funcionarios de instituciones penitenciarias españolas: mediación de variables personales $\mathrm{y}$ organizacionales. $8^{\circ}$ Congreso Nacional de Psicología Social. Torremolinos. España.

Topa Cantisano, G., Alonso, E. y Palaci, F. (2002). TASQ. Una medida de socialización. Aplicación en un estudio longitudinal con soldados 
profesionales españoles. Metodología de las Ciencias del Comportamiento, volumen especial, 544-549.

Trice, H. y Bayer, J.M. (1993). The cultures of Work Organizations. Englarwood Cliffs, N.J: Prentice Hall.

Van de Berg, T. y Wilderom, C.P.M.(2004). Defining, Measuring, and Comparing Organizational Cultures. Applied Psychology: an International Review, 53(4),570-582.

Van Maanen, J. y Barley, S.R. (1985). Cultural Organization. Fragments of a Theory en Frost, P.J. et.al (eds). Organizational Culture, Beoverly Hills, Ca, pp. 31-53. Van Maanen, J.(1988). Tales of the field. Chicago : University of Chicago. Press.

Van Muijen, J. (1998). Organizational culture. En P.J.D. Drenth, H. Thierry y C.J. de Wolff (eds)., Handbook of Work and Organizational Psychology, $2^{\circ}$ eg., vil4 Organizational Psychology (pp.113-131Ç). Hove, East Sussex: Psychology Press.

Wang, X. (2006). Relationships among organizacional learning cultura, job satisfaction, and organizacional commitment in Chinese state-owned and privately owned enterprises. Tesis Doctoral, UM:AAI3203994.

Warterman, R. H. (1994). En Busca de la Excelencia. Lecciones de las Empresas Mejor Gestionadas de los Estados Unidos. Barcelona, Folio.

Weick, K. E. (1985) The significance of corporate culture” Organizational Culture (Cap22). Sage, Berverly Hills, Ca.

Weick, K. E.(1995). Sensemaking in Organizations. Thousand Oaks, CA: Sage,

Wilkins, A. L. y Dyer,J.R. (1988). Toward Culturally Sensitive Theories of Culture Change Acad Manag. Review, vol 13,4, pp. 522-533. 
Yeung, A.K.O, y Brockban, J.W. y Ulrich, D.O.(1991). Organizational Culture and Human Resource Practices: an Empirical Assessment School of Business Administration: University of Michigan Comunicacion.

Zander, L. (2005). Dialogue on identifying Culture. International Journal of Cross Cultural Management. 4(3). 275-290 
ANEXOS

-212 - 
1. INSTRUCCIONES PARA LA COMPLETAR EL CUESTIONARIO CNO2 Y EL CUESTIONARIO DE COMPROMISO ORGANIZACIONAL

Para completar el cuestionario adecuadamente se va a desarrollar en dos partes; en la primera parte se pasará los cuestionarios a miembros de alguna organización o empresa; en la segunda parte se realizará, partiendo de unos supuestos teóricos, un análisis de los datos recogidos y un comentario sobre los resultados y su aplicación a la práctica organizacional.

\section{$1^{\text {a }}$. ETAPA}

Se pasará los cuestionarios a dos grupos de, al menos, 5 sujetos que actualmente trabajen en alguna organización (empresas, hospitales, administración, colegios, ayuntamientos, etc) y que sean miembros del mismo departamento, sección o grupo de trabajo sin que tengan que estar realizando trabajos o funciones similares. Si tiene posibilidades de recoger información de más grupos, mejor, ya que de esa forma, en la $2^{\mathrm{a}}$ etapa, podrá tener una muestra mayor para analizar los datos.

Como podrá comprobar, se le envían dos grupos de cuestionarios; el primero se compone del cuestionario de Conductas normativas organizacionales (CNO-2) y el de Compromiso con la organización;

Puede pasar los cuestionarios de forma individual o en grupo, según las circunstancias más favorables

Para la presentación de los cuestionarios a los sujetos explíqueles brevemente que se necesita su ayuda para adaptarlos a la situación española y que los datos que proporcionen serán anónimos. 
Procure comportarse de igual manera con todos ellos durante el tiempo de recogida de los datos sin proporcionarles ningún tipo de información que pueda influir en sus respuestas.

La forma de realizar la $2^{\mathrm{a}}$ ETAPA a los sujetos se les indica" Ahora póngase en la situación hipotética en que su grupo de trabajo (departamento, sección, equipo, etc.) ha logrado un ambiente de trabajo que es colectivamente beneficioso para el bienestar organizacional del grupo” para rellenar los cuesionarios 


\section{DATOS BIOGRÁFICOS.}

Conteste, por favor, a los siguientes preguntas rodeando con un círculo la respuesta apropiada allí donde proceda.

-Edad:

-Sexo: 1. Hombre 2. Mujer.

-Empresa en que trabaja: 1. Pública 2. Privada.

-Tiempo que lleva perteneciendo a este equipo o grupo de trabajo:

$$
\text { años( ), meses ( ). }
$$

-Tiempo que lleva trabajando en esta empresa o entidad:

años( ), meses ( ).

-Nivel educativo al que han llegado sus estudios:

1: Universidad.

2: Formación Profesional

3: BUP

4: Enseñanza Media.

GRACIAS POR SU COLABORACIÓN 


\section{CUESTIONARIO DE CONDUCTAS NORMATIVAS ORGANIZACIONALES}

(CNO-2):

Primera parte:

A continuación encontrará una serie de conductas que se pueden dar en las organizaciones. Piense únicamente en el grupo de trabajo al que Ud. pertenece (departamento, sección, equipo, etc) e indique en el espacio (__ ${ }_{(}$) que precede a cada una en qué medida esa conducta es característica de su lugar de trabajo según la siguiente escala:

$\begin{array}{ccccl}\mathbf{0} & \mathbf{1} & \mathbf{2} & \mathbf{3} & \mathbf{4} \\ \text { Nada } & \text { Algo } & \text { A media } & \text { Bastante } & \text { Muy } \\ \text { característico } & \text { característico } & \text { característico } & \text { característico } & \text { característico }\end{array}$

1. La gente se reúne para discutir los proyectos.

2. Se es preciso y meticuloso en el trabajo.

3. Se ponen en práctica las sugerencias que hacen los compañeros.

4. La gente rechaza criticar a espaldas de los demás.

5 . Se ve a la gente con ganas de realizar proyectos nuevos.

6. La gente es resuelta y atrevida a la hora de actuar.

7. La gente no duda en consultar sus problemas de trabajo con los jefes.

8. Se asume la responsabilidad del puesto, sintiéndose obligado a responder de las propias acciones.

9. Se intentan superar anteriores resultados.

10. Se soportan con ánimo los aplazamientos de las acciones.

11. Se evitan crear problemas que la gente considera "inútiles"

12. Se hace el trabajo de la manera que cada uno cree es la mejor.

13. Se ayuda a los compañeros del grupo a resolver sus diferencias.

14. Se realizan las tareas de "cualquier manera".

15. Se proporciona apoyo y ayuda cuando se presenta la ocasión.

16. Se trata a todos como iguales.

17. Se acogen con indiferencia las propuestas de ideas nuevas. 
18. La gente es emprendedora y enérgica en las cosas difíciles y arriesgadas.

19. Hay grandes reparos en discutir las ideas con los superiores.

20. Se es serio y riguroso en el cumplimiento de compromisos, reuniones, citas,

21. Se trata de superar a otros grupos competidores

22. Se aceptan los retrasos en las acciones sin impacientarse.

23. La gente apacigua los conflictos que son 'costosos' para todos.

24. La gente utiliza los propios criterios para solucionar sus problemas del trabajo.

25. Aquí cada uno va a lo suyo.

26. Se pone en el trabajo el debido interés.

27. Se rechazan las propuestas y sugerencias de los demás

28. Se intenta que la gente se sienta a gusto en el trabajo diario.

29. Se busca la innovación, introduciendo métodos recién aparecidas o conocidas.

30. Se trabaja hasta más allá de lo establecido

31. Se llega con facilidad a acuerdos con los jefes en la realización del trabajo.

32. Cada uno hace lo que debe.

33. Se estimula a superar el trabajo de los demás.

34. Se mantiene la tranquilidad cuando la situación es incierta.

35. La gente actúa sin preocuparse de normas ni costumbres

36. La gente actúa en el trabajo sin limitarse a los indicaciones recibidas.

37. La gente se junta para participar en actividades fuera del trabajo.

38. Se informa puntualmente de los cambios en las normas y criterios del trabajo.

39. Se comunica la información o los conocimientos para facilitar el trabajo a los demás.

40. En asuntos importantes se busca la aceptación de la gente antes llevarlos adelante.

41. Se intentan nuevas formas de hacer las cosas.

42. La gente se esfuerza el tiempo que requiera el trabajo.

43. Se dificulta que la gente proponga y discuta sus ideas con los jefes.

44. La gente se desentiende de las obligaciones de su trabajo

45. La gente no se preocupa de superar a los demás.

46. La gente es inadadaptable a las situaciones y a las circunstancias imprevistas.

47. La gente es fiel a las reglas y costumbres.

48. Cada uno en su puesto establece su propia manera de hacer las cosas

49. Se toman las decisiones que son aceptadas por la mayoría.

50. Se tratan las cosas del trabajo de forma seria.

51. Se comparte la información con los compañeros de trabajo. 
52. Se actúa con equidad en el reparto del trabajo.

53. Se experimentan y ensayan nuevas cosas, en cuanto se presenta la ocasión.

54. La gente es firme y constante en la acción

55. La gente intenta que las ideas propias las apoyen los jefes.

56. .No se esfuerza la gente en lo que hace.

57. La gente es luchadora, compitiendo con otros que aspiran a las mismas cosas.

58. Se esperan pacientemente los resultados de las decisiones.

59. Se pasa por alto la disciplina y el cumplimiento de las normas.

60. La gente sigue el reglamento del puesto según su propio juicio.

61. Se busca que el propio trabajo esté coordinado con el de los demás.

62. Se hacen las cosas sin planificarlas.

63. Se está disponible cuando otros los necesitan.

64. Se respetan las opiniones de los demás.

65. Se continúan haciendo las mismas cosas del mismo modo..

66. La gente no se apasiona con el trabajo.

67. Se comentan con los jefes los problemas personales.

68. La gente trata de hacer las cosas mejor que los demás.

69. Se espera cuanto sea necesario para actuar en el momento oportuno.

70. Se actúa sin demora en los problemas importantes.

71. Se tiene una total iniciativa para organizarse el trabajo.

72. La gente actúa sin tener en cuenta a los demás

73. Se pierde el tiempo porque no se sabe lo que se tiene que hacer.

74. Se trabaja en colaboración con los demás.

75. Se felicita a la gente que lo hace bien.

76. La gente se aferra a las formas establecidas de hacer las cosas.

77. Continuamente se busca hacer cosas, a llevarlas a cabo.

78. Se retrasa la acción hasta el momento oportuno.

79. Rápidamente se pone orden y concierto en las situaciones caóticas.

80. Se toman las decisiones sin dar explicaciones.

81. Se ofrece resistencia a cambiar la forma de hacer las cosas

82. La gente hace su trabajo respetando las reglas establecidas. 


\section{CUESTIONARIO DE COMPROMISO CON LA ORGANIZACIÓN}

Por favor, conteste a las siguientes afirmaciones indicando en el espacio que precede a cada pregunta el número de la siguiente escala que mejor expresa su grado de acuerdo o desacuerdo. No se detenga demasiado a pensar la respuesta.

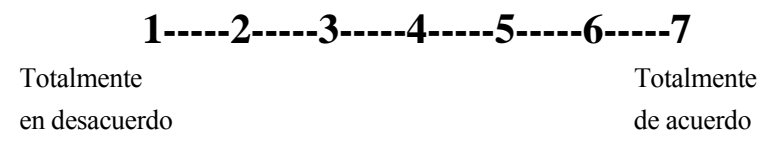

1. Cuanto más tiempo llevo en esta organización me es más difícil dejarla.

2. Estoy dispuesto a esforzarme en el trabajo más de lo que normalmente se espera de mí para ayudar a esta organización a que tenga éxito.

3. Me sería difícil adaptarme a otra organización

4. Esta organización me estimula las ganas de dar un buen rendimiento.

5. Muchos cambios tendrían que producirse en la situación en que estoy para que decidiera dejar esta organización

6. Estoy contento de haber encontrado esta organización en lugar de otras cuando buscaba trabajo.

7. Sería duro para mi familia si decidiera dejar en este momento esta organización

8. Encuentro que mis valores personales y los de esta organización son semejantes.

9. Aceptaría casi cualquier clase de puesto para seguir trabajando en esta organización

10. Me preocupa lo que pueda suceder en el futuro a esta organización

11.Me sería fácil tomar la decisión de dejar esta organización y perder todos los beneficios que hasta ahora he acumulado aquí.

12. Hablo de esta organización a mis amigos como de un buen lugar de trabajo.

13. Estaría dispuesto a quedarme en esta organización hasta que me retire.

14. Normalmente estoy de acuerdo con la política de personal que tiene esta organización.

15. Si decidiera dejar esta empresa, me sería difícil poderlo explicar a mi familia y amigos.

16. Me siento orgulloso de poder decir que formo parte de esta organización

17. Perdería muchas cosas si dejara esta organización

18. Para mi, ésta es una de las mejores organizaciones en que trabajar. 
19. Estoy agradecido por las oportunidades que se me han brindado en esta organización.

\section{CUESTIONARIO DE CONDUCTAS NORMATIVAS ORGANIZACIONALES}

(CNO-2):

Segunda parte:

Ahora póngase en la situación hipotética en que su grupo de trabajo (departamento, sección, equipo, etc.) ha logrado un ambiente de trabajo que es colectivamente beneficioso para el bienestar organizacional del grupo. Indique en el espacio (__ q que precede a cada pregunta en qué medida cada una de las conductas que se indican a continuación es característica de ese grupo según la siguiente escala:

$\begin{array}{ccccl}\mathbf{0} & \mathbf{1} & \mathbf{2} & \mathbf{3} & \mathbf{4} \\ \text { Nada } & \text { Algo } & \text { A media } & \text { Bastante } & \text { Muy } \\ \text { característico } & \text { característico } & \text { característico } & \text { característico } & \text { característico }\end{array}$

1. La gente se reúne para discutir los proyectos.

2. Se es preciso y meticuloso en el trabajo.

3. Se ponen en práctica las sugerencias que hacen los compañeros.

4. La gente rechaza criticar a espaldas de los demás.

5. Se ve a la gente con ganas de realizar proyectos nuevos.

6. La gente es resuelta y atrevida a la hora de actuar.

7. La gente no duda en consultar sus problemas de trabajo con los jefes.

8. Se asume la responsabilidad del puesto, sintiéndose obligado a responder de las propias acciones.

9. Se intentan superar anteriores resultados.

10. Se soportan con ánimo los aplazamientos de las acciones.

11. Se evitan crear problemas que la gente considera "inútiles"

12. Se hace el trabajo de la manera que cada uno cree es la mejor.

13. Se ayuda a los compañeros del grupo a resolver sus diferencias.

14. Se realizan las tareas de "cualquier manera".

15. Se proporciona apoyo y ayuda cuando se presenta la ocasión.

16. Se trata a todos como iguales. 
17. Se acogen con indiferencia las propuestas de ideas nuevas.

18. La gente es emprendedora y enérgica en las cosas difíciles y arriesgadas.

19. Hay grandes reparos en discutir las ideas con los superiores.

20. Se es serio y riguroso en el cumplimiento de compromisos, reuniones, citas,

21. Se trata de superar a otros grupos competidores

22. Se aceptan los retrasos en las acciones sin impacientarse.

23. La gente apacigua los conflictos que son 'costosos' para todos.

24. La gente utiliza los propios criterios para solucionar sus problemas del trabajo.

25. Aquí cada uno va a lo suyo.

26. Se pone en el trabajo el debido interés.

27. Se rechazan las propuestas y sugerencias de los demás

28. Se intenta que la gente se sienta a gusto en el trabajo diario.

29. Se busca la innovación, introduciendo métodos recién aparecidas o conocidas.

30. Se trabaja hasta más allá de lo establecido

31. Se llega con facilidad a acuerdos con los jefes en la realización del trabajo.

32. Cada uno hace lo que debe.

33. Se estimula a superar el trabajo de los demás.

34. Se mantiene la tranquilidad cuando la situación es incierta.

35. La gente actúa sin preocuparse de normas ni costumbres

36. La gente actúa en el trabajo sin limitarse a los indicaciones recibidas.

37. La gente se junta para participar en actividades fuera del trabajo.

38. Se informa puntualmente de los cambios en las normas y criterios del trabajo.

39. Se comunica la información o los conocimientos para facilitar el trabajo a los demás.

40. En asuntos importantes se busca la aceptación de la gente antes llevarlos adelante.

41. Se intentan nuevas formas de hacer las cosas.

42. La gente se esfuerza el tiempo que requiera el trabajo.

43. Se dificulta que la gente proponga y discuta sus ideas con los jefes.

44. La gente se desentiende de las obligaciones de su trabajo

45. La gente no se preocupa de superar a los demás.

46. La gente es inadadaptable a las situaciones y a las circunstancias imprevistas.

47. La gente es fiel a las reglas y costumbres.

48. Cada uno en su puesto establece su propia manera de hacer las cosas

49. Se toman las decisiones que son aceptadas por la mayoría.

50. Se tratan las cosas del trabajo de forma seria. 
51. Se comparte la información con los compañeros de trabajo.

52. Se actúa con equidad en el reparto del trabajo.

53. Se experimentan y ensayan nuevas cosas, en cuanto se presenta la ocasión.

54. La gente es firme y constante en la acción.

55. La gente intenta que las ideas propias las apoyen los jefes.

56. .No se esfuerza la gente en lo que hace.

57. La gente es luchadora, compitiendo con otros que aspiran a las mismas cosas.

58. Se esperan pacientemente los resultados de las decisiones.

59. Se pasa por alto la disciplina y el cumplimiento de las normas.

60. La gente sigue el reglamento del puesto según su propio juicio.

61. Se busca que el propio trabajo esté coordinado con el de los demás.

62. Se hacen las cosas sin planificarlas.

63. Se está disponible cuando otros los necesitan.

64. Se respetan las opiniones de los demás.

65. Se continúan haciendo las mismas cosas del mismo modo..

66. La gente no se apasiona con el trabajo.

67. Se comentan con los jefes los problemas personales.

68. La gente trata de hacer las cosas mejor que los demás.

69. Se espera cuanto sea necesario para actuar en el momento oportuno.

70. Se actúa sin demora en los problemas importantes.

71. Se tiene una total iniciativa para organizarse el trabajo.

72. La gente actúa sin tener en cuenta a los demás

73. Se pierde el tiempo porque no se sabe lo que se tiene que hacer.

74. Se trabaja en colaboración con los demás.

75. Se felicita a la gente que lo hace bien.

76. La gente se aferra a las formas establecidas de hacer las cosas.

77. Continuamente se busca hacer cosas, a llevarlas a cabo.

78. Se retrasa la acción hasta el momento oportuno.

79. Rápidamente se pone orden y concierto en las situaciones caóticas.

80. Se toman las decisiones sin dar explicaciones.

81. Se ofrece resistencia a cambiar la forma de hacer las cosas.

82. La gente hace su trabajo respetando las reglas establecidas. 

- 224 - 